\title{
Large-scale hydrogen production and storage technologies: current status and future directions
}

\author{
A.G. Olabi ${ }^{1,2,3^{*}}$, Adel saleh bahri ${ }^{1}$, Aasim Ahmed Abdelghafar ${ }^{1}$, Ahmad Baroutaji $^{4}$, Enas Taha Sayed ${ }^{2,5}$, \\ Abdul Hai Alami ${ }^{1}$, Hegazy Rezk6 ${ }^{6,7}$, Mohammad Ali Abdelkareem ${ }^{1,2,5^{*}}$ \\ ${ }^{1}$ Dept. of Sustainable and Renewable Energy Engineering, University of Sharjah, P.O. Box 27272, Sharjah, United \\ Arab Emirates \\ ${ }^{2}$ Center for Advanced Materials Research, University of Sharjah, 27272, Sharjah, United Arab Emirates \\ ${ }^{3}$ Mechanical Engineering and Design, School of Engineering and Applied Science, Aston University, Aston \\ Triangle, Birmingham B4 7ET, UK \\ ${ }^{4}$ School of Engineering, University of Wolverhampton, Telford Innovation Campus, TF2 9NT, UK \\ ${ }^{5}$ Chemical Engineering Department, Faculty of Engineering, Minia University, Egypt \\ ${ }^{6}$ College of Engineering at Wadi Addawaser, Prince Sattam Bin Abdulaziz University, KSA \\ ${ }^{7}$ Electrical Engineering Department, Faculty of Engineering, Minia University, Egypt;
}

Corresponding author: A.G. Olabi (aolabi@sharjah.ac.ae), M. A. Abdelkareem (mabdulkareem@sharjah.ac.ae).

\begin{abstract}
Over the past years, hydrogen has been identified as the most promising carrier of clean energy.

In a world that aims to replace fossil fuels to mitigate greenhouse emissions and address other environmental concerns, hydrogen generation technologies have become a main player in the energy mix. Since hydrogen is the main working medium in fuel cells and hydrogen-based energy storage systems, integrating these systems with other renewable energy systems is becoming very feasible. For example, the coupling of wind or solar systems hydrogen fuel cells as secondary energy sources is proven to enhance grid stability and secure the reliable energy supply for all times. The current demand for clean energy is unprecedented, and it seems that hydrogen can meet such demand only when produced and stored in large quantities. This paper presents an overview of the main hydrogen production and storage technologies, along with their challenges. They are presented to help identify technologies that have sufficient potential for large-scale energy applications that rely on hydrogen. Producing hydrogen from water and fossil fuels and storing it in underground formations are the best large-scale production and storage technologies. However, the local conditions of a specific region play a key role in determining
\end{abstract}


the most suited production and storage methods, and there might be a need to combine multiple strategies together to allow a significant large-scale production and storage of hydrogen.

Keywords: Hydrogen production; hydrogen storage; renewable energy; underground hydrogen storage; metal hydrides.

\section{Introduction}

The advances in technology and the increase of the population resulted in increased energy consumption. The main energy source is a fossil fuel that is not only limited in resources and fluctuated in price, but also it has a severe environmental impact $[1,2]$. The rely on the fossil fuel can be decreased and/or eliminated through improving the efficiency of the current processes [3, 4] and/or through the usage of renewable energy sources such as solar thermal [5], solar PV [6-8], geothermal [9, 10], wind [11], hydro [12], and biomass energy [13-16]. Hydrogen is conserved as an energy carrier that can be used for decarbonization of several sectors. Hydrogen has several advantages such as abundant as it forms almost 90 atomic $\%$ of all the atoms in the universe, has one of the highest energy density fuel (gravimetric one), environmentally friendly as it produces water as a byproduct, and sustainable. Hydrogen can be obtained from both fossil fuels and renewable energy sources. Although hydrogen exists in large amounts in the universe, it is not available freely in its elemental form. Elemental hydrogen is usually obtained from compounds through different chemical and electrochemical processes. Although hydrogen is the simplest element by composition, it possesses the highest energy per unit mass as shown in Table 1 with other properties of hydrogen [17], while Table 2 shows the energy content of hydrogen compared to other chemical energy sources (fuels). Obviously, the energy content of hydrogen is significantly greater than the other fuels [18]. Hydrogen is sustainable, non-toxic, and clean when used as a fuel since it produces only water as a byproduct. Therefore, hydrogen has a potential solution for global energy requirements with minimum pollution. Fuel cells [19-21] are efficient energy conversion devices that can use hydrogen as a fuel and have a high potential for application in transportation and other power generation (stationary) systems [22]. Also, hydrogen can be burned in turbines and/or internal combustion engines [23-26] to generate electricity through kinetic and mechanical energy conversions. Hydrogen has economic feasibility for future global economic prosperity [27]. For all these 
advantages, hydrogen can be considered as a key solution to combat global warming and other environmental issues [28, 29]. Nowadays, hydrogen is used in oil refining and production of ammonia, but it is not used widely in transportation and power generation. However, it is expected to grow in these sectors, too [30]. Table 1 shows the different properties of hydrogen, and Table 2 shows a comparison between hydrogen and other common fuels.

Table 1: Properties of hydrogen [17]

\begin{tabular}{|c|c|c|}
\hline Property & Value & Unit \\
\hline Molecular weight & 2.016 & Amu \\
\hline r (gas) & 0.0838 & $\mathrm{~kg} / \mathrm{m}^{3}$ \\
\hline r (liquid) & 70.8 & $\mathrm{~kg} / \mathrm{m}^{3}$ \\
\hline $\mathrm{T}$ (boiling) & 20.3 & $\mathrm{~K}$ \\
\hline $\mathrm{T}$ (self-ignition) & 858 & $\mathrm{~K}$ \\
\hline $\mathrm{T}$ (flame) & 2318 & $\mathrm{~K}$ \\
\hline \multirow{2}{*}{$\mathrm{HHV}$} & 141.90 & $\mathrm{MJ} / \mathrm{kg}$ \\
\hline & 11.89 & $\mathrm{MJ} / \mathrm{m}^{3}$ \\
\hline \multirow{2}{*}{ LHV } & 119.9 & $\mathrm{MJ} / \mathrm{kg}$ \\
\hline & 10.05 & $\mathrm{MJ} / \mathrm{m}^{3}$ \\
\hline \multicolumn{3}{|c|}{ Critical point } \\
\hline Temperature & 32.94 & $\mathrm{~K}$ \\
\hline Pressure & 1284 & $\mathrm{kN} / \mathrm{m}^{2}$ \\
\hline Density & 31.40 & $\mathrm{~kg} / \mathrm{m}^{3}$ \\
\hline Ignition limit in air & $4-75$ & vol.\% \\
\hline Stoichiometric mixture in air & 29.53 & vol. $\%$ \\
\hline $\mathrm{D}$ & 0.61 & $\mathrm{~cm}^{2} / \mathrm{s}$ \\
\hline $\mathrm{Cp}$ & 14.89 & $\mathrm{~kJ} /(\mathrm{kg} . \mathrm{K})$ \\
\hline
\end{tabular}


Table 2: Comparison of some selected energy contents of fuels [18]

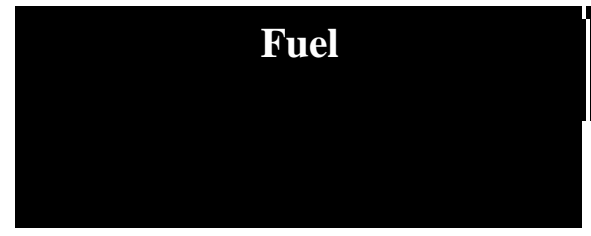

\section{Energy content $[\mathrm{MJ} / \mathrm{kg}]$}

Lower heating value Higher heating value

\begin{tabular}{|c|c|c|}
\hline Gaseous hydrogen & 119.96 & 141.88 \\
\hline Liquid hydrogen & 120.04 & 141.77 \\
\hline Natural gas & 47.13 & 52.21 \\
\hline Liquefied natural gas (LNG) & 48.62 & 55.19 \\
\hline Liquefied petroleum gas (LPG) & 46.60 & 50.14 \\
\hline Crude oil & 42.68 & 45.53 \\
\hline Still gas (in refineries) & 46.89 & 50.94 \\
\hline Conventional gasoline & 43.44 & 46.52 \\
\hline Reformulated or low sulfur & 42.35 & 45.42 \\
\hline \multicolumn{3}{|l|}{ Gasoline (RFG) } \\
\hline Conventional diesel & 42.78 & 45.76 \\
\hline Low sulfur diesel & 42.60 & 45.56 \\
\hline Coal (wet basis) & 22.73 & 23.96 \\
\hline Cooking coal (wet basis) & 28.60 & 29.86 \\
\hline Bituminous coal (wet basis) & 26.12 & 27.26 \\
\hline Ethanol & 26.95 & 29.84 \\
\hline Methanol & 20.09 & 22.88 \\
\hline
\end{tabular}


Although there is a considerable work that have been done to summarize the hydrogen production [31-33] and hydrogen storage [34, 35], there is still a need for a work that covers both the production and storage with emphasizing on the large scale ones, as well as the recent progress in storing hydrogen in salt caverns and porous rock reservoirs are needed. Moreover, this work covers the recent work done in the fast hydrolysis of the metal hydrides.

\section{Large scale applications of hydrogen}

Hydrogen is widely used in various industrial sectors, such as oil, chemicals, food, plastics, metals, electronics, glass, and electrical power [36]. Table 3 summarises different applications of hydrogen in different sectors. Additionally, hydrogen can be used at large-scale energy conversion applications such as direct combustion in internal combustion engines or in fuel cells in automotive industry [37]. The main advantages of combustion-based engines are their economy and the less stringent purity restrictions on hydrogen compared to fuel cells [38]. This will be discussed in the following sections.

Table 3: Hydrogen usage in industries [11]

\begin{tabular}{|c|c|}
\hline Industry & Uses \\
\hline \multirow{4}{*}{ Metals } & Welding torches \\
\hline & Oxygen scavenger. \\
\hline & $\begin{array}{l}\text { Heat treatment to improve ductility and machining quality, to increase the } \\
\text { tensile strength, to relieve stress, to harden, changing electrical or } \\
\text { magnetic characteristics. }\end{array}$ \\
\hline & The reductive atmosphere for the production of iron, molybdenum, ... etc \\
\hline \multirow[t]{2}{*}{ Plastics } & $\begin{array}{l}\text { It is cracking used plastics to produce lighter molecules that can be } \\
\text { recycled. }\end{array}$ \\
\hline & Synthesize of nylons, polyesters, polyurethane, and polyolefin. \\
\hline \multirow[t]{3}{*}{ Glass } & Heat treatment of optical fibers \\
\hline & The reductive atmosphere for the float glass process \\
\hline & High temperature cutting torches \\
\hline
\end{tabular}




\begin{tabular}{|l|l|}
\hline & Glass polishing. \\
\hline Electronics & Heat bonding materials. \\
\hline Epitaxial growth of polysilicon \\
\hline Electric power & Manufacture of vacuum tubes. \\
\hline Chemical & Coolant for large generation of motors. \\
\hline Food & Synthesized of methanol, ammonia.....etc. \\
\hline Conversion of edible oils to fats. \\
\hline & Conversion of tallow and grease to animal feed. \\
\hline Conversion of sugar to polyols. \\
\hline Oil
\end{tabular}

\subsection{Hydrogen-fueled internal combustion engines}

The internal energy of hydrogen can be released by burning it directly inside internal combustion engines. There are two types of internal combustion engines suitable for burning hydrogen, i.e., spark ignition and diesel cycle engines. Hydrogen is considered as a clean and effective fuel that can replace gasoline in spark-ignition engines [38, 39]. Shivaprasad [40] reported that a spark ignition engine fueled by hydrogen exhibited higher thermal efficiency than gasoline. Another experimental study by Elsemary [41] conducted on a single-cylinder spark ignition engine at different volumetric dilution ratios of hydrogen with gasoline. The results showed that higher hydrogen ratios generate higher efficiency values, coupled with the intrinsically better environmental impacts.

For diesel cycles, pure hydrogen can not be used as a fuel, but it can be introduced in a mixture with other fuels [42]. Adding hydrogen to the fuel mixture in diesel engines increases the environmental appeal of such engines as both carbon monoxide, and carbon dioxide emissions 
are reduced. However, adding $\mathrm{H}_{2}$ results in increasing the $\mathrm{NO}_{\mathrm{x}}$ emissions [43]. Hamdan et al. [44] reported that increasing $\mathrm{H} 2$ into the fuel of diesel engines results in increasing the thermal efficiency and increasing the $\mathrm{NO}_{\mathrm{x}}$.. Ghazal [45] tested a compressed ignition engine operating on hydrogen/diesel fuel mixture and reported that adding hydrogen has augmented the performance and resulted in less harmful emissions and smoother (less noise) engine operation. Koten [46] investigated the performance of diesel engines fueled by a mixture of diesel and hydrogen at different loads and showed that increasing the amount of hydrogen increases the thermal efficiency but resulted in higher fuel consumption for all loads. Hydrogen additions (up to 80 lpm) also resulted in less soot formation but caused higher $\mathrm{NO}_{\mathrm{x}}$ emissions.

\subsection{Hydrogen fuel cells}

Fuel cells are devices that directly convert chemical energy into electrical energy [47-49]. They consist of an anode (where fuel oxidation takes place) a cathode, and a suitable electrolyte that allows ion transfer in between [50]. Fuel cells are highly efficient devices, with a conversion efficiency of around 60-70\% [51]. There are many types of fuel cells, and the most commercialized ones are proton exchange membrane fuel cells (PEMFCs) [52, 53], solid oxide fuel cells (SOFCs) [54, 55] and molten carbonate fuel cells (MCFCs) [56, 57]. Isfahani and Sedaghat [58] built a setup consisting of a hybrid power system involving: (i) solid oxide fuel cell (SOFC), (ii) a micro gas turbine, and (iii) three-reactor chemical looping for hydrogen production (TRCL) along with carbon monoxide capturing. They routed the hydrogen produced from the TRCL is used in the SOFC for generating electricity, and the excess hydrogen is combusted in the micro gas turbine. This hybrid system has an efficiency of $51.4 \%$ based on the lower heating value. Concurrently, the system could be capable of capturing $100 \%$ of the produced carbon monoxide, ushering in a clean power production system. Another solarpowered hydrogen fuel station termed i-NEXT is built In Italy [59]. The power plant is used to generate electricity and simultaneously supply hydrogen to vehicles. In this system, an alkaline electrolyzer is used, which can produce hydrogen with $99.995 \%$ purity. The generated hydrogen is stored under compression in tanks that can be used later as fuel for vehicles. Conventional fuels are still preferable than PEMFC due to the high cost and poor durability of the latter one [60]. However, with the advent of all-electrical vehicles such as Tesla, Hyundai Tucson, Toyota Mirai, Honda FCX Clarity, and Mercedes-Benz GLC has pushed interest in fuel cells for vehicle 
propulsion further [37]. Mehrjerdi [61] designed an off-grid station for electrical and hydrogen vehicles. The station is powered by solar PV. Part of the electrical power delivered by the PV is used for charging electrical cars, and the rest is used for hydrogen production by electrolysis. A fuel cell was added to generate electricity using hydrogen fuel. The electricity from the fuel cells will be used for charging the electrical cars during hours of low solar irradiance, while a diesel generator is also added as backup. The design revealed $97 \%$ of the electrical power generated by the PV will be converted to hydrogen and stored. Error! Reference source not found. [61], shows a schematic of the proposed system.

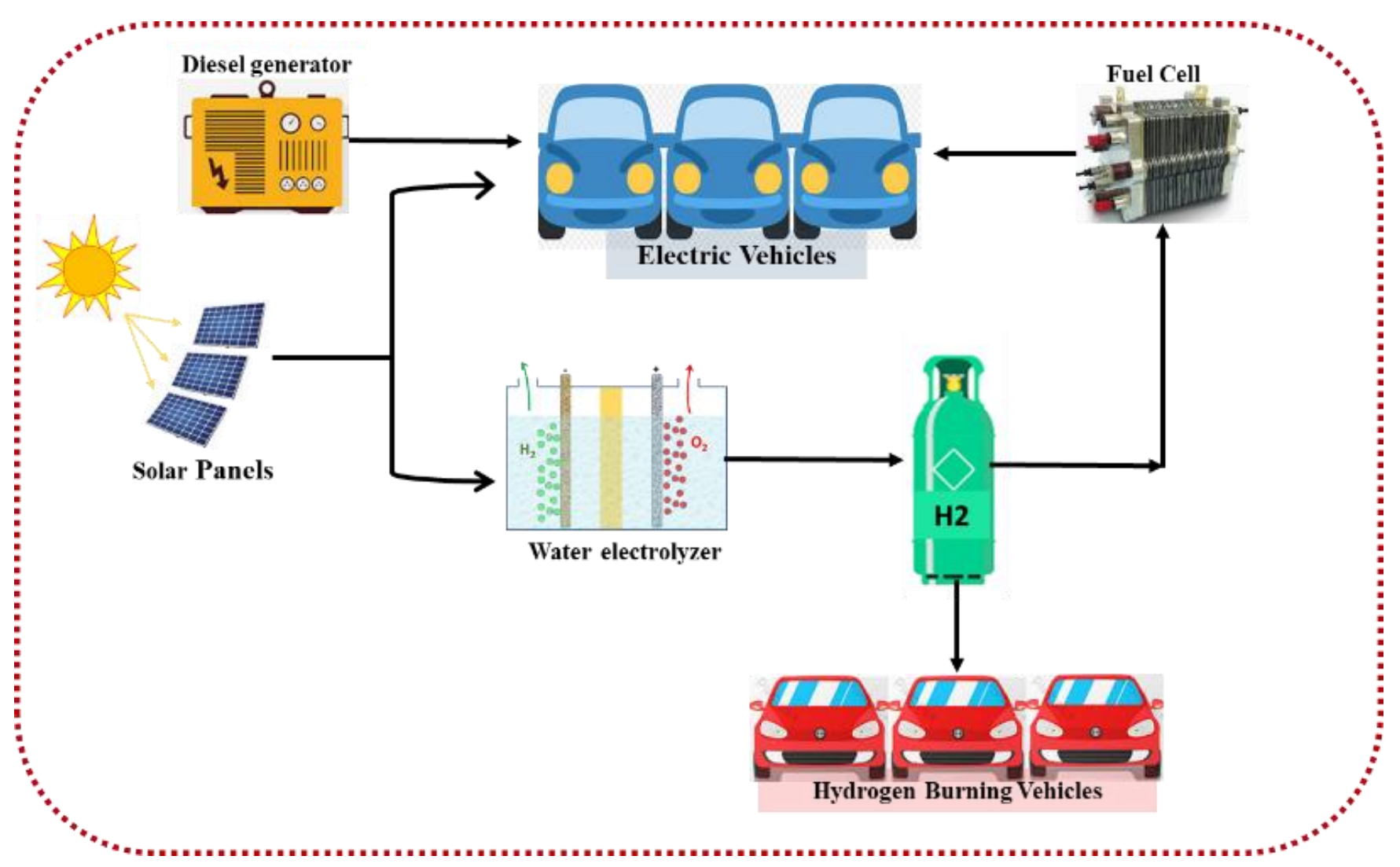

Figure 1: Schematic for an electrical/hydrogen station powered by PV.

\section{Hydrogen production technologies}

Currently, hydrogen can be produced from a wide variety of resource such natural gas [62-64], coal [65], biomass [66, 67], water [68-70]; metal hydrides [71-73], $\mathrm{H}_{2} \mathrm{~S}$ [74-77], and biological sources such as biomass [78-81]. Although of the progress in the hydrogen market as promising energy source, the conventional production routes, i.e., from fossil fuel, have negative 
environmental impacts [82]. Therefore, renewable energy sources such as wind energy, solar energy, and even nuclear energy are preferred if clean production of hydrogen is sought [83]. Hydrogen can also be produced from the biomass via chemical, microbial routes [84, 85], or electrolytic routes [86]. Other methods that have been tried for producing hydrogen include steam reforming of methane, gasification, water electrolysis, liquid thermochemical, water- splitting, photo- biological, and photoelectrochemical [87, 88].

Being a highly active gas, hydrogen production must include many provisions to ensure safe production and storage, which may increase the production cost. For example, it requires high sealing pressures of storage containers and transportation pipelines to ensure no leakage [89]. Another roadblock to widespread adaptation as a primary resource, hydrogen production, is struggling with government legislations on its production and storage [83]. With 120 billion tons of hydrogen are being produced each year, and 2/3 of it is pure hydrogen, while the rest is a mixture of gases [83]. Several countries have made an approach to green hydrogen recently, including Germany, Netherlands, Japan, Australia, France, Canada, and China, and for this, it is expected that the production of green hydrogen will grow worldwide more rapidly [83]. Even though hydrogen production by renewable energies has moved forward in strides in the past few years, it is still suffering from higher cost compared to fossil fuel, especially with the current crisis of 2020. For example, Figure 2: Hydrogen production cost by renewable and nonrenewable energies in 20192 compares hydrogen production cost using renewable and nonrenewable energy sources in 2019. The average price of producing hydrogen by solar PV and wind energy is much higher than that of fossil fuel, while the decrease in the price of solar PV and wind energy is considered competitive. The International Renewable Energy Agency (IRENA) is expecting that the cost of hydrogen production via renewable energies will fall and become even cheaper than fossil fuel in 2050 [83]. 


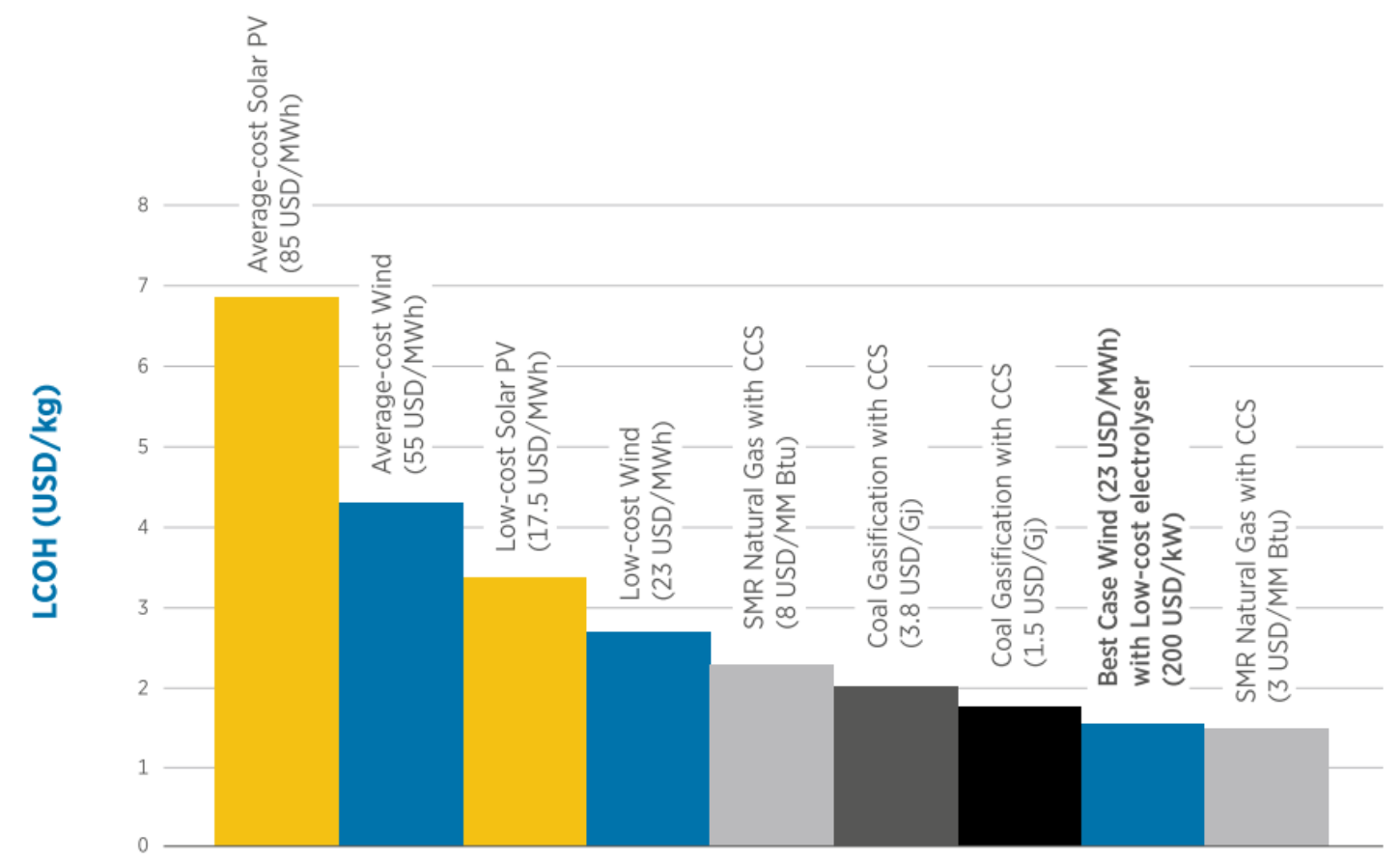

Notes: Electrolyser capex: USD 840/kW; Efficiency: 65\%; Electrolyser load factor equals to either solar or wind reference capacity factors. For sake of simplicity, all reference capacity factors are set at $48 \%$ for wind farms and $26 \%$ for solar PV systems.

Source: IRENA analysis

Figure 2: Hydrogen production cost by renewable and non-renewable energies in 2019 [83]

\subsection{Hydrogen Production from fossil fuels:}

Steam reforming of methane (SMR) is a common method used for producing hydrogen from natural gas. In SMR, the natural gas is mixed with steam at high temperature over a catalyst surface, where a mixture of hydrogen and carbon monoxide is produced [89]. Afterward, this mixture undergoes a water-gas shift reaction to obtain hydrogen and carbon dioxide $\left(\mathrm{CO}_{2}\right)$, where hydrogen is purified from $\mathrm{CO}_{2}$. This process has an efficiency of $65-75 \%$ and can reach more than $80 \%$ for large reformers. Also, it is considered as the most economical method [28, 89, 90]. Eq.1 shows the chemical reaction of SMR [91].

The steam methane reforming process is shown in Figure 3: Flow diagram of the steam methane reforming process 3 (adapted from [92]). As shown in the figure that before the reforming process, methane is desulfurized (sulfur impurities are removed to avoid poisoning of the 
catalysts). The reforming process is established under very high temperatures to obtain syngas, i.e., mixture of $\mathrm{H}_{2}$ and $\mathrm{CO}$. The reforming is followed by a shift converter, where extra $\mathrm{H}_{2}$ is produced from $\mathrm{CO}$ by steam addition. A pressure swing adsorption (PSA) is then used to remove the $\mathrm{CO}_{2}$ gases yielding pure $\mathrm{H}_{2}$ as an outcome of the process [32, 92].

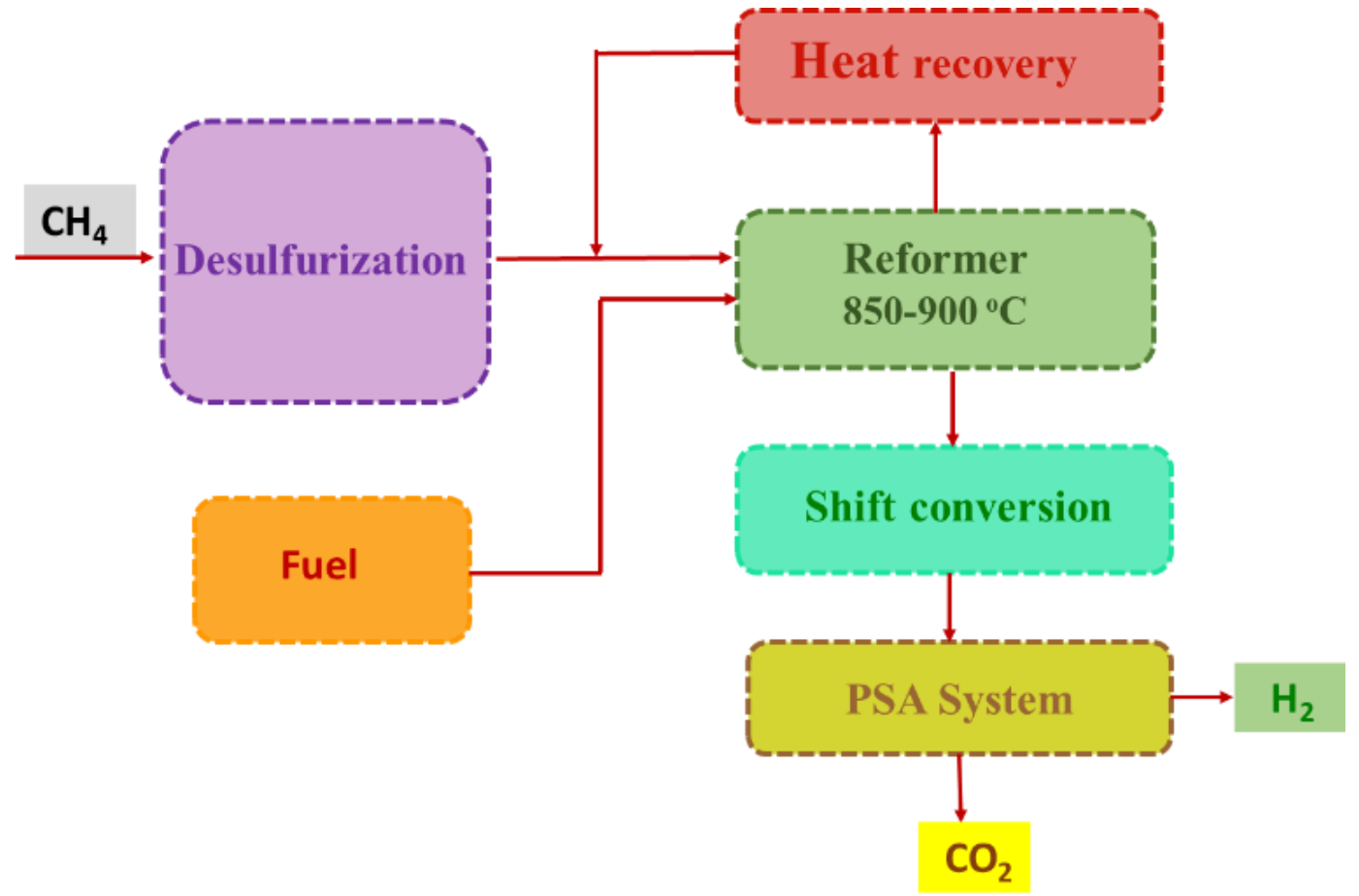

Figure 3: Flow diagram of the steam methane reforming process.

Gasification is also widely used for hydrogen production. In the coal gasification process, coal is partially oxidized with oxygen and/or steam under high pressure and temperature. Carbon monoxide $(\mathrm{CO})$ and $\mathrm{H}_{2}$ are the main products of this partial oxidation. A shift reaction is then conducted to increase hydrogen yield. The high carbon content of coal that results in producing large amounts of $\mathrm{CO}_{2}$ compared to other feedstocks is the major drawback of coal gasification. Carbon Capture and Storage (CCS) technologies can be coupled with this process for minimizing unwanted $\mathrm{CO}_{2}$ emissions during coal gasification. Compared to the steam reforming of methane, the cost of coal gasification is higher, and thus it is not widely used [90]. 


\subsection{Water electrolysis:}

Water electrolysis is a process through which water is split into hydrogen and oxygen by adding electricity [93], as described in Eq.2.

Water electrolysis is considered to be the cleanest method for producing hydrogen since no carbon emissions are generated [94]. The electrolyzer consists of positive and negative electrodes. Many electrolyzer types are available, such as proton exchange membrane (PEM), alkaline, and solid oxide electrolyzers [95, 96]. After the electrolyzer, a compressor is usually used to store hydrogen. The schematic in Fig. 4 (adapted from [94]) summarizes the steps for hydrogen production and storage by water electrolysis. The source of input power can be renewable energy, making the whole process even more sustainable. The coming sections will detail various renewable energy technologies (solar energy, wind, biomass, and geothermal energies) that are coupled with water electrolysis for hydrogen generation.

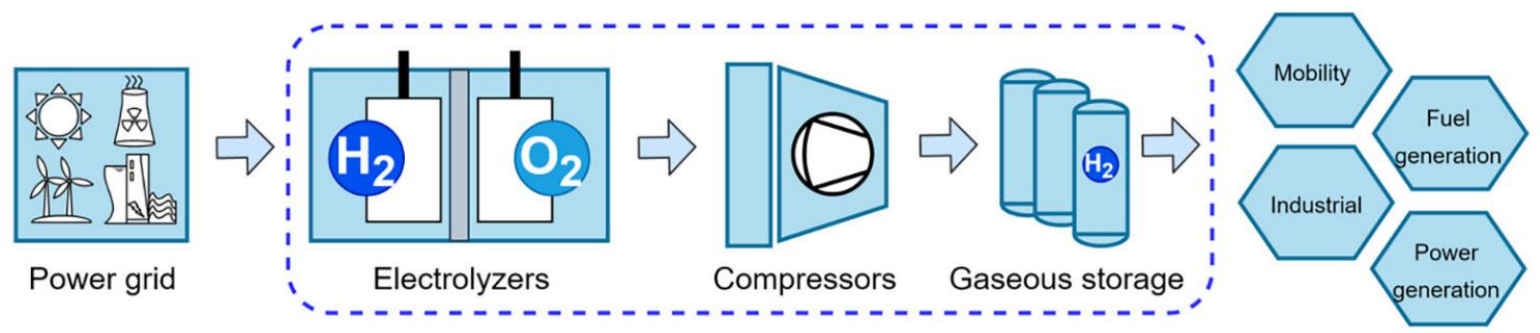

Figure 4: Schematic diagram for hydrogen production by water electrolysis adapted from [94].

\subsubsection{Water electrolysis by photovoltaic solar energy:}

Solar power is available and abundant and is a clean source of energy [97]. However, the power that can be extracted from photovoltaic solar cells is limited to $10-20 \%$ of incident power depending on different parameters such as shade, dust, and operating temperatures [98]. Therefore, it is a challenge for solar PV to independently supply the required electrical demand [99]. Additionally, solar power has limited availability as it is only available during daytime, which limits accessibility to it. Such limitation could be decreased or eliminated through using hybrid systems consists of other renewable energy sources and/or storage systems [8, 100]. An 
electrical power produced by solar PV modules could be used to produce hydrogen through an electrolyzer. The schematic in Fig. 5 (adapted from [101]) shows the coupling of a solar PV system and water electrolyzer used for hydrogen production. Having a PV system with higher efficiency will produce higher energy for the same module area, and hydrogen production will also increase [102]. This coupling is considered as one of the cleanest systems for hydrogen production [88].

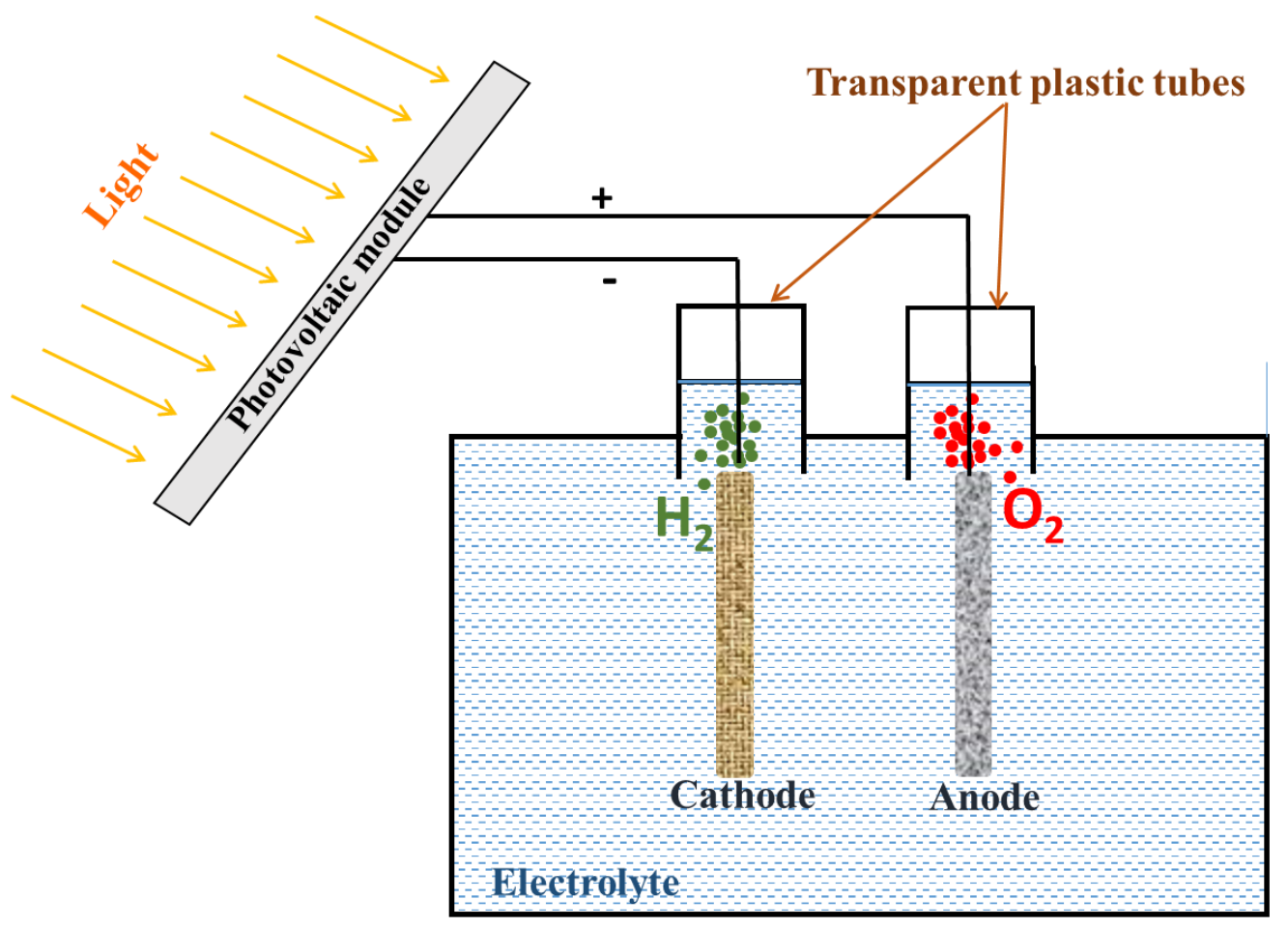

Figure 5: Hydrogen production by solar PV system.

The disadvantages of producing hydrogen by PV system are the high installation costs and the lower exergic performance compared to fossil fuel [33]. However, PV production costs are in a steady decline with a lower cost per $\mathrm{kWh}$. The system can be coupled with other energy resources to enhance efficiency and not limit hydrogen production to daytime. For example, Al Sharifi et al. in Saudi Arabia [103] used 2 kW PV array integrated with 3 wind turbines and 7 batteries to produce sustainable hydrogen with acceptable efficiency. Another case study with promising results was conducted by Qolipour et al. in Iran [104] using a hybrid PV-wind power plant. On an annual basis, a 3,153,762 kWh electrical energy was produced, and 31,680 kg of hydrogen was produced. Also, Fereidoono et al. [101] demonstrated that for a $20 \mathrm{~kW}$ PV power 
station in Iran could reveal an annual electricity production of $36.91 \mathrm{MWh}$ and 373 ton of hydrogen. Another study by Rezaei et al. [105] in Iran for a hybrid wind/PV system showed that the PV system is capable of producing a maximum of $20 \mathrm{~kg}$ of hydrogen per day, which is capable of driving 20 cars for a week. On the solar thermal utilization side, using simulation for a solar pond, a flat plate solar collector for producing hydrogen showed that it could produce 2.25 $\mathrm{kg}$ of hydrogen per day [106].

\subsubsection{Water electrolysis by wind energy}

This method has the same principle as the previous one except that water electrolysis is achieved by the energy produced by wind turbines. Producing hydrogen by wind energy is the simplest and cleanest mechanism in terms of producing emissions. Also, it is the best mechanism for producing hydrogen in terms of cost/energy compared to other renewable sources [107]. However, hydrogen production by wind energy has some difficulties to overcome, which are mature wind turbine structure, having electrolyzer that accepts wind fluctuations, and a suitable hydrogen storage system [108]. A study by Rodríguez et al. [109] in Argentina showed that producing hydrogen by electricity delivered from wind turbines is ten times higher than the hydrogen required for a vehicle in the province of Córdoba as a case study. Another study [110] in Argentina showed that it is possible to produce 1 billion tons of hydrogen for a year from wind energy. Also, the study done by Loisel et al. [111] in France showed that an off-shore wind farm for hydrogen production has a cost of 4-13 €/ $\mathrm{kg}$ of Hydrogen. Moreover, Iqbal et al. [112] investigated hydrogen production by wind turbines in different cities in Pakistan, and Mostafaeirpour [113] studied those in Iran. Another study by Rezaie et al. [105] in Iran for

Wind/PV system showed that using a Gasima G47 wind turbine would produce $91 \mathrm{~kg}$ of hydrogen per day, which is capable of driving 91 cars for a week. Also, the feasibility of wind turbines application in different wind turbines in South Africa was performed by Ayodele et al. [114]. They reported that the site with the highest wind potential showed hydrogen production 6.51- 226.82 metric-tons of hydrogen depending on the capacity of the turbine, while the best turbine in terms of cost/energy is capable of producing energy of $0.23 \$ / \mathrm{kWh}$. A study by Fang et al. [115] for wind/hydrogen integrated system concluded that the wind/hydrogen system has a better economic performance compared to a regular wind farm. The combination of fuel cells with wind turbines will play an important role in clarifying the wind's fluctuations. Finally, a 
recent study performed in Iran [116] shown in Table 4: Hydrogen Production by two wind turbines in different cities in Iran "using two turbines T1 of $3.5 \mathrm{~kW}$ and T2 of $100 \mathrm{~kW}$ " revealed that high hydrogen production is in Ardebil city of 5253.1kg per year could be achieved.

Table 4: Hydrogen Production by two wind turbines in different cities in Iran [116]

\begin{tabular}{|c|c|c|c|c|}
\hline NO. & Ardebil & Khalkhal & Namin & Meshkinshahr \\
\hline T1 "3.5 kW" & 99.1 & 53 & 80.3 & 58.7 \\
\hline T2 "100 kW" & 5253.1 & 3242.6 & 4553.9 & 3556.9 \\
\hline
\end{tabular}

\subsubsection{Hydrogen production by geothermal energy}

Geothermal energy is a natural resource of energy stored as heat beneath the surface of the earth $[117,118]$. In terms of utilization, it is among the relatively cheap energy resource and has a low adverse environmental impact $[119,120]$. Compared to other renewable sources like solar and wind, geothermal energy is considered to be the most consistent, with no temporal interruptions or fluctuations [9]. Geothermal energy could be classified based on temperature; the higher the temperature, the higher the energy potential. For hydrogen production, geothermal energy can be used to generate electricity for water electrolysis. In order to achieve this, the thermal input should be greater than $150 \quad[119,120]$. Using high-temperature geothermal energy, the study done by Belta et al. [119] demonstrated an energy and exergy efficiencies of $87 \%$ and $86 \%$, respectively, for water electrolysis. Also, the electrolysis system was found to consume 3.34 at 230 and generates $573 \mathrm{~mol} / \mathrm{s}$ of hydrogen. Moreover, the study showed that the higher temperature of the geothermal well, the higher exergy efficiency of the process. A study done by Kanoglu [121] exhibited an annual hydrogen production of 34,800 tones with a cost of $1.6 € / \mathrm{kg}$. The work done by Bicer and Dincer [122] for a combined geothermal/solar combined hydrogen production system showed that the production part of the geothermal was dominant, with $18 \mathrm{~kg}$ of hydrogen produced each hour. Table 5: Geothermal-based power plants for hydrogen production shows geothermal-based large scale power plants for hydrogen production in Hawaii, USA [123], and Treiceria, Portugal [124], and Iceland [125, 126]. 
Table 5: Geothermal-based power plants for hydrogen production [119].

\begin{tabular}{lllcccc}
\hline \multicolumn{1}{c}{ Location } & $\begin{array}{c}\text { Type of } \\
\text { study }\end{array}$ & $\begin{array}{c}\text { Source of } \\
\text { type }\end{array}$ & $\begin{array}{c}\text { Production } \\
\text { type }\end{array}$ & $\begin{array}{c}\text { Geothermal } \\
\text { capacity (MW) }\end{array}$ & $\begin{array}{c}\text { Electrolyser } \\
\text { capacity } \\
\text { (MW) }\end{array}$ & $\begin{array}{c}\text { Hydrogen } \\
\text { production } \\
\text { (kg/day) }\end{array}$ \\
\hline Iceland & Modeling & Geothermal & HTE & - & - & - \\
Treiceria, Portugal & Modeling & Geothermal & Electrolysis & 250 & 234 & - \\
Hawaii, USA & Modeling & Geothermal & Electrolysis & 3 & 2.6 & 462 \\
& Modeling & Geothermal & Electrolysis & 2.4 & 1.9 & 347 \\
\hline
\end{tabular}

\subsubsection{Hydrogen Production from biomass:}

Biomass energy is the main source of energy production. It is available from agricultural residues and wastes of industries and households. It can be used for generating biogas, biodiesel, hydrogen, or even electricity in microbial fuel cells [127-130]. Hydrogen is produced from biomass mainly by thermo-chemical processes and biochemical processes [131]. However, the technologies are all in the research stage. Thermo-chemical processes require less time compared to the biochemical process [132]. However, thermochemical processes require higher energy input and continual removal of tar from the products [133]. Also, thermochemical processes have higher efficiency and less cost compared to biochemical [134].

Thermochemical hydrogen production utilizes pyrolysis and gasification of biomass, as shown in Fig. 6 (adapted from [135]). Pyrolysis is defined as a high-temperature degradation of the carbonaceous material process that produces a mixture of gases or bio-oil, which can be used for hydrogen production [136]. However, the hydrogen produced from this method is very small and not commercialized [137]. On the other hand, gasification is considered one of the most efficient methods for hydrogen production from biomass [134]. The challenge facing gasification is low efficiency [135]. The researcher conducted several studies for large-scale production of hydrogen through biomass gasification [138, 139]. The biochemical process is based on micro-organisms that convert organic materials into a mixture of various compounds, including hydrogen. Different studies have been done to optimize the performance of dark fermentation as a promising method for hydrogen production [140-142]. 


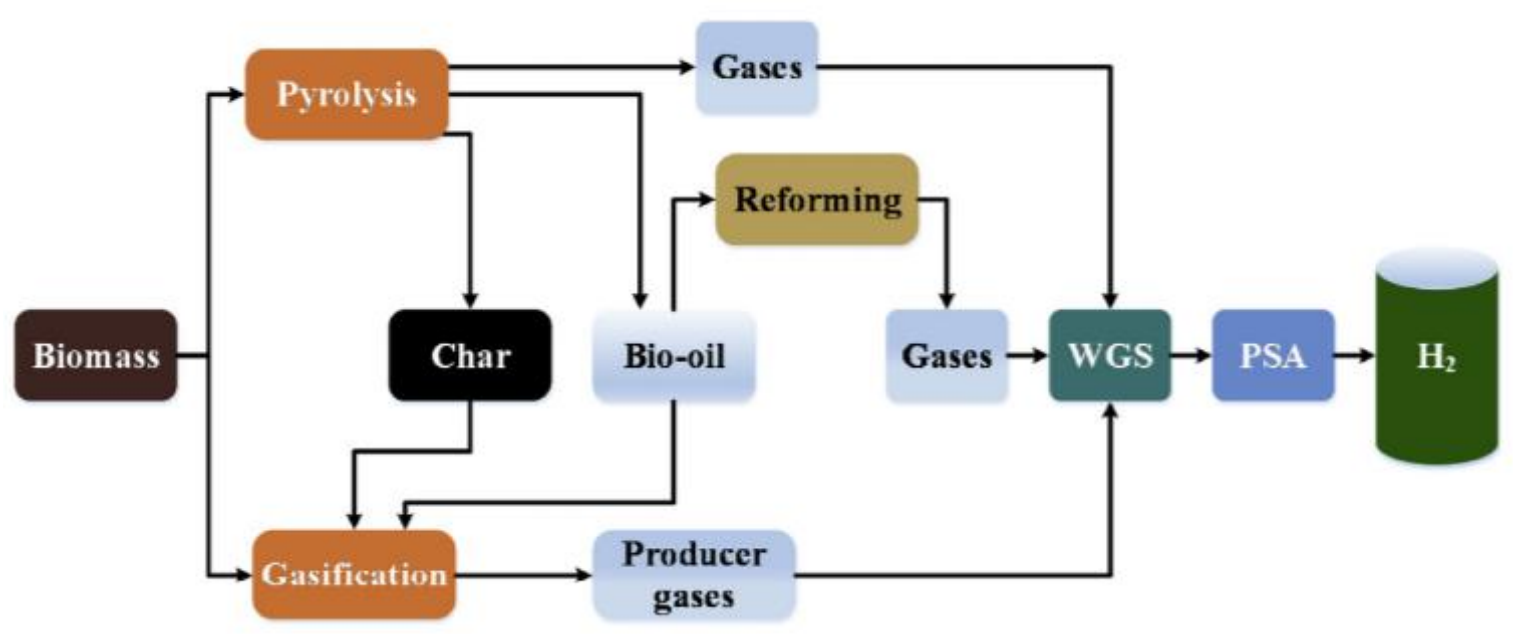

Figure 6: Hydrogen production by thermo-chemical conversion of biomass.

\subsubsection{Hydrogen Production by solar thermal energy:}

Recently, solar concentrating power plants have been adopted for hydrogen production, which is one of the best methods for hydrogen production through a thermochemical process [143]. Such a method has high efficiency and does not require precious catalysts [144]. Basically, incident solar energy is focused on a smaller area using mirrors, parabolic dishes, or power towers to increase the available temperature that can be used for hydrogen production [145, 146]. Thermochemical processes include reforming, gasification, cracking, and water thermolysis [147]. The cleanest method among them is water thermolysis, and hence it is the most popular one. The main challenges facing its wide adaptation are the very high operational temperatures [2500-3000K], limiting the materials that can withstand these high temperatures and be at an available cost [148]. Also, it requires an effective separation system to avoid the recombination of hydrogen and oxygen [149]. Chang et al. [150] summarized the latest technologies for water thermolysis, highlighting the different methods used to enhance the yield and efficiency of thermolysis, such as using two stages instead of a single stage to operate on a lower temperature. The first stage in this method is an endothermal reaction (TR phase), and the second stage is an 
exothermal reaction (WS phase) [151], as being shown in

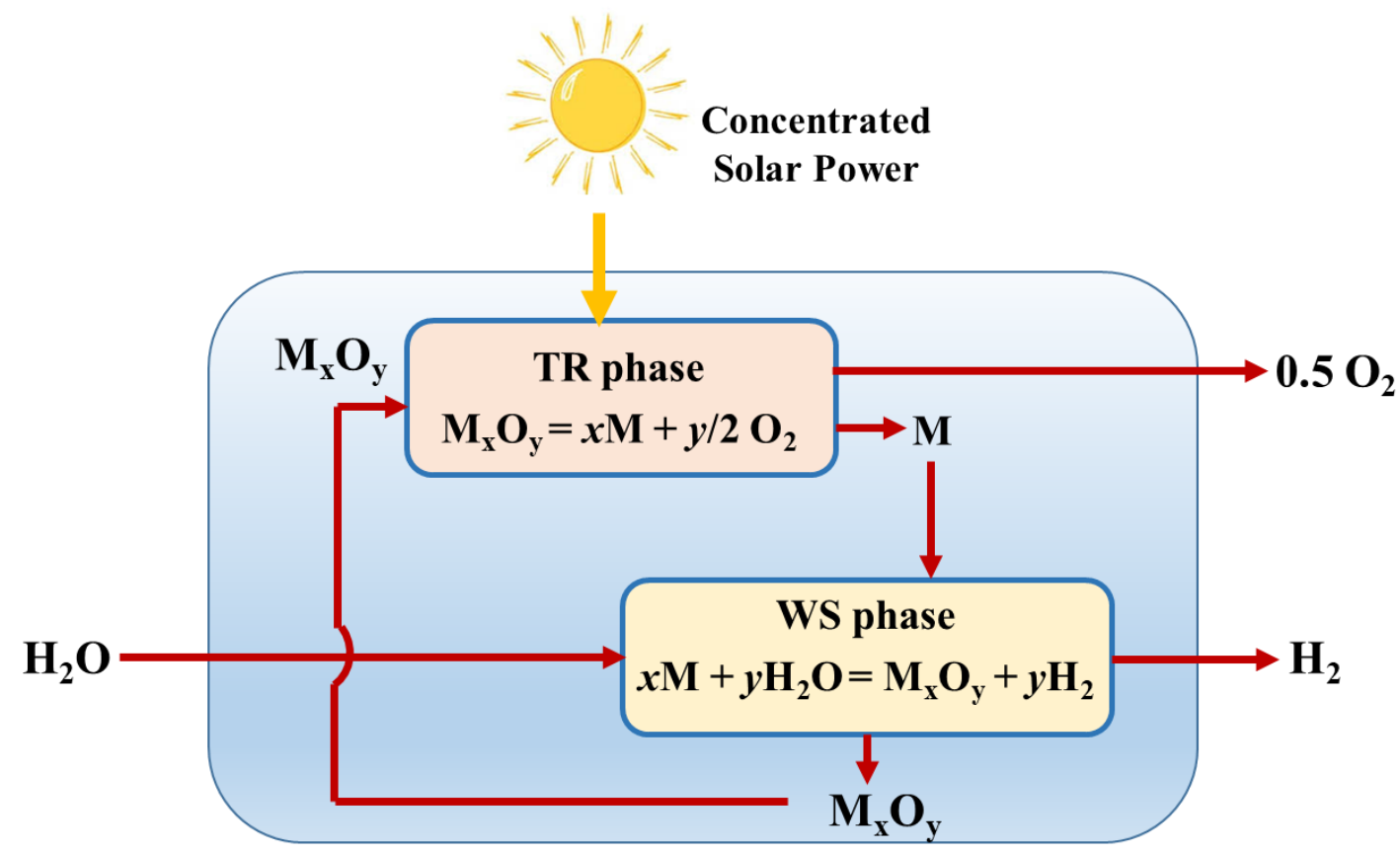

Figure 7: Two stages of the water-splitting process [152].. Wang et al. [152] proposed a new solar receiver/reactor structure that can be used to increase the thermal efficiency by 8.35$15.85 \%$ of a methane steam reforming powered by CSP.

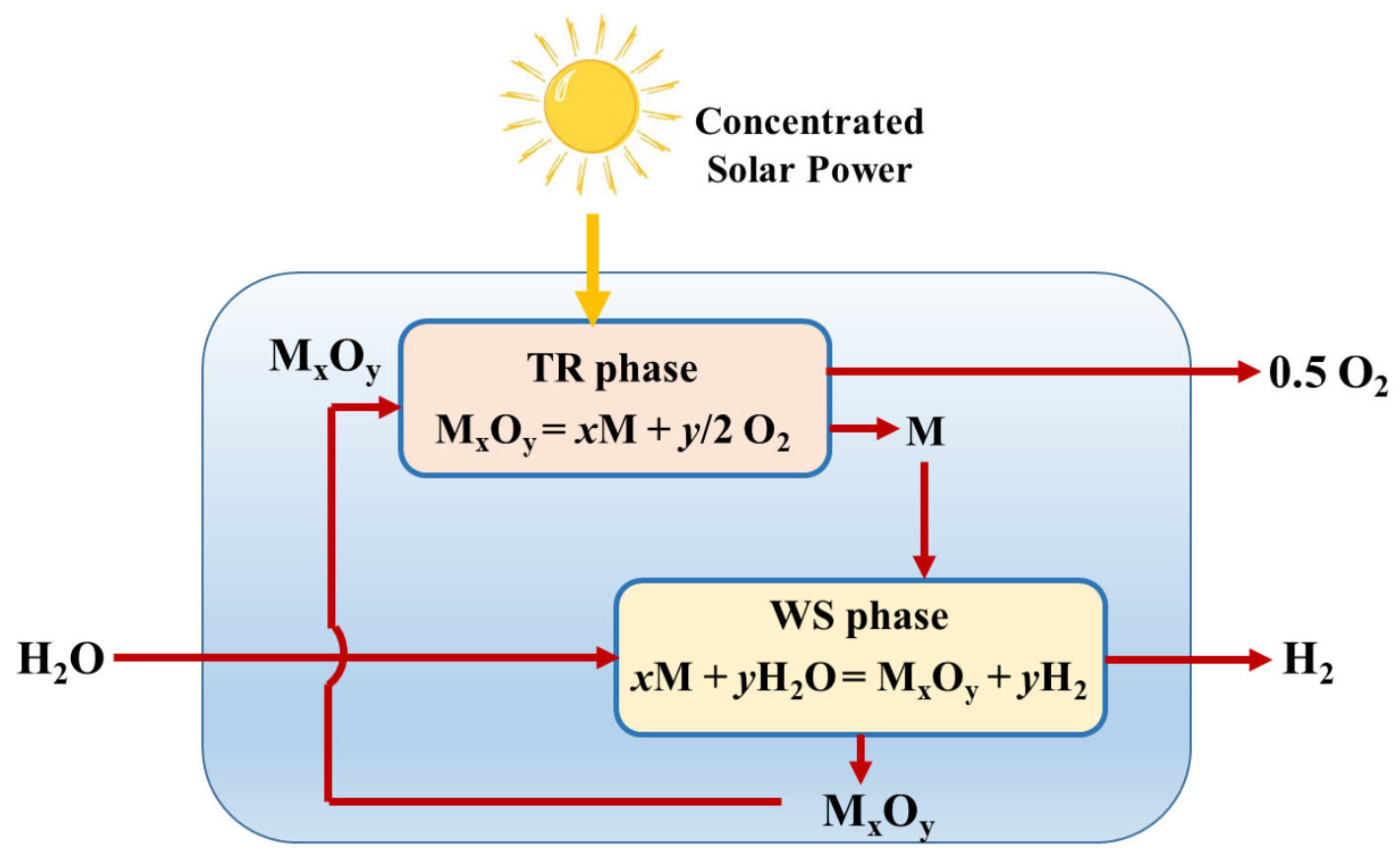

Figure 7: Two stages of the water-splitting process [152]. 


\subsection{Comparative evaluation of current hydrogen production technologies}

Literature has a large number of excellent work dedicated to hydrogen generation. These contributions can be broken down into a simple schematic shown in Figure 8. The Figure shows that such technologies can be divided into two main categories according to the resources, i.e., renewable and nonrenewable. Non-renewable sources mainly from fossil fuel and used in two main processes, which are gasification and steam reforming. Also, hydrogen is produced by renewable sources, which is considered more important these days due to high carbon emissions and other environmental issues. Solar PV, wind energy, and geothermal energy are mainly used in water electrolysis for hydrogen. $\mathrm{H}_{2}$ from renewable sources is recommended due to its high purity, and it is used for storing the surpass energy production for solar and wind. However, it faces difficulty in storing hydrogen and relatively high cost. Biomass energy is considered as one

of the major sources for hydrogen production. It has different features, including the fact that it uses wastes for producing useful Hydrogen, and it's the cheapest source that is available everywhere. The thermo-chemical process is considered better than the biological due to its higher production rate. The advantages and disadvantages of hydrogen production by different renewable sources is summarized in Table 6. 


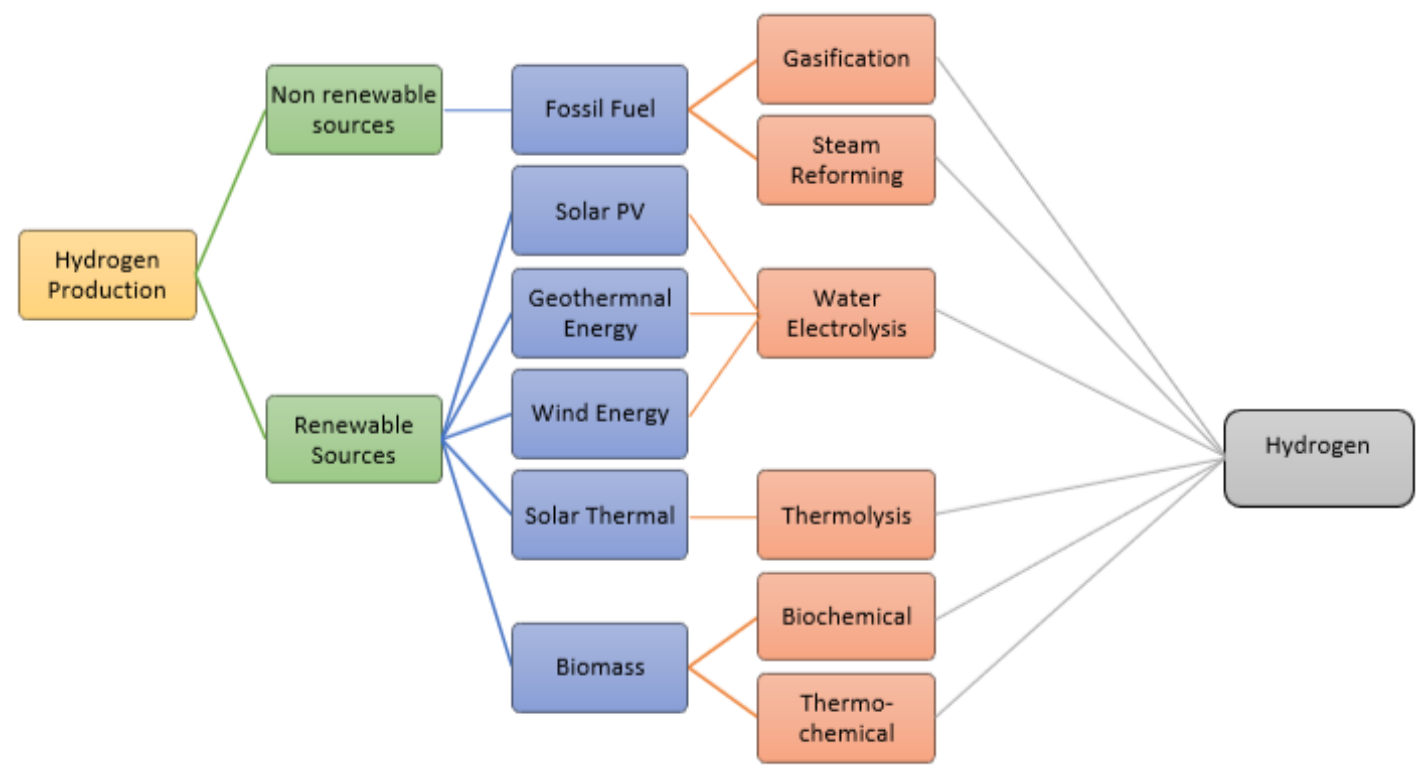

Figure 2: Hydrogen Production methods from renewable and non-renewable methods.

Table 6: Comparison of different hydrogen production sources

\begin{tabular}{|c|c|c|}
\hline $\begin{array}{c}\text { Hydrogen } \\
\text { Production Source }\end{array}$ & Advantages & Disadvantages \\
\hline \multirow{2}{*}{ Biomass } & - Available everywhere & $\begin{array}{l}\text { Requires high energy } \\
\text { input. }\end{array}$ \\
\hline & - $\quad$ Cheap & o Very low productivity. \\
\hline \multirow{2}{*}{ Wind } & $\begin{array}{l}\text { - } \begin{array}{l}\text { Simple and clean } \\
\text { mechanism }\end{array} \\
\end{array}$ & $\begin{array}{ll}\text { Oluctuations in energy } \\
\text { production. }\end{array}$ \\
\hline & & $\begin{array}{l}\text { O Mature turbine } \\
\text { structure. }\end{array}$ \\
\hline \multirow{2}{*}{ Solar thermal } & - Very clean & $\begin{array}{l}\text { O Requires handling } \\
\text { high temperature. }\end{array}$ \\
\hline & - Very efficient & \\
\hline \multirow{2}{*}{ Solar PV } & $\begin{array}{l}\text { - Clean energy and zero } \\
\text { emission. }\end{array}$ & $\begin{array}{l}\text { Solar energy is not } \\
\text { stable }\end{array}$ \\
\hline & $\begin{array}{l}\text { - Very high purity of } \\
\text { hydrogen. }\end{array}$ & o High installation \\
\hline
\end{tabular}




\begin{tabular}{|l|l|l|}
\hline \multirow{2}{*}{ Geothermal } & $\bullet \begin{array}{l}\text { Low environmental } \\
\text { impact }\end{array}$ & $\begin{array}{l}\text { Requires handling } \\
\text { high temperature. }\end{array}$ \\
\cline { 2 - 3 } & $\begin{array}{l}\text { More stable than wind } \\
\text { and solar PV }\end{array}$ & \\
\hline
\end{tabular}

\section{Hydrogen and energy storage}

Energy storage plays an important role in overcoming the intermittent character of the different renewable energy sources such as wind, tidal, and solar energy [153]. The common energy storage technologies "capacity vs time" is shown in Figure 9. In the regard of the increased interest in the industrial sector to replace fossil fuels with renewable energy sources [154, 155], Hydrogen is considered as a promising energy storage medium, especially with its potential to be used in the transportation sector using fuel cells. However, hydrogen, with its low density in the gaseous state, requires a huge volume for a small mass of hydrogen, and this would have an implication on its usage for energy storage applications. For instance, one kilogram of hydrogen occupies one cubic meter under normal pressure and temperature conditions [156]. Therefore, significant research efforts are directed towards increasing hydrogen density, such as using pressurized vessels and/or liquefaction. However, such methods require a large amount of energy in the form of work, heat, and hydrogen-binding materials in some cases. Hydrogen can also be used for storing seasonal energy; however, the basic requirement to bring these synergies into action is low-cost hydrogen storage techniques [83].

Based on the analysis done by the International Renewable Energy Agency (IRENA), the need for storage to incorporate massive shares of solar and wind powers will rise significantly in 2050, compared to today [157]. Production of a relatively huge quantity of renewable hydrogen integrated with hydrogen storage can support the system to be flexible in the long term, as shown in Figure 10. 


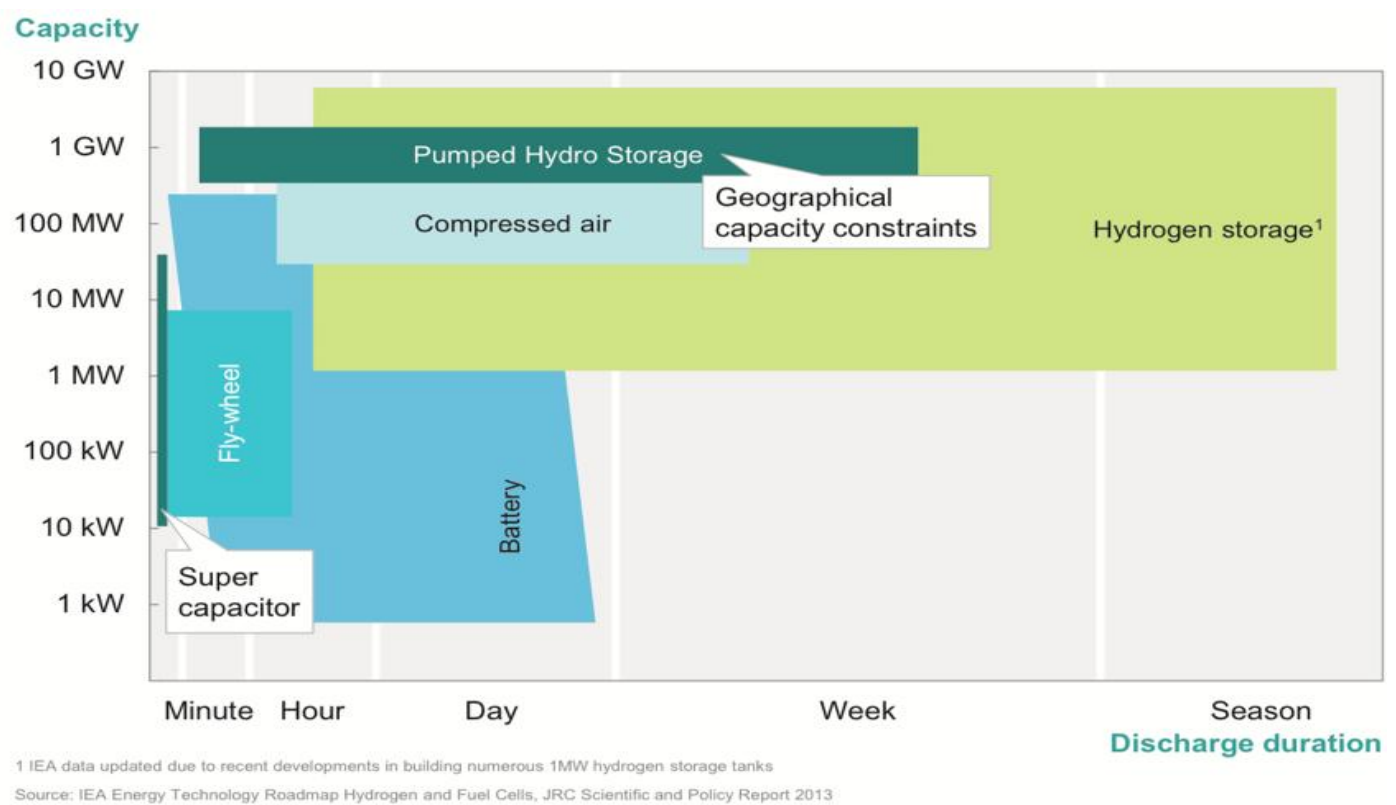

Fig 9. The current technologies of energy storage [158].

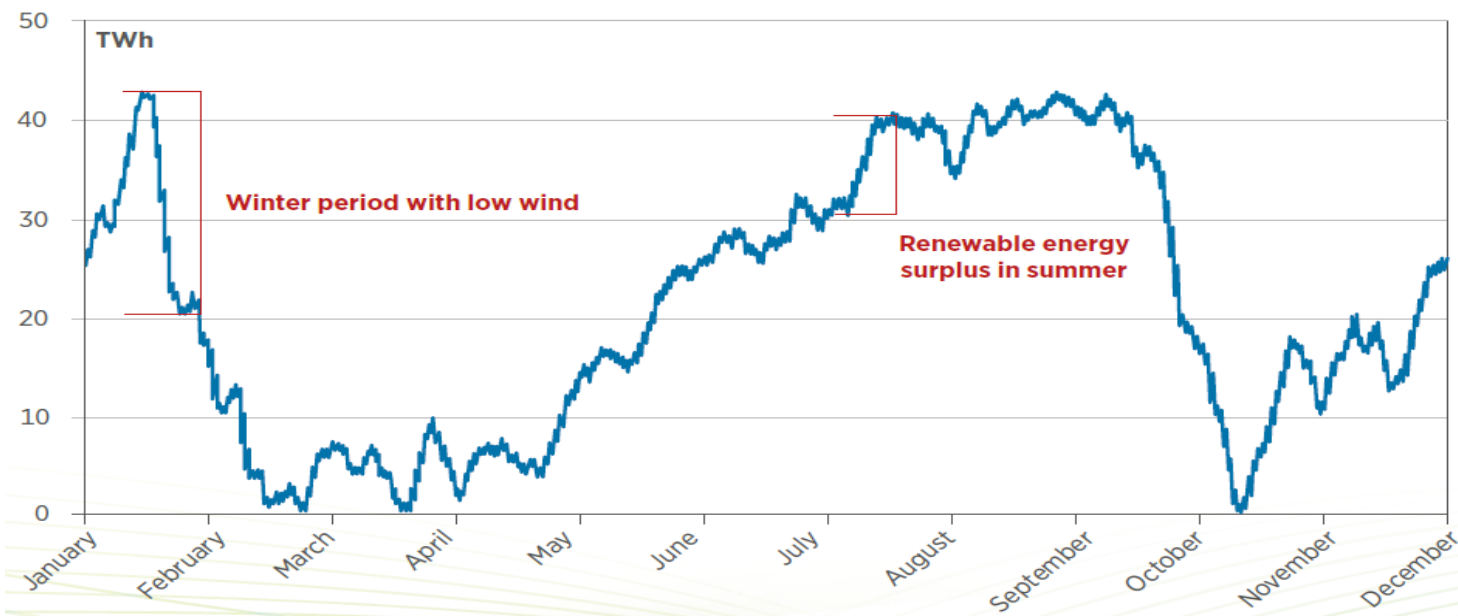

Fig 10. Hydrogen storage profile in 2050 [83].

The main hydrogen storage technologies is shown in Figure 11. This splits the technologies of hydrogen storage into three primary categories: (1) the physical storage of hydrogen in pure gas or liquid forms, that doesn't involve any chemical or physical bonding with other substances, (2) adsorption in which hydrogen is combined with other materials via relatively weak van der Waals bonds, and (3) chemical storage in which hydrogen forms chemical bonds with other materials such as metal hydrides and chemical hydrides. The following section will focus on the different methods for hydrogen storage, focusing on large-scale ones. 


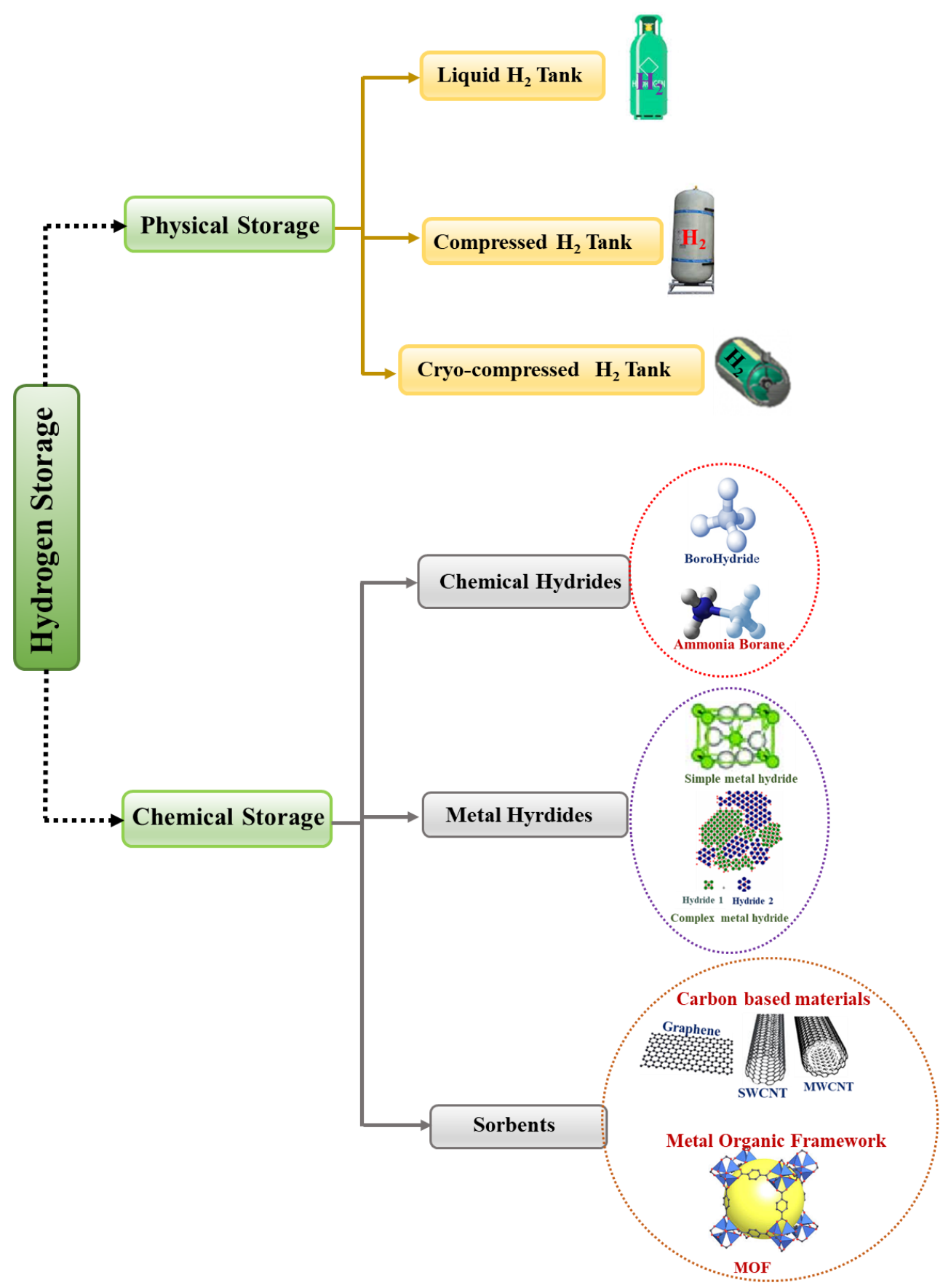

Fig 11. Different approaches for hydrogen storage.

\subsection{Technologies of hydrogen storage}

Hydrogen stockpiling should be possible truly, artificially, and electrochemically. The materials utilized for hydrogen stockpiling are alloys, metal-natural structures, nanotubes, nanoribbons, nanofibers, carbon-based materials like graphene, and so on [159]. As a result of high 
gravimetric and volumetric hydrogen limits and fascinating cation and hydrogen dissemination properties, complex hydrides and complex hydrides-based materials have been intensely explored as a material for vitality stockpiling [160]. In worry of hydrogen stockpiling, the fundamental constraint of this class of materials is the high working temperatures and weights, the low hydrogen retention and desorption rates, and the helpless cyclability [161]. In this way, the nanomaterial-based strong state hydrogen stockpiling techniques are being utilized. Because of the consumption of petroleum derivatives and the impact on environmental change, and conceived hydrogen economy is a reasonable option in contrast to ensuing vitality issues. Hydrogen creation, stockpiling, dissemination, and usage make up the principal components of a visualized hydrogen economy framework. To accomplish a hydrogen economy, hydrogen stockpiling remains the hugest test, for that reason several nanomaterials and nanocomposites being utilized as an expected possibility for strong state hydrogen stockpiling. The sane plan of nanomaterials could assume a significant part in accomplishing a sustainable power source based economy, which is a framework for long haul answers for a protected vitality future [159]. In past years, the hydrogen delivery and take-up component of the immaculate and catalyzed materials and portrayal of the thermodynamic perspectives are engaged to normally pick the creation and the stoichiometry of the frameworks regarding hydrogen dynamic stages and impetuses/destabilizing operators [162]. To discover frameworks with properties reasonable for viable ready and fixed application, new materials have been found and described. New roads open up for the transformation and use of sustainable power source assets by the quick improvement of nanostructured materials plans. The sunlight based hydrogen creation strategy is utilized for the pragmatic utilization of sustainable assets, which incorporate photoelectrochemical water parting (PEC) and photocatalytic hydrogen creation, strong state hydrogen stockpiling, and proton trade layer power devices (PEMFCs) [163]. The ordinary hydrogen stockpiles are not productive in ready applications. Thus, in strong state hydrogen stockpiling strategy completed either by compacted gas or by liquefaction [164]. The advancement of ease, lightweight hydrogen stockpiling improvement framework with a high limit, and quick energy can evade the troubles of installed applications [161]. Different techniques used to upgrade hydrogen stockpiling limit like "Kubas" infraction (metal hydrides or compound hydrides experience the ill effects of moderate charge-release energy and helpless reversibility on account of solid restricting cooperation between hydrogen atoms and metals), 
overflow impact (utilization of heterogeneous impetus are utilized), functionalization (use carbon base nanomaterials) [165]. The physical storage of pure hydrogen in its gas and liquid phases are the most suitable technology for large scale storage applications [166, 167].

\subsubsection{Gaseous hydrogen storage}

\subsubsection{Natural underground hydrogen storage}

Underground hydrogen storage facilities, similar to the traditional ones that are used for storing natural gas, maybe constructed at sites with favorable geological conditions. The criteria and specifications for the identification of a deposit or formation as a suitable site for underground hydrogen storage should be dependent on detailed geological evaluation. The main deposit's features of interest for hydrogen storage are structural depth thickness, tightness, tectonic and seismicity issues, hydrogeological and geothermal issues, reservoir pressure, reservoir characteristics, porosity and permeability, geomechanical properties, and the suitable characteristics of the insulating roof rocks [168, 169]. Underground hydrogen storage systems have a round trip efficiency in the range of $30 \%$ to $40 \%$, and it can be enhanced by up to $50 \%$ if additional efficient technologies are improved effectively [169]. Obviously, systems based on the storage of compressed hydrogen gas have two main parts, including the storage chamber and the compressor, which is important to increase the pressure. As a result of initial and operating costs as well as the special materials from which storage containers need to be made, hydrogen gas is usually stored at pressures of less than 100 bar in aboveground containers. Otherwise, underground containers or caverns are more suitable for pressures up to 200 bar [170]. Since storage pressures are limited, the attainable hydrogen gas storage density at 100 bar and 20 is approximately $7.8 \mathrm{~kg} /$. Achieving a large specific volume involves higher investments and operating costs $[171,172]$. Generally, the aboveground hydrogen storage's investment costs are significantly higher than the underground one, and thus the latter is the preferred option for large-scale storage. Underground hydrogen storage sites were identified in many countries around the globe. HyFrance 3 analyzed the measurements of hydrogen mass storage and the costs associated with the growth of energy networks in certain French regions, including Rhône-Alpes and PACA (Provence-Alpes-Côted'Azur), over the next few decades (up to 2050). Various underground French facilities such as depleted oil fields, aquifers, excavated rock mines, and salt 
caverns were considered, and the study specifically concentrated on thick salt deposits due to their good cycling performance, acceptable depths, and cushion gas requirements [173]. Teeside, UK, and Texas, USA, have already verified that salt cavities are capable of storing large amounts of hydrogen underground [174]. Northern Germany is also geologically accessible for salt caverns storage, where the geological criteria include a sufficient thickness of at least $200 \mathrm{~m}$ in salt, a minimum to top salt depth of about $500 \mathrm{~m}$, and a maximum salt depth of about $1400 \mathrm{~m}$, as well as a maximum insoluble content of $30 \%$ in rock salt, besides a total hydrogen storage potential of 8.8 billion in all available regions in Germany that can be used for hydrogen storage [175]. Midland Valley of Scotland has three hydrogen storage potentials in: (1) the Devonian Stratheden and Inverclyde Groups; (2) the upper part of the Carboniferous Strathclyde Group; and (3) the lower part of the Carboniferous Clackmannan Group [176]. Four potential sites in Romania have been chosen for hydrogen storage inside salt caverns including Ocna Mures, Targu Ocna, Ocnele Mari and Cacica [177]. Permian salt-bearing formations were also suggested as potential sites for hydrogen storage in Poland [178]. Figure 12 shows the concept of underground hydrogen storage. 


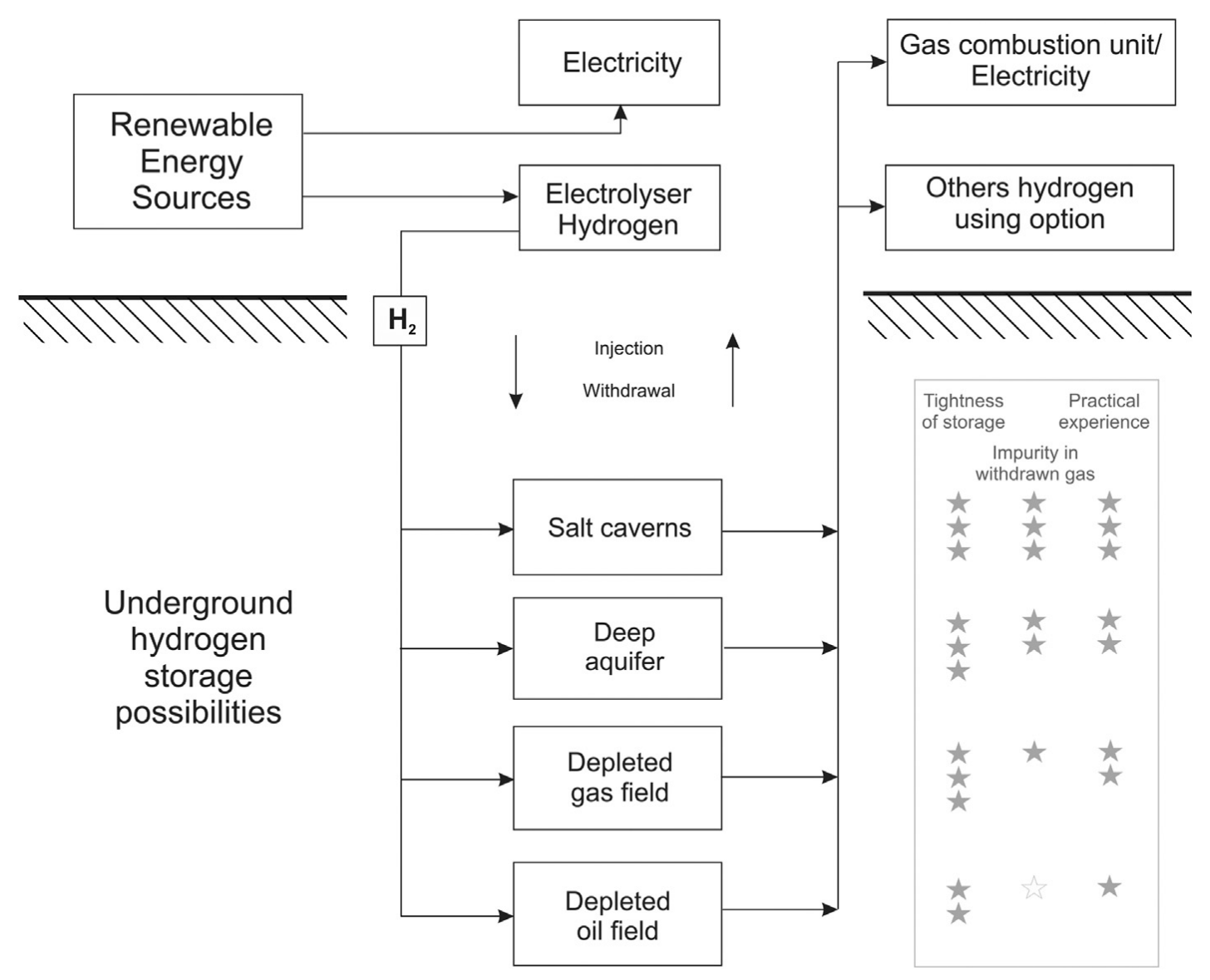

Fig 12. The concept of underground hydrogen storage in geological structures [168].

Salt cavities are the most favorable type for underground hydrogen storage for many reasons, such as low construction costs, rapid withdrawal, and injection rates, minimal leakage rates, relatively low requirements of cushion gas, and minimum hydrogen contamination hazards [179]. There are three main geological conditions that should be satisfied in order to construct salt caverns including (1) functionally qualified salt at an acceptable volume, with sufficient thickness and without an overload of insoluble, (2) suitable feed of freshwater for salt draining, (3) environmentally friendly and cost-effective brine disposal ways [179]. Based on the requirements and technical feasibility, they can be built at depths of up to $2000 \mathrm{~m}$, with volumes of up to 1,000,000, with average heights of 300-500 m, and with a diameter of 50-100 m. Based on the size, they can be powered at pressures up to or above 200 bar, enabling very large quantities of gas to be stored [175]. It is worth mentioning that the geological requirements for underground salt cavities construction are not yet available for all sites, and therefore alternative 
solutions are needed for hydrogen storage in those regions [179]. Storage caverns in salt layers and salt domes are illustrated in figure 13, and within a large-scale hydrogen storage system in figure 14 .

Aquifers are basically type of porous and permeable rock formations with pore space occupied by fresh or saltwater (in higher depths). These are popular in all sedimentary lakes around the world and may provide an option for underground storage of hydrogen in places where there are no evacuated hydrocarbon reserves or salt caverns. The main requirements for using porous media formations as underground hydrogen storage sites are: (1) the porous media formations are made up by a preamble tank such as sandstones, (2) the rocks were chosen for disposal have strong tank properties and are overlaid with impermeable roof rocks to avoid the diffusion of the extracted gas, (3) the porous media formations are constructed to act as traps for side inclusion, (4) porous media formations should be located at reasonable depths, typically in the range of 500 to $2000 \mathrm{~m}[16,28,29]$. Table 7 summaries the general criteria and requirements of salt caverns and porous rock reservoirs [179], and Table 8 shows the comparison between salt caverns and aquifers.

Table 7.General criteria for salt caverns and porous rock reservoirs [179].

\begin{tabular}{|c|c|c|}
\hline \multirow[t]{2}{*}{ Criteria } & \multicolumn{2}{|c|}{ Requirements } \\
\hline & salt caverns & porous rock reservoirs \\
\hline Geology Rock Type & Salt formation & $\begin{array}{c}\text { Sandstones and } \\
\text { conglomerate, preferably }\end{array}$ \\
\hline Structure & Salt Domes Bedded Salt & Anticline or dome \\
\hline Composition & $95 \%$ of Halite & \\
\hline Caprock & Anydrite, Gypsum, Limestone & $\begin{array}{c}\text { Shale, Siltstone, Carbonate } \\
\text { rocks }\end{array}$ \\
\hline $\begin{array}{l}\text { Minimum caprock } \\
\text { thickness }\end{array}$ & - & $6 \mathrm{~m}$ \\
\hline
\end{tabular}




\begin{tabular}{|c|c|c|}
\hline Depth & 200 to $2000 \mathrm{~m}$ & $200-2000 \mathrm{~m}$ \\
\hline Height & Typical values around $300 \mathrm{~m}$ & \\
\hline Porosity & & $\geq 10 \%$ \\
\hline Diameter (D) & Typical values around $70 \mathrm{~m}$ & \\
\hline Permeability & - & $>300 \mathrm{md}$ \\
\hline $\begin{array}{l}\text { Height/Diameter Ratio } \\
\text { (H/D) }\end{array}$ & Typical value 5 ; range from 5 to 20 & \\
\hline Vertical Closure & - & $\geq 10 \mathrm{~m}$ \\
\hline $\begin{array}{l}\text { Distance between caverns } \\
\text { (S) }\end{array}$ & Typical value around $300 \mathrm{~m}$ & \\
\hline $\begin{array}{l}\text { Separation/Diameter } \\
\text { Ratio (S/D) }\end{array}$ & $\begin{array}{c}\text { Typical value }>4 \text {; range from } 2 \text { to } \\
10\end{array}$ & - \\
\hline Thickness & - & $\geq 10 \mathrm{~m}$ \\
\hline $\begin{array}{l}\text { Maximum Salt } \\
\text { temperature }\end{array}$ & $80^{\circ} \mathrm{C}$ & \\
\hline Discovery Pressure & - & $2-8 \mathrm{MPa}$ \\
\hline Volume of Storage & $\begin{array}{c}300000-750000 \mathrm{~m} 3 \text { (Salt domes); } \\
100000 \mathrm{~m} 3 \text { (Bedded Salt) }\end{array}$ & - \\
\hline Lifetime of Salt Cavern & $30-50$ years & - \\
\hline
\end{tabular}



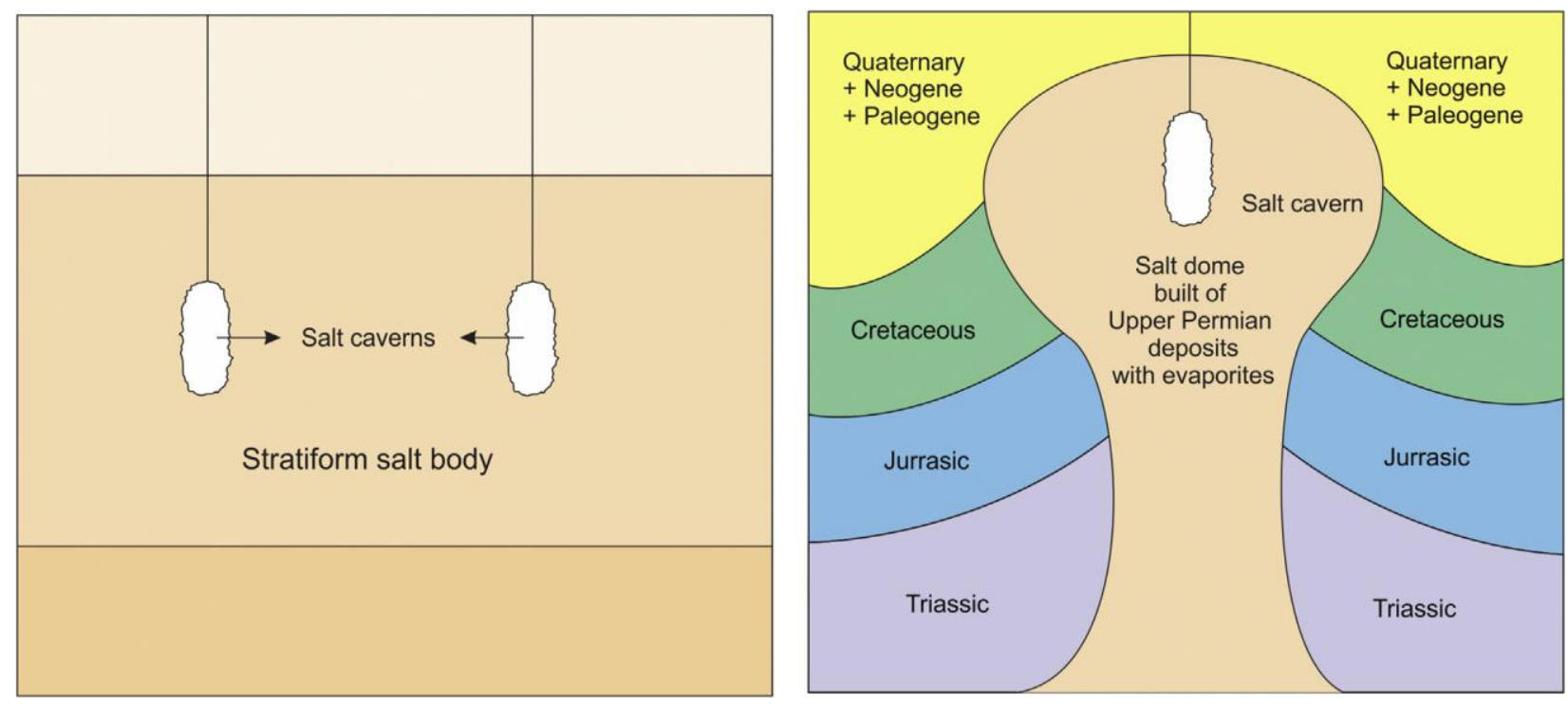

Fig 13. Storage caverns in salt layers (left) or salt domes (right) [178].

Table 8. Comparison between salt caverns and aquifers.

\begin{tabular}{|c|c|c|}
\hline $\begin{array}{l}\text { Underground } \\
\text { storage type }\end{array}$ & Salt formation ( salt caverns ) & Porous media formation ( Aquifers ) \\
\hline $\begin{array}{l}\text { General criteria } \\
\text { requirements }\end{array}$ & $\begin{array}{l}\text { Functionally qualified salt at } \\
\text { acceptable volume, with } \\
\text { sufficient thickness and } \\
\text { without overload of insoluble. } \\
\text { - Suitable supply of fresh water } \\
\text { for salt draining. } \\
\text { Brine disposal methods should } \\
\text { be environmentally and } \\
\text { economically reasonable. }\end{array}$ & $\begin{array}{l}\text { The porous media formations are } \\
\text { made up by a preamble tank. } \\
\text { The rocks chosen for disposal } \\
\text { have strong tank properties and are } \\
\text { overlaid with impermeable roof } \\
\text { rocks to avoid the diffusion of the } \\
\text { extracted gas. } \\
\text { The porous media formations } \\
\text { should be constructed to act like } \\
\text { traps for side inclusion. } \\
\text { Porous media formations should } \\
\text { be located at reasonable depths. }\end{array}$ \\
\hline Advantages & $\begin{array}{l}\text { - } \text { Cheap construction cost. } \\
\text { - } \text { Minimum rates of leakage. } \\
\text { - } \quad \text { Rapid injection and discharge. } \\
\text { - } \quad \text { Low requirements of gas } \\
\text { cushion. } \\
\text { - } \text { Minimal hydrogen } \\
\text { contamination risks }\end{array}$ & $\begin{array}{l}\text { - No risk of hydrogen contamination } \\
\text { with hydrocarbon leftovers } \\
\text { compared to depleted hydrocarbon } \\
\text { fields. }\end{array}$ \\
\hline & - The need to dispose massive & - Reaction of hydrogen with \\
\hline
\end{tabular}




\begin{tabular}{|l|l|l|}
\hline Limitations & amounts of salt brine. & $\begin{array}{l}\text { minerals might occur. } \\
\bullet\end{array}$ \\
& $\begin{array}{l}\text { Hydrogen might react with } \\
\text { microorganisms }\end{array}$ \\
\hline
\end{tabular}

Along with storage containers options that are represented previously, a massive underground gas storage container (lined rock cavern) is located in Skallen, Sweden. Such lined rock caverns are in cylindrical shape that lined with steel for gas tight purposes, enabling a maximum storage pressure of 200 bar [180].

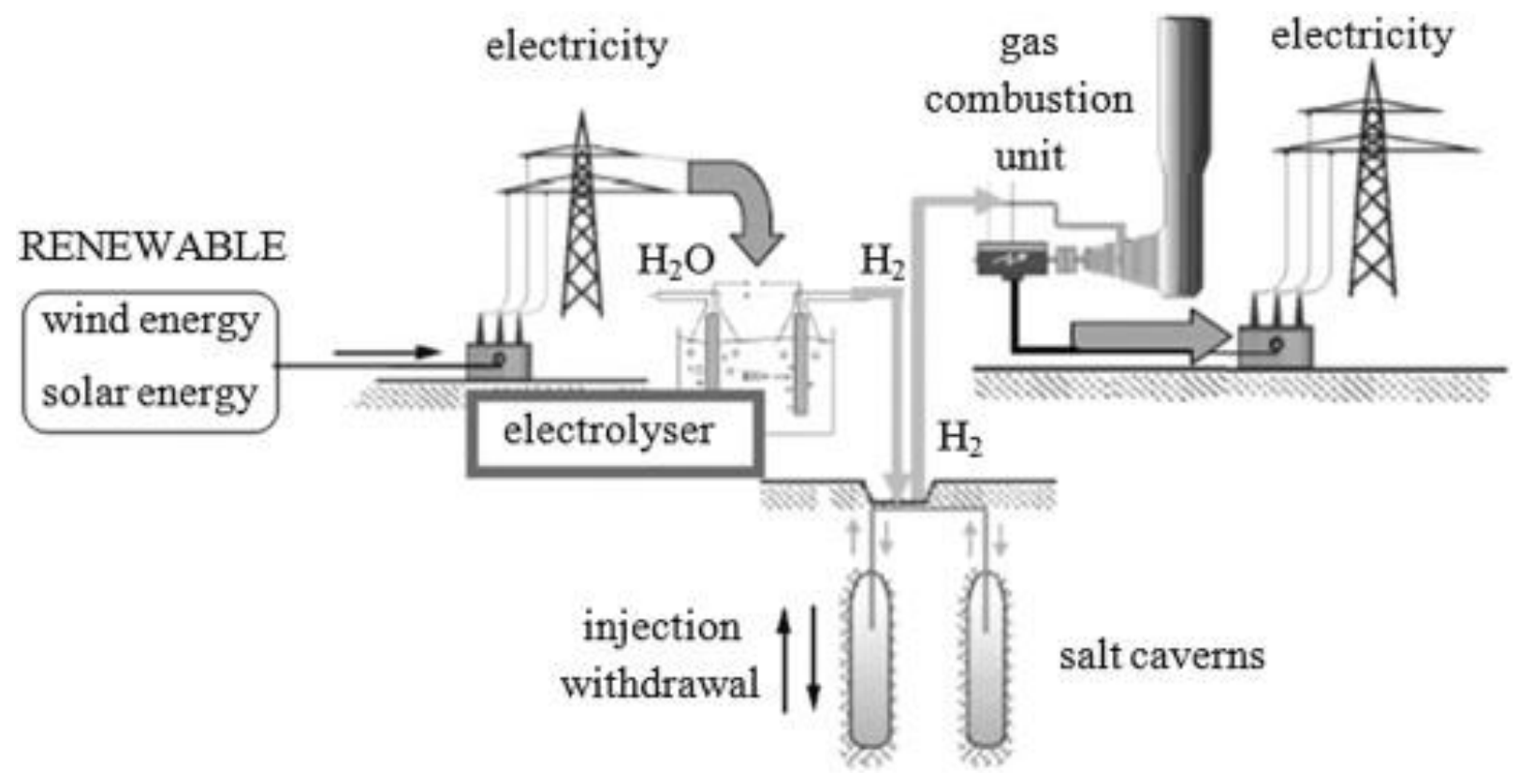

Fig 14. Salt caverns in large-scale hydrogen storage system [181].

\section{4..1.1.2 Metallic containers}

Despite increasing the investment cost, metallic containers can be a viable alternative for gas storage as they guarantee storage steadiness, purity of stored hydrogen, and can be implemented independently on the site. If there are potential safety concerns regarding long term integrity of the containers (due to climatic conditions), the containers can be buried a few meters underneath the surface level. Generally, using underground containers provide many advantages including 
space saving, additional protection against physical impacts and weather, and reducing the insulating costs. On the other hand, when it is underground, storage inspection becomes more challenging and effective protection against corrosion, using exterior coatings, becomes essential [179].

Currently, there are three main types of metallic containers that can be used to store larger amounts of natural gas including gas holders featuring a storage pressure slightly higher than atmospheric pressure, spherical containers with maximum storage pressure of approximately 20 bar, and pipe storage with maximum storage pressure of approximately 100 bar [166]. Due to its capability of providing high storage pressures, pipe storage can be considered as the most attractive choice for large scale hydrogen storage. The construction of hydrogen pipe storage system is comparatively simple where it consists of a set of pipelines connected together where the total length of the pipeline could reach several of kilometers and is placed few meters below the surface level [166]. Some technical issues related to the construction of hydrogen pipe for storage and transportation are now well-known and have their own standards and codes [182, 183]. A word of caution is due, however, against hydrogen embrittlement encountered by pipes and containers with its negative effects on the mechanical characteristics of pipe materials, will increase the overall construction cost of hydrogen pipe storage system [184]. The cost of Type IV 350 bar hydrogen pressure vessel is analyzed based on the validated compressed natural-gas (CNG) cost model, the cost breakdown of modeled CNG pressure vessels as well as cost analysis of type IV 350 bar vessel are graphically shown in Figure 15 and Figure 16, respectively [185]. It is clear from the two figure the significant decrease in the price with the increase of the number of the systems. 


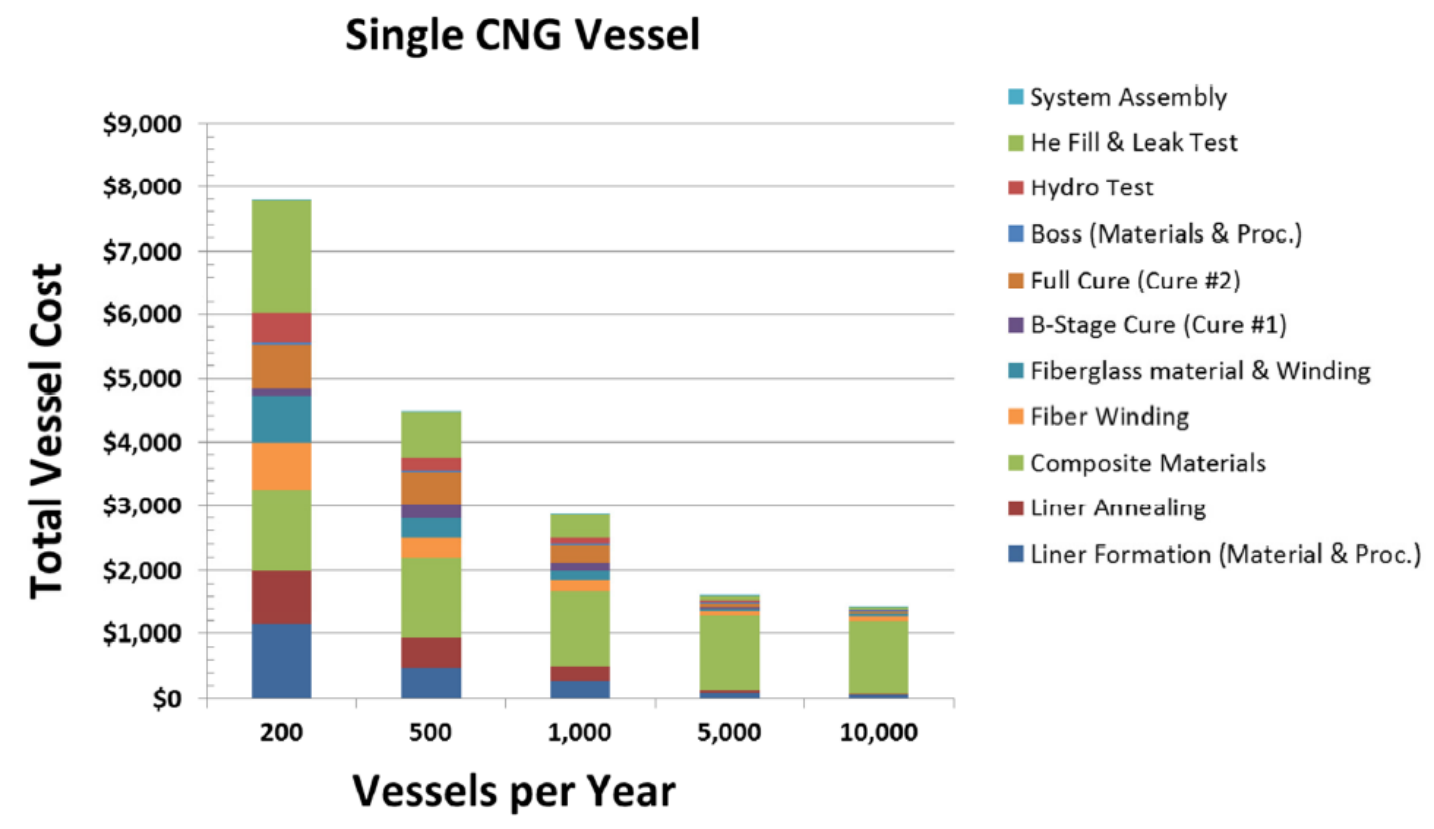

Fig 15. Cost breakdown for modeled 275 L 250 bar type IV CNG vessels at multiple production volumes [185].

\section{MPa Compressed Gas Storage System}

Single tank holding $5.6 \mathrm{kgH}_{2}$ usable, cost in $2007 \$$

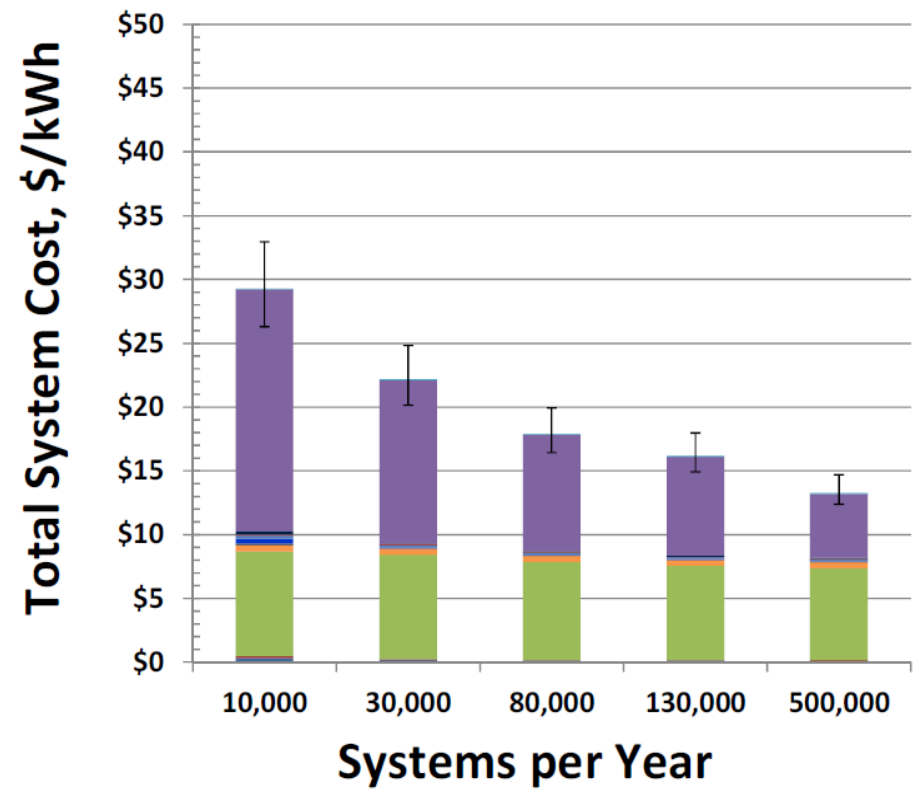

\footnotetext{
- System Assembly

- Balance of Plant (BOP) Items

- He Fill \& Leak Test

Hydro Test

Boss (Materials \& Proc.)

- Full Cure (Cure \#2)

口-Stage Cure (Cure \#1)

Fiber Winding

Composite Materials

- Liner Annealing

- Liner Formation (Material \& Proc.)
}

Fig 16. Cost breakdown for modeled 275 L 250 bar type IV CNG vessels at multiple production volumes [185]. 


\subsubsection{Liquid hydrogen storage}

In addition to the compression option, liquefaction of pure hydrogen can also be used to increase its density. Liquefaction allows the density of hydrogen to reach around $70 \mathrm{~kg} / \quad$ at the atmospheric pressure [184]. Magnificently, liquid hydrogen has gained massive interest due to several splendid reasons such as it is the cleanest fuel, has the best energy to weight ratio among other fuels, has good chemical and physical properties, and stores around 2.8 times the energy of gasoline [10]. However, the energy-intensive liquefaction mechanism remains a significant challenge of the liquid hydrogen storage. As it is known, the boiling point of hydrogen is very low, approximately $-253^{\circ} \mathrm{C}$ at 1 bar, as well as hydrogen gas does not cool down during throttling (adiabatic, isenthalpic expansion) at temperatures more than $73^{\circ} \mathrm{C}$ and therefore, the hydrogen requires pre-cooling, using evaporating liquid nitrogen, during the liquefaction process which increases the energy requirements of the process [186]. Table 9 represents both advantages and disadvantages of liquid hydrogen.

\section{Advantages}

Disadvantages

- Zero emissions production.

- Best energy to weight ratio among other fuels.

- 2.8 times the energy storage capacity of gasoline

- Higher density compared to hydrogen gas
- High flammability

- Expensive

- The hydrogen Liquefaction process requires extreme energy levels

- Requires Special storage tank design

Table 9. Advantages and disadvantages of liquid hydrogen.

The conventional hydrogen liquefaction process consists of three main steps as shown in Figure 17. In the first step, pure and dry hydrogen is compressed at a pressure higher than the critical hydrogen pressure (process $1 \rightarrow 2$ ). After the compression, the compressed hydrogen is 
cooled down to a low temperature (process $2 \rightarrow 4$ ) via two stages;(a) pre-cooling stage (process $2 \rightarrow 3$ ) and (b) final cooling stage (process $3 \rightarrow 4$ ). In the precooling stage, the hydrogen is cooled down from the ambient temperature to a lower temperature, called as liquid nitrogen temperature level, where the heat flow ( $\quad$ ) is removed from the hydrogen feed in this stage. Following that, Hydrogen is cooled down again to a temperature in the final cooling stage where the heat flow is removed from the hydrogen feed. In the final step, Hydrogen is expanded from high pressure to low pressure using a valve (process $4 \rightarrow 5$ ).

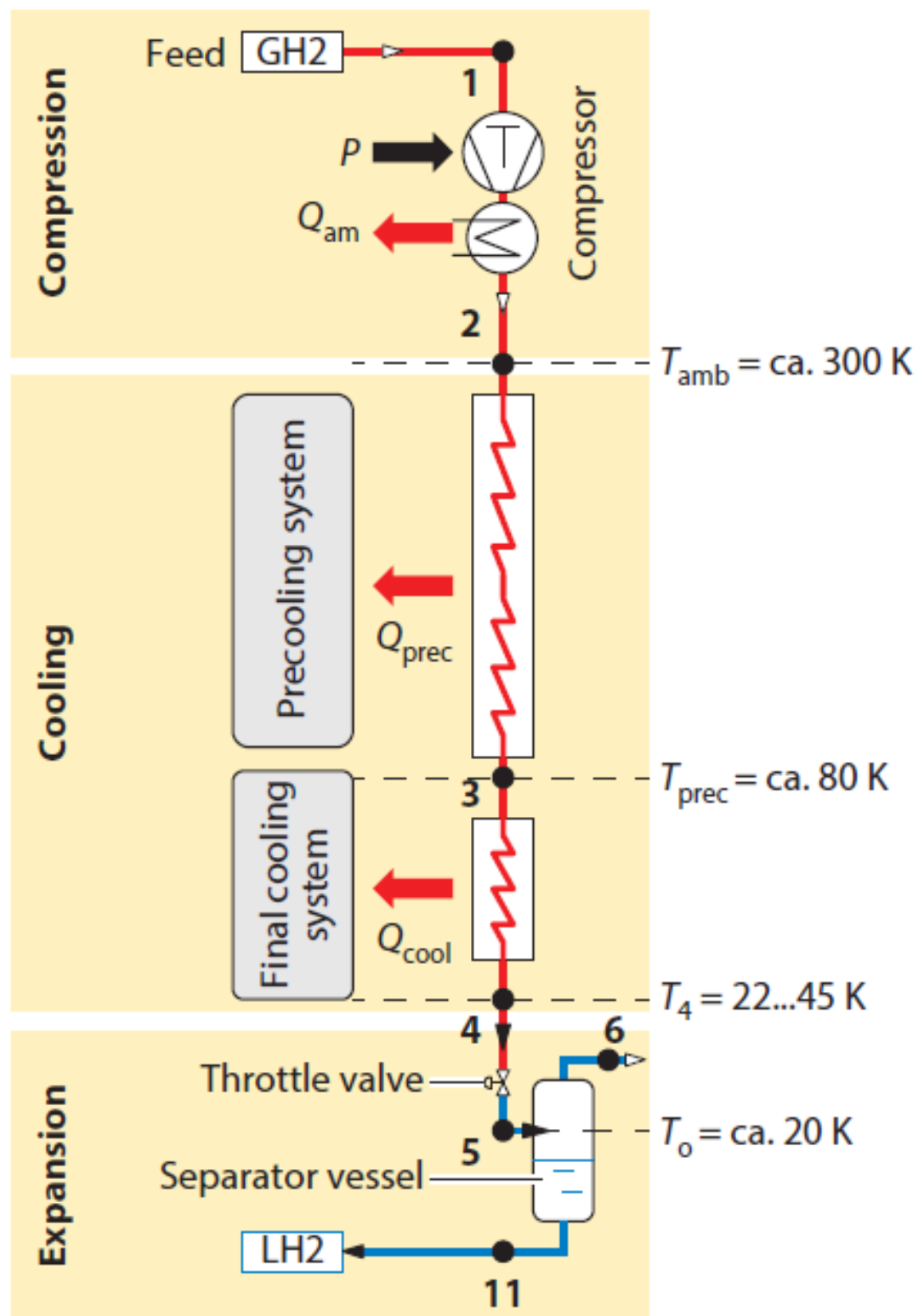


Fig 17. The general principle of hydrogen liquefaction [187].

There are two novel approaches developed for large-scale hydrogen liquefaction, including High-pressure hydrogen Claude cycle and dual hydrogen-neon cascade cycle [161]. The high-pressure hydrogen Claude cycle design consists of extremely efficient reciprocating compressors and turboexpanders supported with the option of energy recovery. In contrast to the conventional Claude cycle process, the operation requires higher-pressure levels as well as extreme pre-cooling temperatures [161]. In the dual hydrogen-neon cascade cycle approach, the process takes place within two cycles, including a reversed Brayton cycle with the hydrogenneon mixture and pure hydrogen Claude cycle, which is responsible for the ultimate supply of liquefaction. The hydrogen-neon Brayton cycle is normally performed in turbo compressors with enhanced enclosure systems capable of reducing the leakage of expensive neon gas [161].

The specific energy consumption of most current plants of hydrogen liquefaction is about 10

$/ \mathrm{kg}$, but it is expected that these figures can be decreased to lower than $6 \quad / \mathrm{kg}$ through conducting distinct process improvements in larger plants [188-190]. Still, capital expenses of a liquefaction-based plant are as yet a critical aspect of the total expenses of liquefaction, even for bigger plants [188]. For example, it has been assessed that the capital investment establishes around 40-50\% of the particular liquefaction costs for a new 100 tonnes per day (tpd) liquefaction plant [161].

The liquid hydrogen is normally stored in containers with double walls and a high vacuum between them in order to reduce the heat transfer rate by convection and conduction [191]. Further materials like polyester sheets coated with alumina; interchanging layers of glass fiber and aluminum foil; or perlite particles, silica, or aluminum are used in order to act as a shield against heat transfer by radiation [166, 192, 193]. Therefore, the strong insulation level and the low ratio of a surface-to-volume result in very small boil-off levels for bigger spherical tanks, usually under $0.1 \%$ per day [194]. Despite their sophisticated design, the tanks used to store liquefied hydrogen are cheaper per hydrogen weight stored than those larger-scale containers used for storing compressed hydrogen gas [166, 193]. 


\subsubsection{Hydrogen absorption}

Hydrogen storage via absorption utilizes the physical bonding of van der Waals between a substance with a big specific surface area and molecular hydrogen. In order to accomplish sufficient densities of hydrogen storage through adsorption, liquid nitrogen is used as a refrigerant in the hydrogen absorption process, and pressure in the range from 10 to 100 bar, based on the adsorbent and the proposed application, is applied [195]. Moreover, the benefits of operating at higher levels of pressure levels off beyond a certain limit as adsorbents cease to enhance the storage capacity of hydrogen exponentially compared to lower pressures, so there exists a tradeoff between the energy needed for compression and added adsorption benefits [196]. Several adsorbents can be for hydrogen storage such as porous carbon-based materials [197], metal-organic frameworks (MOFs) [198], porous polymeric materials [199], and zeolites [200]. Activated carbons and MOFs are the most effective adsorbents as they are able to obtain extra hydrogen absorption between $8-10 \%$ (wt) of hydrogen at $-196^{\circ} \mathrm{C}$ [201-203].

Since most adsorbents used have low densities and with the required additives for heat conductivity optimization during the process, there is a limit to the density levels of hydrogen to be stored to be greater than $40-50 \mathrm{~kg} / \mathrm{m}^{3}$, which could be difficult to achieve via available adsorbents [204, 205]. Additionally, heat management is the most crucial defiance for hydrogen storage via absorption. Although the interplay is the week between the adsorbent and the hydrogen, usually 3-10 kJ per mol of hydrogen, the process of adsorption remains exothermic. The generated heat should be effectively removed to make sure a reasonable degree of adsorption can be attained.

\subsubsection{Metal hydrides}

Metal hydrides form strong chemical bonds with hydrogen. In fact, these bonds cannot be broken easily compared to the ones formed in the hydrogen absorption process. Therefore, a high level of energy is required to release the hydrogen from metal hydrides. The strong bonding associated with metal hydrides empowers the hydrogen to have high storage density even at atmospheric conditions [206]. Hydrogen is trapped during hydrogenation and experiences an exothermic reaction in order to form the metal hydride, but in the dehydrogenation process, the metal hydride goes through an endothermic reaction at elevated temperature and relatively low pressure so that hydrogen can be released back again [207]. 
Hydrogen can be extracted from metal hydrides by two methods, including thermolysis, in which metal hydrides is heated to a certain temperature, and hydrolysis, in which the metal hydrides react with water. The aforementioned strategies are quite different from each other. The thermolysis is endothermic and reversible, needs high temperatures, and takes place in solids, whereas hydrolysis is exothermically irreversible, takes place in solutions, and might happen spontaneously at room temperature [196]. Sodium boro-hydride $\left(\mathrm{NaBH}_{4}\right)$ is the most remarkable and promising metal hydride used for storage based on hydrolysis [208]. An example of thermolysis is that of $\mathrm{LiAlH}_{4}$ salts that is initiated by the melting of $\mathrm{LiAlH}_{4}, T_{\mathrm{mp}}\left(\mathrm{LiAlH}_{4}\right)=125$ ${ }^{\circ} \mathrm{C}$, which subsequently decomposes into solid $\mathrm{Li}_{3} \mathrm{AlH}_{6}$ and $\mathrm{Al}$ accompanied by an exothermic release of hydrogen gas in the temperature range $150-220^{\circ} \mathrm{C}[150]$.

\subsubsection{Elemental metal hydrides}

Binary hydrogen compounds can be formed by most metallic hydrides, such as elemental hydrides. However, most of these elemental hydrides are not appropriate for storing hydrogen as they only provide low capacity of hydrogen storage [209]. Magnesium hydride $(\mathrm{Mg}$ as well as aluminum hydride (Al are considered the most auspicious for large-scale hydrogen storage [150].

There are two reasons that make magnesium hydride very attractive for hydrogen storage applications, including its high capacity of hydrogen storage, around $7.6 \%$ (wt), and the low cost of magnesium metal [210, 211]. However, the bonding between magnesium and hydrogen is very strong, where the dehydrogenation enthalpy is around $75 \mathrm{~kJ}$ per mol. Additionally, the hydrogenation and dehydrogenation reactions kinetics are slow due to the fact that molecular hydrogen dissociates slowly on the magnesium surface and hydrogen distribution through the hydride phase is also slow [211-213]. Multiple techniques have been introduced to boost the kinetics of dehydrogenation and hydrogenation reactions [212-215]. While more advanced techniques such as nanoconfinement [216] have been implemented successfully on the laboratory-scale, the most promising prototype-scale storage systems were basically dependent on particle size reduction by ball grinding, alloying, and inclusion of transition metal additives to maximize the material's thermal conductivity [217-219]. Magnesium-based hydrogen storage materials can be produced by just using mix of the mentioned techniques with special properties such as, good heat transfer, long term stability as well as swift kinetics. 
However, the most crucial drawback for magnesium hydride as a hydrogen storage material is the high temperature required for both dehydrogenation and hydrogenation. On the other hand, the enthalpy of aluminum hydride dehydrogenation is around $7 \mathrm{~kJ} / \mathrm{mol}$ with a theoretical release of $10.1 \%(\mathrm{wt})$ of hydrogen. This is due to relatively weak chemical bonding between aluminum hydride and hydrogen allowing the hydrogen to be released swiftly at $100^{\circ} \mathrm{C}$.

\subsubsection{Intermetallic hydrides}

The concept of making use of intermetallic hydrides is that an $\mathrm{AxByHz}$ alloy composed of single element A, which intensely bonds with hydrogen, and single element B, which weakly bonds with hydrogen, will gain intermediate hydrogen storage characteristics compared to its corresponding elements [209]. Furthermore, the selection of elements A and B as well as their percentages, are changeable. Thus it is feasible to have a bunch of distinct intermetallic

hydrides. , and are intermetallic hydrides crystal structures which are employed in hydrogen storage applications. Typically, the hydrogen storage capacity of intermetallic hydrides is lower than $2 \%(\mathrm{wt})$ which is considered to be suitable for Fuel Cell Vehicles (FCVs) and some stationary applications [209, 220]. Even though the gravimetric densities for hydrogen storage of intermetallic hydrides are low, their volumetric capacity for storage is not necessary to be less than that of other metal hydrides when taking into consideration parameters such as porosity and density of packing [206, 221]. The high cost is the main challenge of the intermetallic hydrides [222]. For example, the price of TiFe, which is one of the least expensive intermetallic hydrides, is approximately $6.9 \$$ per $\mathrm{kg}$ [223]. Besides, the hydrogen storage capacity of TiFe is around $1.9 \%$, where the hydrogen storage cost within TiFe is around $367 \$$ per $\mathrm{kg}$. Practically, extra costs should be taken into account regarding the metallurgical processes such as annealing as well as melting that may raise the material cost by over 100\% [209]. Despite its high cost, intermetallic hydrides have shown success in many applications of hydrogen storage since 1970s [222, 224].

\subsubsection{Complex metal hydrides}

Hydrogen can be available as part of a complex anion bonded to a metallic cation. The primary complex metal hydrides groups considered to have significant importance for hydrogen storage are alanates (contain anion), borohydrides (contain anion), and amides (contain

anion) [225]. In contrast to intermetallic hydrides, complex metal hydrides are mainly composed of light elements. In other words, this gives the complex metal hydrides the feature of 
being characterized with gravimetrically massive hydrogen storage capacities, which has sparked a great deal of interest in utilizing these materials in FCV applications [226]. However, for their dehydrogenation through thermolysis, extremely high temperatures are needed by most of the complex metal hydrides, and only a few can be dehydrogenated reversibly, and usually only in the existence of effective catalysts or additives [227]. There are three main types of complex metal hydrides, namely; alanates, borohydrides, and amides.

Sodium alanate ( is the most inspected complex metal hydride substance for hydrogen storage [220, 228]. In fact, the hydrogen storage capacity of doped with Ti is $3.5-4 \%$ (wt) which is considerably higher than intermetallic hydrides but less than what is really needed for FCV applications [225, 226, 229]. A hydrogen storage density of $54 \mathrm{~kg} / \quad$ is achievable by the compaction of Ti-doped [230]. The dehydrogenation of is a discrete multi-step process. $3.7 \%$ (wt) of hydrogen is firstly produced due to the sodium aluminum hexahydride and elemental aluminum formation which is dehydrogenated to sodium hydride $\mathrm{NaH}$ and extra elemental aluminum dischargeing further $1.8 \%$ of hydrogen. Furthermore, the hydrogenation pressure of can be minimized compared to which is useful in reducing the cost of both storage containers as well as hydrogen compression. The compaction of results in volumetric hydrogen storage density of $11.1 \mathrm{~kg} /$ [231].

The hydrogen storage capacity of borohydrides is considered to be the highest among all other complex metal hydrides. For instance, Lithium borohydride ( has hydrogen storage capacity of $18.5 \%$ (wt) [232]. Elemental hydrides that are very stable, such as Lithium hydride $\mathrm{LiH}$, are predisposed to form on the dehydrogenation of borohydrides causing a significant reduction in the storage capacity [233]. There are no feasible applications of hydrogen storage materials based on borohydrides. Therefore, there are two promising methods that can improve the approachability of hydrogen storage within borohydrides; one is based on mixing borohydrides with metal hydrides to produce reactive hydride composite (RHCs), and the second is dehydrogenation based on hydrolysis [233, 234]. Currently, the and $\mathrm{Mg}$ composition is the most well-inspected RHC [235, 236]. Mixing these hydrides is beneficial as when pure undergoes dehydrogenation process, the exothermic formation of magnesium diboride takes place, reducing the total dehydrogenation endothermicity to 46 
kJ per mol [237]. The volumetric hydrogen storage density of compacted pellets that are made of $\quad-\mathrm{Mg} \quad \mathrm{RHC}$ is around $68 \mathrm{~kg} / \quad$ [238].

A solution consists of $20 \%$ (wt) of $\quad, 10 \%$ (wt) of $\mathrm{NaOH}$ and $70 \%$ (wt) of water has gravimetric and volumetric hydrogen storage capacities of $4.2 \%$ (wt) and $42.3 \mathrm{~kg} /$, respectively [239]. Keeping the content stricktly at or below $20 \%$ is essential so that adverse accumulation of hydrolysis materials and hydrated borates can be prevented by blocking the active sites to avoid the contamination of catalysts [240]. Cobalt (Co) catalysts are used for hydrolysis since they are cheaper compared to Ru-based catalysts that are known to more active [72]. Interestingly, the kinetics of the dehydrogenation process based on hydrolysis is fast at room temperature, and the process itself has excessive exothermicity of $240 \mathrm{~kJ}$ per mol, simple hydrogen liberation regulation, and cold starting opportunities [239]. On the other hand, the usage of produces hydrated borates, which are very stable, causing difficulties in regenerating $\mathrm{NaBH}_{4}[241]$.

Storage systems based on amides consist of mixtures of two compounds, including a metal amide and an elemental hydride. The presence of the elemental hydride is critically important as the amide alone, without the elemental hydride, would unleash ammonia during the thermolysis instead of hydrogen [242]. Nevertheless, most of the materials containing amides discharge trace amounts of ammonia throughout thermolysis, decreasing reversibility due to the loss of active material.

The most interesting amides are the mixture of $\mathrm{Mg}$ and since substituting $\mathrm{LiH}$ with $\mathrm{Mg} \quad$ lowers the enthalpy dehydrogenation reaction from $51 \mathrm{~kJ} / \mathrm{mol}$ down to $34 \mathrm{~kJ} / \mathrm{mol}$ [243]. A mixture composed of $2.0 \quad 0.1 \quad, 1.1 \mathrm{Mg} \quad$, and $3 \%(w \mathrm{w})$ of $\quad$ has the ability to reversibly store $4.5-5.2 \%$ (wt) of hydrogen dehydrogenate at 1 bar and $150^{\circ} \mathrm{C}$, and hydrogenate at 70 bar $150^{\circ} \mathrm{C}[244]$.

\subsubsection{Chemical hydrides}

From the name, the hydrogen is bonded chemically in the chemical hydrides. Since chemical hydrides are made of lighter elements, their characteristics are not similar to the metal hydrides ones. Maybe the major difference is that chemical hydrides usually exist in liquid form at normal conditions. They are further simplifying their transportation and storage as well as the transfer 
of mass and heat through dehydrogenation and hydrogenation processes. Examples of chemical hydrides for hydrogen storage include, but are not limited to, ammonia, formic acid, and methanol, which are usually synthesized from natural gas as bulk chemicals.

Methanol is considered as the simplest alcohol which has gravimetric and volumetric hydrogen storage capacities of $12.5 \%$ (wt) and $100 \mathrm{~kg} / \quad$, respectively. Renewable methanol production can be done by the hydrogenation of carbon dioxide ( ) [245] or from different biomass resources [246]. Hydrogen extraction from methanol can be achieved in different methods, including steam reforming, partial oxidation, or thermolysis (decomposition) [247]. The distinct advantage of steam reforming is its ability to liberate three moles of hydrogen per one mole of methanol [248]. Additionally, the methanol-water mixture is not only used for hydrogen storage but also for storage.

Ammonia ( $\mathrm{N}$ is quite interesting for hydrogen storage due to its high hydrogen content with a gravimetric density of $17.7 \%$ (wt) and volumetric density of $123 \mathrm{~kg} / \quad$ available in its liquid phase at 10 bars [249]. The favored method for the synthesis of ammonia in the Haber- Bosch process, which is an exothermic reaction $(-30.7 \mathrm{~kJ} / \mathrm{mol})$ and doesn't require any heat [250]. However, intensive pressure levels are required in order to achieve the desired thermodynamic properties where the typical conditions for the ammonia synthesis process are $300-550^{\circ} \mathrm{C}$ and 200-350 bars [249]. The dehydrogenation process is the most challenging part of using ammonia as a hydrogen storage medium in large-scale applications. The conversion of ammonia into hydrogen can be done through its thermolysis as the ammonia starts decomposing normally at temperatures above $200^{\circ} \mathrm{C}$. The complete conversion of ammonia requires temperatures higher than $650^{\circ} \mathrm{C} \quad[251,252]$. Ruthenium $(\mathrm{Ru})$ is the most active catalyst used for ammonia decomposition, but it is costly. Thus, catalysts based on cobalt, nickel, and iron are under investigation to replace $\mathrm{Ru}$ [252]. Since the activity of these catalysts is lower than $\mathrm{Ru}$, higher temperatures are necessary to fully complete the ammonia conversion [253]. New catalysts made of light metal amides or imides have been proposed recently, which are less expensive than transition metal catalysts. However, these catalysts also require high temperatures, above $500^{\circ} \mathrm{C}$, so that the full conversion of ammonia can be achieved [254].

Formic acid has the lowest volumetric and gravimetric hydrogen storage capacity among the previously mentioned chemical hydrides of $53 \mathrm{~kg} /$ and $4.4 \%$ (wt), respectively. The 
advantage of formic acid as a hydrogen storage medium over methanol and ammonia is that it can be dehydrogenated at room temperature [255]. The comparatively effortless decomposition of formic acid to produce hydrogen and is the main reason why this medium is impressive for hydrogen storage. However, the critical limitation is that the formic acid might decompose into $\mathrm{CO}$ instead of and hydrogen during heating, depending on the type of catalysis. Homogenous catalysts have proved to have a positive effect in reducing $\mathrm{CO}$ during the dehydrogenation of formic acid [255, 256]. Additionally, formic acid decomposition reaction has promising thermodynamics which allows releasing hydrogen with high pressure, at around 1200 bars, with low CO content (<6 ppm) [257, 258]. Releasing high-pressure hydrogen is a very special aspect for formic acid, among other chemical hydrides. On the other hand, the dehydrogenation process also involves the formation of high-pressure

Liquid organic hydrogen carriers (LOHCs) are another set of materials under the chemical hydrides umbrella. They are known for their reversibility in hydrogenation and dehydrogenation as well as their liquid phase in both hydrogenated and dehydrogenated forms. Even though formic acid and methanol are organic liquids, they are not classified as LOHCs because their products from the dehydrogenation process are only gaseous [259]. Nethylcarbazole and dodecahydro-Nethylcarbazole (NEC-DNEC), Methylcyclohexane, and toluene (MCH-TOL), and dibenzyltoluene and perhydro-dibenzyltoluene (DBT-PDBT) are the most well-investigated LOHCs [260]. The gravimetric hydrogen storage densities are 6.1\% (wt) for MCH-T, 6.2\% (wt) for DBT-PDBT, and 5.8\% (wt) for NEC-DNEC, while the volumetric hydrogen storage densities are $47 \mathrm{~kg} / \quad$ for MCH-TOL, $64 \mathrm{~kg} / \quad$ for DBT-PDBT, and $54 \mathrm{~kg}$ / for NECDNEC [261].

\subsubsection{Hydrolysis and regeneration of metal hydrides}

Furthermore, the reaction of $\left(\mathrm{MgH}_{2}\right)$ with water at room temperature can effectively produce up to $15.2 \% \mathrm{wt}(1503 \mathrm{mg} / \mathrm{L})$ of hydrogen, making it a super attractive hydrogen supplier for various applications, such as hydrogen-based vehicles [262, 263]. Yet, the presence of $\mathrm{Mg}(\mathrm{OH})_{2}$ layer located at the surface of $\mathrm{MgH}_{2}$ swiftly blocks the hydrolysis process [264]. Several approaches, including ball milling [265], plasma-assisted milling [266], changing the 
aqueous solution as well as alloying, have been studied in order to solve the issue of $\operatorname{Mg}(\mathrm{OH})_{2}$ layer formation and enhance the characteristics of hydrolysis reaction [267, 268]. Ball-milling of $4 \mathrm{MgH}_{2}-\mathrm{LiNH}_{2}$ mixture for $5 \mathrm{~h}$ yields $887.2 \mathrm{mg} / \mathrm{L}$ hydrogen within $1 \mathrm{~min}$. Likewise, it was reported that adding calcium hydride $\left(\mathrm{CaH}_{2}\right)$ is super advantageous in improving the hydrolysis process of $\mathrm{MgH}_{2}$. In other words, the amount of heat released done by the reaction of $\mathrm{CaH}_{2}$ additive has intensively reinforced the kinetics of Mg-based hydrolysis, and it also attributed to the formation of micro-holes on the surface of $\mathrm{Mg}$ particles, providing easy access for water to reach the unreacted $\mathrm{Mg}$ portions [269]. In addition to that, the preparation of $\mathrm{MgH}_{2}-\mathrm{CaH}_{2}$ composite by ball-milling for $10 \mathrm{~h}$ has successfully obtained $80 \%$ of the hydrogen generated within $30 \mathrm{~min}$ [270]. Moreover, it has been investigated that chloride salts could be highly efficient in accelerating the rate of the hydrolysis process. For instance, manganese chloride $\left(\mathrm{MgCl}_{2}\right)$ greatly stimulates the hydrolysis of $\mathrm{MgH}_{2}$, which results in attaining $96 \%$ of hydrogen conversion at a temperature of $303 \mathrm{~K}$ within $30 \mathrm{~min}$ [271]. It was observed in one of the studies that the addition of $\mathrm{NH}_{4} \mathrm{Cl}$ is quite functional due to the fact that it boosted up the hydrolysis reaction kinetics of $\mathrm{MgH}_{2}$ as well as helped in achieving $1660 \mathrm{mg} / \mathrm{L}$ of hydrogen production [272]. The composite of $\mathrm{Mg}-\mathrm{Mg}_{2} \mathrm{Si}$ [164] or $\mathrm{Mg}-\mathrm{MoO}_{3}$ [273], exhibited better evolution of hydrogen than pure magnesium. In another study, the hydrolysis of $\mathrm{MgH}_{2}$ was examined in two solutions of $0.1 \mathrm{M}$ and $0.5 \mathrm{M} \mathrm{AlCl}_{3}$ concentrations. Comparatively, the amount of hydrogen extracted from hydrolysis in $0.1 \mathrm{M} \mathrm{AlCl}_{3}$ solution at $303 \mathrm{~K}$ was $805 \mathrm{mg} / \mathrm{L}$ within $10 \mathrm{~min}$, however in $0.5 \mathrm{M} \mathrm{AlCl}_{3}$ solution the kinetics of the hydrolysis process were much better, and hydrogen generation of $1487 \mathrm{mg} / \mathrm{L}$ for the same temperature and duration was successfully acquired [274]. Additionally, $\mathrm{AlCl}_{3}$ solution could significantly reduce the activation energy of the hydrolysis reaction. In other words, the higher concentration of $\mathrm{AlCl}_{3}$, the lower the activation energy will be. The addition of elemental materials, covering metals, metal oxides, carbon-based additives, hydroborons, amides, metal sulfides, and halides could also be magnificently beneficial in improving the behavior of $\mathrm{MgH}_{2}$ hydrolysis. For instance, $\mathrm{Mg}$ milling catalyzed by Ti lattice coated with Pt enhanced the kinetics performance of hydrolysis reaction [275-277].

Lithium hydride $(\mathrm{LiH})$ is another splendid material that could be utilized as source of hydrogen and implemented in tons of novel technologies, including fuel cells, shielding neutrons as well as a regulated fusion [278]. However, the practices of LiH require absolutely accurate 
handing of storage since the reaction of $\mathrm{LiH}$ with water unleashes extreme levels of heat. In these situations, controlling the increase in temperature during the exothermic reaction is highly significant [279]. Thus, $\mathrm{LiH}$ should be maintained carefully in tough conditions in order to avoid any type of unneeded atmospheric reactions with humidity that could lead to a number of risks, such as burning [280]. The hydrolysis of $\mathrm{LiH}$ by introducing water steam to the reaction was conducted in work as the kinetics of the process were analyzed, assessed, and measured at different temperatures of $150 \quad 300$ and 500 [281]. When the hydrolysis reaction was carried out at an initial temperature of 150 , around $96 \%$ of the maximum theoretical amount of hydrogen was successfully produced. Taking into account that the hydrogen production in at the first stages of hydrolysis at 150 was greater than in the upcoming stages of the reaction, this could be simply justified by the hygroscopic nature of hydride powders, which grants them the ability to soak up water steam at the start of hydrolysis. On the other side, the by-products layers formed during the middle stages of $\mathrm{LiH}$ hydrolysis slow down the sawing of water to $\mathrm{LiH}$ zones that have not been reacted yet, results in extending the time needed to reach $90 \%$ of hydrogen production for extra $15 \mathrm{~min}$. Fig 18 illustrates the capacity of hydrogen production and the temperature changes of $\mathrm{LiH}$ hydrolysis at 150 , and the by-products effect on the quickness of hydrogen generation. Conducting the hydrolysis process of $\mathrm{LiH}$ at higher temperature of 300 has produced roughly $60 \%$ of the maximum theoretical amount of hydrogen just after 3 min from the start of the reaction. In addition to that, in the final phase of hydrolysis at 300 , specifically after the fifth minute the percentage of hydrogen released jumps to $97 \%$ of the total theoretical production. Moreover, hydrogen generation of $15 \%$ at early stages was recorded in the case of subjecting the $\mathrm{LiH}$ hydrolysis at a temperature of 500 , once the temperature of the reactor reached 700 , hydrogen yield of approximately 100\% was achieved after 6 min were passed. 
(a)

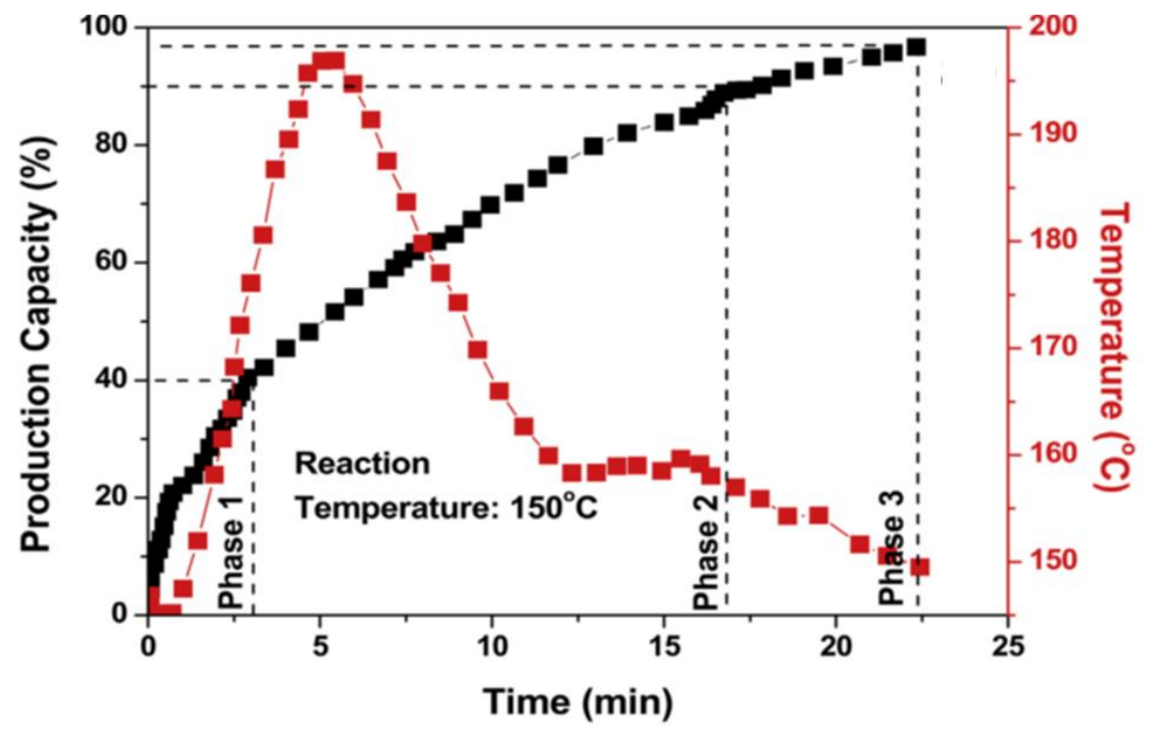

(b)

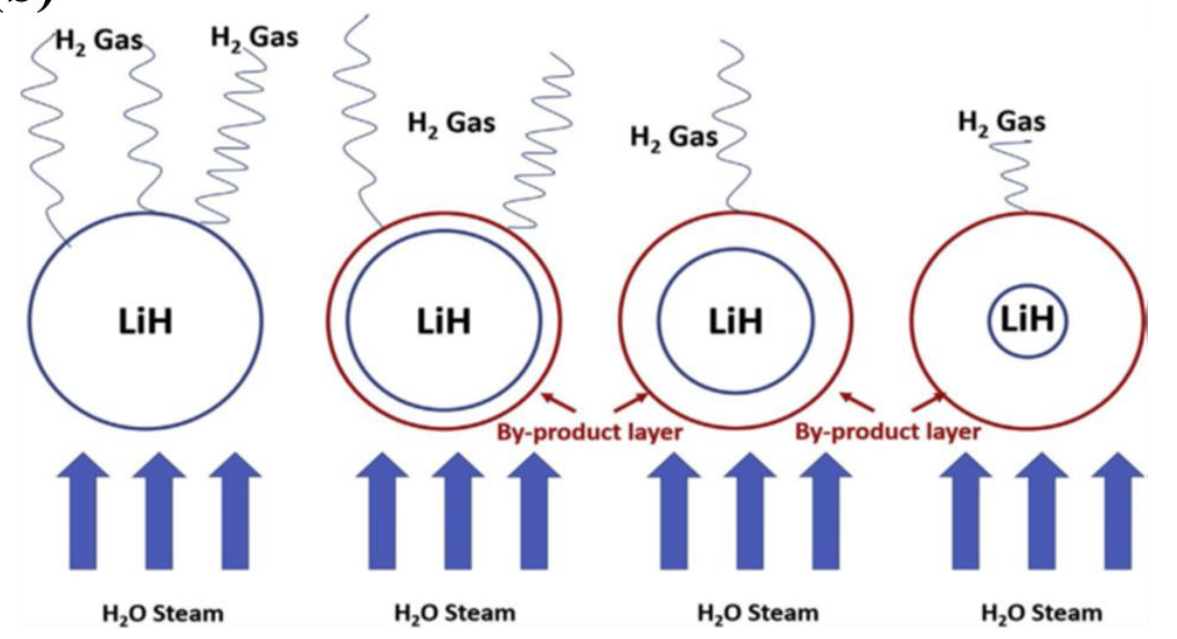

Figure 38. (a) the capacity of hydrogen production and the temperature changes of $\mathrm{LiH}$ hydrolysis at 150 , (b) by-products effect on the quickness of hydrogen generation [281].

Chen et al. [282] reported that ball milling of $\mathrm{LiBO} 2 \cdot 2 \mathrm{H} 2 \mathrm{O}$ with $\mathrm{Mg}$ under ambient conditions is cheap "five times lower than that of $\mathrm{NaBH}_{4}$." and an effective way for $\mathrm{LiBH}_{4}$ regeneration. Regarding the regeneration of $\mathrm{NaBH}_{4}$, Ouyang et al. [283] demonstrated that the cost of the regeneration of the $\mathrm{NaBH}_{4}$ could be significantly decreased, and the process can be done at room temperature through $\mathrm{NaBO}_{2} \cdot 2 \mathrm{H}_{2} \mathrm{O}$ and $\mathrm{NaBO}_{2} \cdot 4 \mathrm{H}_{2} \mathrm{O}$ with $\mathrm{Mg}$ instead of $\mathrm{NaBO}_{2}$. The same group suggested that the cost of the regeneration of the $\mathrm{NaBH}_{4}$ could also be decreased, 
and the process can also be facilitated by reacting $\mathrm{NaBO}_{2}$ with $\mathrm{CO}_{2}$ in aqueous solution producing $\mathrm{Na}_{2} \mathrm{~B}_{4} \mathrm{O}_{7} \cdot 10 \mathrm{H}_{2} \mathrm{O}$ and $\mathrm{Na}_{2} \mathrm{CO}_{3}$. The latter materials are ball- milled with $\mathrm{Mg}$ to form $\mathrm{NaBH}_{4}$ under normal operating conditions.

\subsection{Comparison of hydrogen storage techniques}

The multiple techniques of hydrogen storage with high energy density demonstrating a promising future of hydrogen utility in many applications such as transportation, however most of these techniques are still in the development stage. Even though salt caverns are not applicable in all regions, their capability of storing hydrogen is very effective. Table 10 briefly demonstrates the gravimetric and volumetric hydrogen storage capacities of hydrogen storage technologies. Figure 19 displays a bar chart of the gravimetric and volumetric hydrogen storage capacities of hydrogen storage technologies. Moreover, the challenges and characteristics of some hydrogen storage/transport pathways are listed in Table 11.

Table 10. Gravimetric and volumetric storage capacities of different hydrogen storage

\begin{tabular}{|c|c|c|}
\hline $\begin{array}{c}\text { Hydrogen storage technology } \\
\text { Gas hydrogen storage at 100 } \\
\text { bar }\end{array}$ & $\begin{array}{c}\text { Gravimetric storage capacity } \\
\%(\mathbf{w t})\end{array}$ & $\begin{array}{c}\text { Volumetric storage capacity (kg } \\
/ \text { ) }\end{array}$ \\
\hline $\begin{array}{c}\text { Liquid hydrogen storage at 1 } \\
\text { bar }\end{array}$ & - & $7.8[171,172]$ \\
\hline Magnesium hydride & - & $70[184]$ \\
\hline Aluminum hydride & $7.6[210,211]$ & - \\
\hline Alanates (Ti-doped & $10.1[284]$ & - \\
\hline with Mg & $3.5-4[225,226,229]$ & $54[225,226,229]$ \\
\hline Amides & - & $68[238]$ \\
\hline Methanol & $4.5-5.2[244]$ & - \\
\hline Ammonia & $12.5[245]$ & $100[245]$ \\
\hline Formic Acid & $17.7[249]$ & $123[249]$ \\
\hline LOHC ( DBT-PDBT ) & $4.4[255]$ & $53[255]$ \\
\hline
\end{tabular}

technologies 


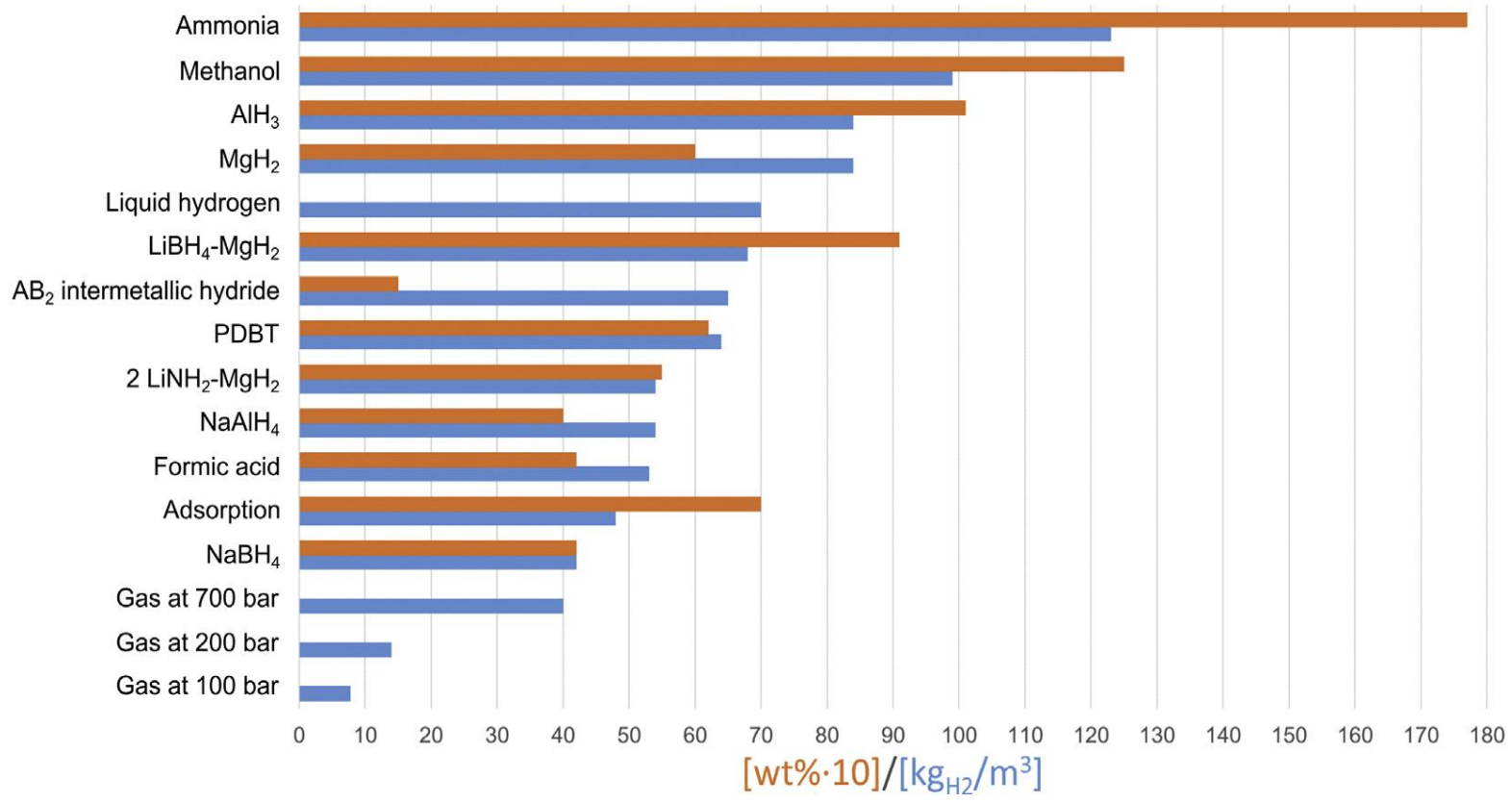

Fig 19. Comparison among different hydrogen storage systems in terms of gravimetric (orange) and volumetric energy (blue) densities [207]. 
Table 11. Challenges and characteristics of some hydrogen storage/transport pathway [83].

\begin{tabular}{|c|c|c|c|}
\hline CHARACTERISTICS & LQUID & TOLUENE-MCH & AMMONIA $\left(\mathrm{NH}_{3}\right)$ \\
\hline Challenges & $\begin{array}{l}\text { - Requires very } \\
\text { low temperature } \\
\text { (about }-250^{\circ} \mathrm{C} \text { ) } \\
\text { - High energy requirement } \\
\text { for cooling/liquefaction } \\
\text { - Demands cost reduction } \\
\text { for liquefaction } \\
\text { - Liquefaction currently } \\
\text { consumes about } 45 \% \text { of } \\
\text { the energy brought by } \mathrm{H}_{2} \\
\text { - Difficult for long-term } \\
\text { storage } \\
\text { - Requires boil-off control } \\
\text { (0.2\%-0.3\% d- }{ }^{1} \text { in truck) } \\
\text { - Risk of leakage }\end{array}$ & $\begin{array}{l}\text { - Requires high-temperature } \\
\text { heat source for } \\
\text { dehydrogenation (higher than } \\
300^{\circ} \mathrm{C} \text {, up to } 300 \text { kilopascal) } \\
\text { - The heat required for } \\
\text { dehydrogenation is about } 30 \% \\
\text { of the total } \mathrm{H}_{2} \text { brought by } \mathrm{MCH} \\
\text { - As } \mathrm{MCH} \text { with molecular weight } \\
\text { of } 98.19 \text { gram per mol- }{ }^{1} \text { only } \\
\text { carries three molecules of } \mathrm{H}_{2} \\
\text { from toluene hydrogenation, } \\
\text { the handling infrastructure } \\
\text { tends to be large } \\
\text { - Durability } \\
\text { (number of cycles) }\end{array}$ & $\begin{array}{l}\text { - Lower reactivity } \\
\text { compared } \\
\text { to hydrocarbons } \\
\text { - Requires treatment } \\
\text { due to toxicity and } \\
\text { pungent smell } \\
\text { - Treatment and } \\
\text { management by } \\
\text { certified engineers } \\
\text { - Consumes very high } \\
\text { energy input in case } \\
\text { of dehydrogenation } \\
\text { (about } 13 \% \text { of } \\
\mathrm{H}_{2} \text { energy) and } \\
\text { purification }\end{array}$ \\
\hline Advantages & $\begin{array}{l}\text { - High purity } \\
\text { - Requires no } \\
\text { dehydrogenation and } \\
\text { purification }\end{array}$ & $\begin{array}{l}\text { - Can be stored in liquid } \\
\text { condition without cooling } \\
\text { (minimum loss during } \\
\text { transport) } \\
\text { - Existing storing } \\
\text { infrastructure } \\
\text { - Existing regulations } \\
\text { - No loss }\end{array}$ & $\begin{array}{l}\text { - Possible for direct } \\
\text { use } \\
\text { - Potentially be the } \\
\text { cheapest energy } \\
\text { carrier } \\
\text { - Existing } \mathrm{NH}_{3} \\
\text { infrastructure and } \\
\text { regulation }\end{array}$ \\
\hline $\begin{array}{l}\text { Development } \\
\text { stage }\end{array}$ & $\begin{array}{l}\text { - Small scale: } \\
\text { application stage } \\
\text { - Large scale: infrastructure } \\
\text { development is being } \\
\text { carried out }\end{array}$ & - Demonstration stage & $\begin{array}{l}\text { - Research and } \\
\text { development stage } \\
\text { - Partly has entered } \\
\text { demonstration stage }\end{array}$ \\
\hline $\begin{array}{l}\text { Required } \\
\text { development/ } \\
\text { actions }\end{array}$ & $\begin{array}{l}\text { - Regulation for } \\
\text { transport loading/ } \\
\text { unloading system } \\
\text { - Development in } \\
\mathrm{H}_{2} \text { engines } \\
\text { - Improvement of energy } \\
\text { efficiency in liquefaction }\end{array}$ & $\begin{array}{l}\text { - Catalysts for both } \\
\text { hydrogenation and } \\
\text { dehydrogenation } \\
\text { - Energy-efficient } \\
\text { dehydrogenation }\end{array}$ & $\begin{array}{l}\text { - High energy } \\
\text { efficiency in } \\
\text { synthesis } \\
\text { - Fuel cell with direct } \\
\mathrm{NH}_{3}\end{array}$ \\
\hline
\end{tabular}

\subsection{Hydrogen transportation}

After producing hydrogen and storing it through different methods, hydrogen needs to be transported from the production sites to the consumption points. Generally, there are two main options for transporting hydrogen, including pipelines for gaseous hydrogen and trucks, trains, or ships for either compressed gas tube trailers or liquefied hydrogen cryogenic tanks [285-287]. In some cases, multiple transportation ways may be needed to deliver the hydrogen to the end-user. Based on the transportation method, there may be storage costs at both the production site and 
dispensing station. The cost of hydrogen delivery can be quite expensive and may determine the overall viability of using hydrogen for a specific power plant. Generally, pipelines are considered the most economical transportation method for hydrogen[184]. It requires high installation costs, but the maintenance and operational costs are very low [288, 289]. Also, for liquid hydrogen transportation, the main limitation is the high energy required for liquidation [290]. Thus, it can be stated that pipelines are better for large scale applications while trucks are preferable for small scale [291]. Supply stations are required for hydrogen transportation, where the stations can be on-site of the production or on another site [292, 293].

\subsection{Life Cycle Assessment of Hydrogen Production:}

Life cycle assessment (LCA) is a methodology used to evaluate the environmental impact throughout the different stages of the product [294, 295]. Such studies are important when more than one alternative energy source is proposed, and it aids in making the most feasible decision, both economically and technically. Several studies focused on LCA for hydrogen production technologies, including gasification and steam reforming of fossil fuel, water electrolysis for solar PV, solar thermal, wind energy sources, and biomass energy-based gasification. For example, Sadeghi et al. [296] compared hydrogen production for solar PV and solar thermal electrolysis with conventional methods like steam methane reforming (SMR) and coal gasification in terms of life cycle analysis [296]. The comparison showed that the unit cost of PV and solar thermal electrolysis is much greater than SMR and gasification. Meanwhile, the emission of PV and solar thermal is much less compared to conventional sources. Table 12 summarizes a comparison for LCA analysis on hydrogen production for the four methods.

Table 12: Comparison of LCA analysis on four selected methods extracted from [296]

\begin{tabular}{|c|c|c|c|c|}
\hline Parameter & SMR & Gasification & $\begin{array}{c}\text { PV } \\
\text { Electrolysis }\end{array}$ & $\begin{array}{l}\text { Solar thermal } \\
\text { Electrolysis }\end{array}$ \\
\hline LCOA $(\$ / \mathrm{kg})$ & 1.09 & 1.95 & 6.85 & 12.04 \\
\hline $\begin{array}{c}\text { GHG Emissions } \\
\left(\mathrm{kg} \mathrm{CO}_{2} \text { eq. } / \mathrm{kg} \mathrm{H}_{2}\right)\end{array}$ & 10.28 & 11.59 & 3.08 & 2.06 \\
\hline $\begin{array}{l}\text { Abatement Costs }(\$ / \mathrm{kg} \\
\left.\mathrm{CO}_{2}\right)\end{array}$ & - & - & 0.786 & 1.373 \\
\hline
\end{tabular}


Alternatively, Salkuyeh et al., assessed LCA for hydrogen production from biomass using different gasification processes, fluidized bed (FB) and entrained flow (EF) [297]. This study indicated that EF method has a higher thermal efficiency (56\%, LHV) compared to FB (45\%). However, EF has a higher hydrogen selling price. Also, LCA indicated a negative cycle on GHG (global warming potential) for all biomass options. Another study of wind-based hydrogen production by water electrolysis showed a total GHG emission of $0.68 \pm 0.05 \mathrm{~kg} \mathrm{CO} 2 \mathrm{eq} . / \mathrm{kg} \mathrm{H} \mathrm{H}_{2}$ power plant. These emissions are shown to be $94 \%$ less than that of SMR based hydrogen. For wind-based hydrogen, most of the emission (65\%) were on the installation stage; however, For MSR most of the emission was on operational stages. Another LCA study for wind-based hydrogen production by water electrolysis obtained a total $\mathrm{GHG}$ emission of $0.68 \pm 0.05 \mathrm{~kg} \mathrm{CO}_{2}$ eq. $/ \mathrm{kg} \mathrm{H}_{2}$, where $65 \%$ of the total emissions are from the installation of the wind power plant [298]. Also, this amount of emissions is less than SMR based hydrogen by 94\%. For conventional hydrogen production methods, most of the emissions are on the operational stages, unlike the wind based, where most emissions are in the installation stage. Figure 20 depicts the GHG emissions level for each stage of the system. The GHG emissions for water electrolysis was the lowest. 


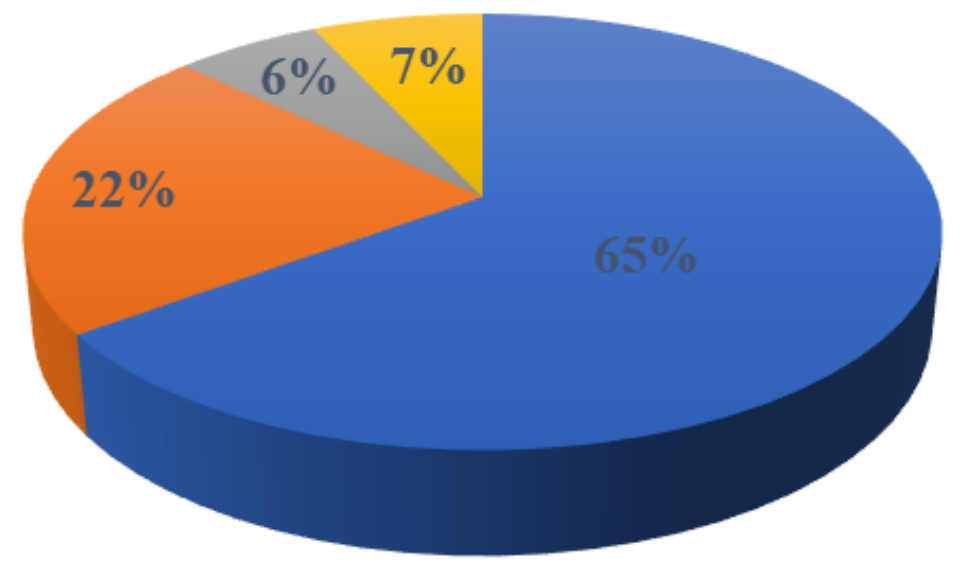

- Wind Power Generation $\quad$ Hydrogen compression

- Hydrogen Transportation $\quad$ Water Electrolysis

Fig. 20: GHG emissions for wind-based water electrolysis [298]

Similarly, Hajjaj et al. studied hydrogen production from biogas reforming and showed that this promising approach had achieved a thermal efficiency of 76-8\% and GHG emission of $5.59 \mathrm{~kg}$ $\mathrm{CO}_{2}$-eq per $\mathrm{kg}$ of $\mathrm{H}_{2}$, which was half the amount $\mathrm{GHG}$ emissions using the conventional SMR method [299]. Another study combined LCA and exergy analysis to compare between hydrogen production by biomass staged gasification (BSGH) and natural gas steam reforming (NGSH) [300]. The study concluded that BSGH was more sustainable and renewable, with a better environmental impact on global warming and ozone formation. However, the thermal pollution for NGSH was slightly less than BSGH. Moreover, LCA analysis for hydrogen production based on biomass gasification (BG) and steam reforming (SMR) using three aspects, environmental aspect, economic aspect, and social aspect, was conducted [301]. This study revealed that BG showed promising results in terms of the environmental aspect. However, it had concerns in the economic and social aspects but developing the method and increasing the efficiency would enhance the process. 


\section{Conclusion}

The global environmental concerns as well as the scarcity and geographical distribution of fossil fuel resources, have led to growing interest in using hydrogen as a fuel for power various applications either via direct combustion or via a fuel cell. Hydrogen technologies can be used to power wide range of applications from small scale, such as electronic devices charging systems, to big-scale, such as vehicles and trains. Developing large-scale production and storage technologies of hydrogen is the only way to support the transition to a hydrogen-powered world. Producing hydrogen from a renewable feedstock, such as biomass, using a renewable energy source, such as wind or solar, is the cleanest production technology. However, in our current time, such a production route can only release small quantities of hydrogen, and for this, it is not suitable for large-scale applications. Obtaining hydrogen from water via different electrolysis methods is capable of providing sufficient amounts of hydrogen for large scale applications. However, utilizing water for producing hydrogen might not be an option for those regions that suffer from a shortage in water resources as a 'water conflict' might arise between the neighboring countries due to this. Alternatively, producing hydrogen from fossil fuel seems to be suitable for large scale production, but a carbon capture technology should be combined and used in order to minimize the environmental consequences of this technology.

The hydrogen can be stored in different states such as solid-state using metal hydrides, liquid state using well-isolated containers, or gaseous state using surface pressure tanks or underground formations. Among the various storage technologies, storing hydrogen in its gaseous state in underground natural sites, such as salt caverns, might be a suitable option for large-scale hydrogen storage due to low energy requirements and investment costs compared with other storage technologies. Additionally, storing hydrogen in its gaseous state will allow transporting it 
to the consuming points via pipelines, which can also be considered as the most economical transporting method. However, underground hydrogen storage might not be possible for some regions due to the local geographical conditions of the storage site, so alternative storage methods should be considered. Therefore, it can be reported that there is no one ideal production or storage technology for large-scale hydrogen applications, but multiple modes should be integrated where the suitable technologies are determined based on the local conditions of the production sites and fueling stations as well as the type of end-user.

The transition to hydrogen age has started but still in the early stages, and arriving final terminal is not going to be achieved in the near future. Despite the recent breakthrough in hydrogen and fuel cell technologies, significant research and governmental efforts are still needed to support the large-scale hydrogen production and storage technologies as they are the key to enabling the hydrogen-based economy. 


\section{References}

1. Elsaid, K., et al., Environmental impact of emerging desalination technologies: A preliminary evaluation. Journal of Environmental Chemical Engineering, 2020. 8(5): p. 104099.

2. Elsaid, K., et al., Environmental impact of desalination processes: Mitigation and control strategies. Science of The Total Environment, 2020. 740: p. 140125.

3. Elsaid, K., et al., Recent progress on the utilization of waste heat for desalination: A review. Energy Conversion and Management, 2020. 221: p. 113105.

4. Olabi, A.G., et al., Waste heat-driven desalination systems: Perspective. Energy, 2020: p. 118373.

5. Rezk, H., et al., Identifying optimal operating conditions of solar-driven silica gel based adsorption desalination cooling system via modern optimization. Solar Energy, 2019. 181: p. 475-489.

6. Rezk, H., et al., A novel statistical performance evaluation of most modern optimization-based global MPPT techniques for partially shaded PV system. Renewable and Sustainable Energy Reviews, 2019. 115: p. 109372.

7. Rezk, H., et al., Fuel cell as an effective energy storage in reverse osmosis desalination plant powered by photovoltaic system. Energy, 2019. 175: p. 423-433.

8. Kamel, A.A., H. Rezk, and M.A. Abdelkareem, Enhancing the operation of fuel cell-photovoltaicbattery-supercapacitor renewable system through a hybrid energy management strategy. International Journal of Hydrogen Energy, 2020.

9. Wilberforce, T., et al., Prospects and challenges of concentrated solar photovoltaics and enhanced geothermal energy technologies. Science of The Total Environment, 2019. 659: p. 851861.

10. Olabi, A.G., et al., Geothermal based hybrid energy systems, toward eco-friendly energy approaches. Renewable Energy, 2020. 147: p. 2003-2012.

11. Mahmoud, M., et al., A review of mechanical energy storage systems combined with wind and solar applications. Energy Conversion and Management, 2020. 210: p. 112670.

12. Soudan, B., Community-scale baseload generation from marine energy. Energy, 2019. 189: $\mathrm{p}$. 116134.

13. Hussain, N., et al., Two dimensional Cu based nanocomposite materials for direct urea fuel cell. International Journal of Hydrogen Energy, 2020.

14. Inayat, A., et al., Fuzzy modeling and parameters optimization for the enhancement of biodiesel production from waste frying oil over montmorillonite clay $K-30$. Science of The Total Environment, 2019. 666: p. 821-827.

15. Nassef, A.M., et al., Fuzzy-modeling with Particle Swarm Optimization for enhancing the production of biodiesel from Microalga. Energy Sources, Part A: Recovery, Utilization, and Environmental Effects, 2019. 41(17): p. 2094-2103.

16. Abdelkareem, M.A., et al., On the technical challenges affecting the performance of direct internal reforming biogas solid oxide fuel cells. Renewable and Sustainable Energy Reviews, 2019. 101: p. 361-375.

17. Veziroglu, T.N. and F. Barbir, Hydrogen Energy Technologies, UNIDO, A1400. Vienna, Austria, 1998.

18. Abe, J., E. Ajenifuja, and O. Popoola, Hydrogen energy, economy and storage: review and recommendation. International Journal of Hydrogen Energy, 2019.

19. Abdelkareem, M.A., E.T. Sayed, and N. Nakagawa, Significance of diffusion layers on the performance of liquid and vapor feed passive direct methanol fuel cells. Energy, 2020. 209: p. 118492. 
20. Sayed, E.T., et al., Direct urea fuel cells: Challenges and opportunities. Journal of Power Sources, 2019. 417: p. 159-175.

21. Nassef, A.M., et al., Maximizing SOFC performance through optimal parameters identification by modern optimization algorithms. Renewable Energy, 2019. 138: p. 458-464.

22. Olabi, A.G., et al., Prospects of Fuel Cell Combined Heat and Power Systems. Energies, 2020. 13(16): p. 4104.

23. Haller, J. and T. Link, Thermodynamic concept for an efficient zero-emission combustion of hydrogen and oxygen in stationary internal combustion engines with high power density. International Journal of Hydrogen Energy, 2017. 42(44): p. 27374-27387.

24. Aydin, K. and R. Kenanoğlu, Effects of hydrogenation of fossil fuels with hydrogen and hydroxy gas on performance and emissions of internal combustion engines. International Journal of Hydrogen Energy, 2018. 43(30): p. 14047-14058.

25. Ammar, N.R. and N.F. Alshammari, Overview of the Green Hydrogen Applications in Marine Power Plants Onboard Ships. Int. J. of Multidisciplinary and Current research, 2018. 6.

26. Xiao, H. and A. Valera-Medina, Chemical kinetic mechanism study on premixed combustion of ammonia/hydrogen fuels for gas turbine use. Journal of Engineering for Gas Turbines and Power, 2017. 139(8).

27. Scipioni, A., A. Manzardo, and J. Ren, Hydrogen economy: supply chain, life cycle analysis and energy transition for sustainability. 2017: Academic Press.

28. Rosen, M.A. and S. Koohi-Fayegh, The prospects for hydrogen as an energy carrier: an overview of hydrogen energy and hydrogen energy systems. Energy, Ecology and Environment, 2016. 1(1): p. 10-29.

29. Fernández-Sevilla, J., F.A. Fernández, and E.M. Grima, Development of Photobioreactors for H2 Production from Algae, in Microalgal Hydrogen Production. 2018. p. 385-418.

30. Doyle, D., et al., Hydrogen Fuel Cell Buses: Modelling and Analysing Suitability from an Operational and Environmental Perspective. 2020, SAE Technical Paper.

31. Dawood, F., M. Anda, and G.M. Shafiullah, Hydrogen production for energy: An overview. International Journal of Hydrogen Energy, 2020. 45(7): p. 3847-3869.

32. Nikolaidis, P. and A. Poullikkas, A comparative overview of hydrogen production processes. Renewable and Sustainable Energy Reviews, 2017. 67: p. 597-611.

33. Hosseini, S.E. and M.A. Wahid, Hydrogen production from renewable and sustainable energy resources: Promising green energy carrier for clean development. Renewable and Sustainable Energy Reviews, 2016. 57: p. 850-866.

34. Preuster, P., A. Alekseev, and P. Wasserscheid, Hydrogen Storage Technologies for Future Energy Systems. Annual Review of Chemical and Biomolecular Engineering, 2017. 8(1): p. 445-471.

35. Zhang, F., et al., The survey of key technologies in hydrogen energy storage. International Journal of Hydrogen Energy, 2016. 41(33): p. 14535-14552.

36. Rand, D.A.J. and R.M. Dell, Hydrogen energy: challenges and prospects. 2007: Royal Society of Chemistry.

37. Sinigaglia, T., et al., Production, storage, fuel stations of hydrogen and its utilization in automotive applications-a review. International journal of hydrogen energy, 2017. 42(39): $p$. 24597-24611.

38. Tsujimura, T. and Y. Suzuki, The utilization of hydrogen in hydrogen/diesel dual fuel engine. International journal of hydrogen energy, 2017. 42(19): p. 14019-14029.

39. Salvi, B. and K. Subramanian, Sustainable development of road transportation sector using hydrogen energy system. Renewable and Sustainable Energy Reviews, 2015. 51: p. 1132-1155. 
40. Shivaprasad, K., et al., Experimental investigation of the effect of hydrogen addition on combustion performance and emissions characteristics of a spark ignition high speed gasoline engine. Procedia Technology, 2014. 14: p. 141-148.

41. Elsemary, I.M., et al., Experimental investigation on performance of single cylinder spark ignition engine fueled with hydrogen-gasoline mixture. Applied Thermal Engineering, 2016. 106: p. 850854.

42. de Morais, A.M., et al., Hydrogen impacts on performance and $\mathrm{CO} 2$ emissions from a diesel power generator. international journal of hydrogen energy, 2013. 38(16): p. 6857-6864.

43. Alrazen, H.A., et al., A review of the effect of hydrogen addition on the performance and emissions of the compression-Ignition engine. Renewable and Sustainable Energy Reviews, 2016. 54: p. 785-796.

44. Hamdan, M.O., et al., Hydrogen supplement co-combustion with diesel in compression ignition engine. Renewable energy, 2015. 82: p. 54-60.

45. Ghazal, O.H., Performance and combustion characteristic of $\mathrm{Cl}$ engine fueled with hydrogen enriched diesel. International Journal of Hydrogen Energy, 2013. 38(35): p. 15469-15476.

46. Koten, H., Hydrogen effects on the diesel engine performance and emissions. International journal of hydrogen energy, 2018. 43(22): p. 10511-10519.

47. Abdelkareem, M.A., et al., Nonprecious anodic catalysts for low-molecular-hydrocarbon fuel cells: Theoretical consideration and current progress. Progress in Energy and Combustion Science, 2020. 77: p. 100805.

48. Abdelkareem, M.A., et al., Synthesis and testing of cobalt leaf-like nanomaterials as an active catalyst for ethanol oxidation. International Journal of Hydrogen Energy, 2020. 45(35): p. 1731117319.

49. Olabi, A.G., et al., Application of graphene in energy storage device - A review. Renewable and Sustainable Energy Reviews, 2021. 135: p. 110026.

50. Sharaf, O.Z. and M.F. Orhan, An overview of fuel cell technology: Fundamentals and applications. Renewable and Sustainable Energy Reviews, 2014. 32: p. 810-853.

51. Zhang, Z. and C. Hu, System design and control strategy of the vehicles using hydrogen energy. International journal of hydrogen energy, 2014. 39(24): p. 12973-12979.

52. Wang, Y., et al., Materials, technological status, and fundamentals of PEM fuel cells-a review. Materials Today, 2020. 32: p. 178-203.

53. Wu, H.-W., A review of recent development: Transport and performance modeling of PEM fuel cells. Applied Energy, 2016. 165: p. 81-106.

54. Savioli, J. and G.W. Watson, Computational Modelling of Solid Oxide Fuel Cells. Current Opinion in Electrochemistry, 2020.

55. Tanveer, W.H., et al., Improving fuel cell performance via optimal parameters identification through fuzzy logic based-modeling and optimization. Energy, 2020. 204: p. 117976.

56. Mehmeti, A., et al., Life cycle assessment of molten carbonate fuel cells: State of the art and strategies for the future. Journal of Power Sources, 2016. 308: p. 97-108.

57. Frangini, S. and A. Masi, Molten carbonates for advanced and sustainable energy applications: Part II. Review of recent literature. International Journal of Hydrogen Energy, 2016. 41(42): p. 18971-18994.

58. Isfahani, S.N.R. and A. Sedaghat, A hybrid micro gas turbine and solid state fuel cell power plant with hydrogen production and $\mathrm{CO} 2$ capture. international journal of hydrogen energy, 2016. 41(22): p. 9490-9499.

59. Dispenza, G., et al., Development of a solar powered hydrogen fueling station in smart cities applications. International Journal of Hydrogen Energy, 2017. 42(46): p. 27884-27893. 
60. Qin, C., et al., Proton exchange membrane fuel cell reversal: a review. Catalysts, 2016. 6(12): p. 197.

61. Mehrjerdi, H., Off-grid solar powered charging station for electric and hydrogen vehicles including fuel cell and hydrogen storage. International journal of hydrogen Energy, 2019. 44(23): p. 11574-11583.

62. Nahar, G. and V. Dupont, Hydrogen production from simple alkanes and oxygenated hydrocarbons over ceria-zirconia supported catalysts: Review. Renewable and Sustainable Energy Reviews, 2014. 32: p. 777-796.

63. Figen, H.E. and S.Z. Baykara, Hydrogen production by partial oxidation of methane over Co based, Ni and Ru monolithic catalysts. International Journal of Hydrogen Energy, 2015. 40(24): p. 7439-7451.

64. Agrafiotis, C., et al., Solar thermal reforming of methane feedstocks for hydrogen and syngas production-A review. Renewable and Sustainable Energy Reviews, 2014. 29: p. 656-682.

65. Rand, D. and R. Dell, Fuels-hydrogen production/ coal gasification. 2009.

66. Hosseini, S.E., et al., A review on biomass-based hydrogen production for renewable energy supply. International journal of energy research, 2015. 39(12): p. 1597-1615.

67. Zeng, K., et al., Solar pyrolysis of carbonaceous feedstocks: A review. Solar Energy, 2017. 156: $p$. 73-92.

68. Rashid, M.M., et al., Hydrogen production by water electrolysis: a review of alkaline water electrolysis, PEM water electrolysis and high temperature water electrolysis. Int. J. Eng. Adv. Technol, 2015. 4(3): p. 2249-8958.

69. Ahmad, H., et al., Hydrogen from photo-catalytic water splitting process: A review. Renewable and Sustainable Energy Reviews, 2015. 43: p. 599-610.

70. Acar, C. and I. Dincer, A review and evaluation of photoelectrode coating materials and methods for photoelectrochemical hydrogen production. International Journal of Hydrogen Energy, 2016. 41(19): p. 7950-7959.

71. Patel, N. and A. Miotello, Progress in Co-B related catalyst for hydrogen production by hydrolysis of boron-hydrides: A review and the perspectives to substitute noble metals. International Journal of Hydrogen Energy, 2015. 40(3): p. 1429-1464.

72. Demirci, U.B., The hydrogen cycle with the hydrolysis of sodium borohydride: A statistical approach for highlighting the scientific/technical issues to prioritize in the field. International Journal of Hydrogen Energy, 2015. 40(6): p. 2673-2691.

73. Liu, B.H. and Z.P. Li, A review: Hydrogen generation from borohydride hydrolysis reaction. Journal of Power Sources, 2009. 187(2): p. 527-534.

74. Guldal, N.O., H.E. Figen, and S.Z. Baykara, Perovskite catalysts for hydrogen production from hydrogen sulfide. International Journal of Hydrogen Energy, 2018. 43(2): p. 1038-1046.

75. Guldal, N.O., H.E. Figen, and S.Z. Baykara, Production of hydrogen from hydrogen sulfide with perovskite type catalysts: LaMO3. Chemical Engineering Journal, 2017. 313: p. 1354-1363.

76. Guldal, N.O., H.E. Figen, and S.Z. Baykara, New catalysts for hydrogen production from H2S: Preliminary results. International Journal of Hydrogen Energy, 2015. 40(24): p. 7452-7458.

77. Reverberi, A.P., et al., A review on hydrogen production from hydrogen sulphide by chemical and photochemical methods. Journal of Cleaner Production, 2016. 136: p. 72-80.

78. Zhang, Z., et al., Photo-bioreactor structure and light-heat-mass transfer properties in photofermentative bio-hydrogen production system: A mini review. International Journal of Hydrogen Energy, 2017. 42(17): p. 12143-12152.

79. Sivagurunathan, P., et al., A critical review on issues and overcoming strategies for the enhancement of dark fermentative hydrogen production in continuous systems. International Journal of Hydrogen Energy, 2016. 41(6): p. 3820-3836. 
80. Singh, L. and Z.A. Wahid, Methods for enhancing bio-hydrogen production from biological process: A review. Journal of Industrial and Engineering Chemistry, 2015. 21: p. 70-80.

81. Zhang, Q., et al., Photo-fermentative hydrogen production from crop residue: A mini review. Bioresource Technology, 2017. 229: p. 222-230.

82. Short, W., N. Blair, and D. Heimiller, Modeling the market potential of hydrogen from wind and competing sources. 2005, National Renewable Energy Lab., Golden, CO (US).

83. IRENA, Hydrogen: A renewable energy perspective. 2019.

84. Sayed, E.T., et al., Recent progress in environmentally friendly bio-electrochemical devices for simultaneous water desalination and wastewater treatment. Science of The Total Environment, 2020: p. 141046.

85. Olabi, A.G., et al., Recent progress of graphene based nanomaterials in bioelectrochemical systems. Science of The Total Environment, 2020: p. 141225.

86. Wang, M., et al., Review of renewable energy-based hydrogen production processes for sustainable energy innovation. Global Energy Interconnection, 2019. 2(5): p. 436-443.

87. Ghazvini, M., et al., Geothermal energy use in hydrogen production: A review. International Journal of Energy Research, 2019. 43(14): p. 7823-7851.

88. Dincer, I. and C. Acar, Review and evaluation of hydrogen production methods for better sustainability. International Journal of Hydrogen Energy, 2015. 40(34): p. 11094-11111.

89. Likkasit, C., et al., Solar-aided hydrogen production methods for the integration of renewable energies into oil \& gas industries. Energy Conversion and Management, 2018. 168: p. 395-406.

90. Acar, C. and I. Dincer, Comparative assessment of hydrogen production methods from renewable and non-renewable sources. International Journal of Hydrogen Energy, 2014. 39(1): p. 1-12.

91. Jabbour, K., Tuning combined steam and dry reforming of methane for "metgas" production: A thermodynamic approach and state-of-the-art catalysts. Journal of Energy Chemistry, 2020. 48: p. 54-91.

92. Ersöz, A., Investigation of hydrocarbon reforming processes for micro-cogeneration systems. International Journal of Hydrogen Energy, 2008. 33(23): p. 7084-7094.

93. Schiebahn, S., et al., Power to gas: Technological overview, systems analysis and economic assessment for a case study in Germany. International Journal of Hydrogen Energy, 2015. 40(12): p. 4285-4294.

94. Nguyen, T., et al., Grid-connected hydrogen production via large-scale water electrolysis. Energy Conversion and Management, 2019. 200: p. 112108.

95. Mergel, J., M. Carmo, and D. Fritz, Status on technologies for hydrogen production by water electrolysis. Transition to renewable energy systems, 2013: p. 425-450.

96. Buttler, A. and H. Spliethoff, Current status of water electrolysis for energy storage, grid balancing and sector coupling via power-to-gas and power-to-liquids: A review. Renewable and Sustainable Energy Reviews, 2018. 82: p. 2440-2454.

97. Olateju, B., J. Monds, and A. Kumar, Large scale hydrogen production from wind energy for the upgrading of bitumen from oil sands. Applied Energy, 2014. 118: p. 48-56.

98. Tripathi, B., et al., Performance analysis and comparison of two silicon material based photovoltaic technologies under actual climatic conditions in Western India. Energy Conversion and Management, 2014. 80: p. 97-102.

99. Zhu, W., et al., High-performance photovoltaic-thermoelectric hybrid power generation system with optimized thermal management. Energy, 2016. 100: p. 91-101.

100. Rezk, H., et al., Comparison among various energy management strategies for reducing hydrogen consumption in a hybrid fuel cell/supercapacitor/battery system. International Journal of Hydrogen Energy, 2019. 
101. Fereidooni, M., et al., A comprehensive evaluation of hydrogen production from photovoltaic power station. Renewable and Sustainable Energy Reviews, 2018. 82: p. 415-423.

102. Abdin, Z., C.J. Webb, and E.M. Gray, RETRACTED: Solar hydrogen hybrid energy systems for offgrid electricity supply: A critical review. Renewable and Sustainable Energy Reviews, 2015. 52: p. 1791-1808.

103. Al-Sharafi, A., et al., Techno-economic analysis and optimization of solar and wind energy systems for power generation and hydrogen production in Saudi Arabia. Renewable and Sustainable Energy Reviews, 2017. 69: p. 33-49.

104. Qolipour, M., A. Mostafaeipour, and O.M. Tousi, Techno-economic feasibility of a photovoltaicwind power plant construction for electric and hydrogen production: A case study. Renewable and Sustainable Energy Reviews, 2017. 78: p. 113-123.

105. Rezaei, M., et al., Energy supply for water electrolysis systems using wind and solar energy to produce hydrogen: a case study of Iran. Frontiers in Energy, 2019. 13(3): p. 539-550.

106. Erden, M., M. Karakilcik, and I. Dincer, Performance investigation of hydrogen production by the flat-plate collectors assisted by a solar pond. International Journal of Hydrogen Energy, 2017. 42(4): p. 2522-2529.

107. Uyar, T.S. and D. Beşikci, Integration of hydrogen energy systems into renewable energy systems for better design of $100 \%$ renewable energy communities. International Journal of Hydrogen Energy, 2017. 42(4): p. 2453-2456.

108. Li, Z., et al., Current status and development trend of wind power generation-based hydrogen production technology. Energy Exploration \& Exploitation, 2019. 37(1): p. 5-25.

109. Rodríguez, C., et al., Analysis of the potential for hydrogen production in the province of Córdoba, Argentina, from wind resources. International Journal of Hydrogen Energy, 2010. 35(11): p. 5952-5956.

110. Sigal, A., E.P.M. Leiva, and C.R. Rodríguez, Assessment of the potential for hydrogen production from renewable resources in Argentina. International Journal of Hydrogen Energy, 2014. 39(16): p. 8204-8214.

111. Loisel, R., et al., Economic evaluation of hybrid off-shore wind power and hydrogen storage system. International Journal of Hydrogen Energy, 2015. 40(21): p. 6727-6739.

112. Iqbal, W., et al., Assessment of wind energy potential for the production of renewable hydrogen in Sindh Province of Pakistan. Processes, 2019. 7(4): p. 196.

113. Mostafaeipour, A., et al., Evaluating the wind energy potential for hydrogen production: A case study. International Journal of Hydrogen Energy, 2016. 41(15): p. 6200-6210.

114. Ayodele, T.R. and J.L. Munda, Potential and economic viability of green hydrogen production by water electrolysis using wind energy resources in South Africa. International Journal of Hydrogen Energy, 2019. 44(33): p. 17669-17687.

115. Fang, R., Life cycle cost assessment of wind power-hydrogen coupled integrated energy system. International Journal of Hydrogen Energy, 2019. 44(56): p. 29399-29408.

116. Mostafaeipour, A., et al., Evaluation of hydrogen production by wind energy for agricultural and industrial sectors. International Journal of Hydrogen Energy, 2019. 44(16): p. 7983-7995.

117. Sani, A.K., et al., A review on the performance of geothermal energy pile foundation, its design process and applications. Renewable and Sustainable Energy Reviews, 2019. 106: p. 54-78.

118. Tsagarakis, K.P., et al., A review of the legal framework in shallow geothermal energy in selected European countries: Need for guidelines. Renewable energy, 2020. 147: p. 2556-2571.

119. Balta, M.T., I. Dincer, and A. Hepbasli, Thermodynamic assessment of geothermal energy use in hydrogen production. International Journal of hydrogen energy, 2009. 34(7): p. 2925-2939.

120. Etemoglu, A. and M. Can, Classification of geothermal resources in Turkey by exergy analysis. Renewable and Sustainable Energy Reviews, 2007. 11(7): p. 1596-1606. 
121. Kanoglu, M., A. Ayanoglu, and A. Abusoglu, Exergoeconomic assessment of a geothermal assisted high temperature steam electrolysis system. Energy, 2011. 36(7): p. 4422-4433.

122. Bicer, Y. and I. Dincer, Development of a new solar and geothermal based combined system for hydrogen production. Solar Energy, 2016. 127: p. 269-284.

123. Liu, S., et al., Economic assessment of hydrogen generation for transportation applications using geothermal energy on the Island of Hawaii. The US Department of Energy Office of Energy Efficiency and Renewable Energy, Sentech Inc, 2006: p. 50624-011.

124. Alves, M., Hydrogen energy: Terceira island demonstration facility. Chemical Industry and Chemical Engineering Quarterly, 2008. 14(2): p. 77-95.

125. Sigurvinsson, J., et al., Can high temperature steam electrolysis function with geothermal heat? International Journal of Hydrogen Energy, 2007. 32(9): p. 1174-1182.

126. Mansilla, C., et al., Heat management for hydrogen production by high temperature steam electrolysis. Energy, 2007. 32(4): p. 423-430.

127. Sayed, E.T. and N. Nakagawa, Critical issues in the performance of yeast based microbial fuel cell. Journal of Chemical Technology \& Biotechnology, 2018. 93(6): p. 1588-1594.

128. Mohamed, H.O., et al., Graphite Sheets as High-Performance Low-Cost Anodes for Microbial Fuel Cells Using Real Food Wastewater. Chemical Engineering \& Technology, 2017. 40(12): p. 22432250.

129. Sayed, E.T., et al., Yeast Extract as an Effective and Safe Mediator for the Baker's-Yeast-Based Microbial Fuel Cell. Industrial \& Engineering Chemistry Research, 2015. 54(12): p. 3116-3122.

130. Sayed, E.T. and M.A. Abdelkareem, Yeast as a biocatalyst in microbial fuel cell. Old Yeasts-New Questions. InTech, 2017: p. 41-65.

131. Singh, V. and D. Das, Chapter 3 - Potential of Hydrogen Production From Biomass, in Science and Engineering of Hydrogen-Based Energy Technologies, P.E.V. de Miranda, Editor. 2019, Academic Press. p. 123-164.

132. Basu, P., Biomass gasification and pyrolysis: practical design and theory. 2010: Academic press.

133. Łukajtis, R., et al., Hydrogen production from biomass using dark fermentation. Renewable and Sustainable Energy Reviews, 2018. 91: p. 665-694.

134. Parthasarathy, P. and K.S. Narayanan, Hydrogen production from steam gasification of biomass: Influence of process parameters on hydrogen yield - A review. Renewable Energy, 2014. 66: p. 570-579.

135. Pandey, B., Y.K. Prajapati, and P.N. Sheth, Recent progress in thermochemical techniques to produce hydrogen gas from biomass: A state of the art review. International Journal of Hydrogen Energy, 2019. 44(47): p. 25384-25415.

136. Anca-Couce, A., Reaction mechanisms and multi-scale modelling of lignocellulosic biomass pyrolysis. Progress in Energy and Combustion Science, 2016. 53: p. 41-79.

137. Dou, B., et al., Hydrogen production from the thermochemical conversion of biomass: issues and challenges. Sustainable Energy \& Fuels, 2019. 3(2): p. 314-342.

138. Iribarren, D., et al., Environmental and exergetic evaluation of hydrogen production via lignocellulosic biomass gasification. Journal of Cleaner Production, 2014. 69: p. 165-175.

139. Lopez, G., et al., Recent advances in the gasification of waste plastics. A critical overview. Renewable and Sustainable Energy Reviews, 2018. 82: p. 576-596.

140. Kargi, F., N.S. Eren, and S. Ozmihci, Hydrogen gas production from cheese whey powder (CWP) solution by thermophilic dark fermentation. International Journal of Hydrogen Energy, 2012. 37(3): p. 2260-2266.

141. Azbar, N., et al., Comparative Evaluation of Bio-Hydrogen Production From Cheese Whey Wastewater Under Thermophilic and Mesophilic Anaerobic Conditions. International Journal of Green Energy, 2009. 6(2): p. 192-200. 
142. Mars, A.E., et al., Biohydrogen production from untreated and hydrolyzed potato steam peels by the extreme thermophiles Caldicellulosiruptor saccharolyticus and Thermotoga neapolitana. International Journal of Hydrogen Energy, 2010. 35(15): p. 7730-7737.

143. Koumi Ngoh, S. and D. Njomo, An overview of hydrogen gas production from solar energy. Renewable and Sustainable Energy Reviews, 2012. 16(9): p. 6782-6792.

144. Carrillo, R.J. and J.R. Scheffe, Advances and trends in redox materials for solar thermochemical fuel production. Solar Energy, 2017. 156: p. 3-20.

145. Romero, M. and A. Steinfeld, Concentrating solar thermal power and thermochemical fuels. Energy \& Environmental Science, 2012. 5(11): p. 9234-9245.

146. Villafán-Vidales, H.I., et al., An overview of the solar thermochemical processes for hydrogen and syngas production: Reactors, and facilities. Renewable and Sustainable Energy Reviews, 2017. 75: p. 894-908.

147. Steinfeld, A., Solar thermochemical production of hydrogen--a review. Solar Energy, 2005. 78(5): p. 603-615.

148. Villafán-Vidales, H.I., et al., Chapter 10 - Hydrogen from solar thermal energy, in Solar Hydrogen Production, F. Calise, et al., Editors. 2019, Academic Press. p. 319-363.

149. Kogan, A., Direct solar thermal splitting of water and on-site separation of the products-II. Experimental feasibility study. International Journal of Hydrogen Energy, 1998. 23(2): p. 89-98.

150. Xu, C., et al., Optical switching and nanothermochromic studies of VO2 (M) nanoparticles prepared by mild thermolysis method. Materials \& Design, 2020. 187: p. 108396.

151. Moser, M., M. Pecchi, and T. Fend, Techno-economic assessment of solar hydrogen production by means of thermo-chemical cycles. Energies, 2019. 12(3): p. 352.

152. Wang, Y., et al., A new solar receiver/reactor structure for hydrogen production. Energy Conversion and Management, 2017. 133: p. 118-126.

153. Ausfelder, F., et al., Energy storage as part of a secure energy supply. ChemBioEng Reviews, 2017. 4(3): p. 144-210.

154. Karakaya, E., C. Nuur, and L. Assbring, Potential transitions in the iron and steel industry in Sweden: Towards a hydrogen-based future? Journal of Cleaner Production, 2018. 195: p. 651663.

155. Otto, A., et al., Power-to-steel: Reducing $\mathrm{CO} 2$ through the integration of renewable energy and hydrogen into the German steel industry. Energies, 2017. 10(4): p. 451.

156. Schlapbach, L. and A. Züttel, Hydrogen-storage materials for mobile applications, in Materials for sustainable energy: a collection of peer-reviewed research and review articles from nature publishing group. 2011, World Scientific. p. 265-270.

157. IEA, CCUS tracking in power sector 2019.

158. Hydrogen storage. 2020; Available from: https://hydrogeneurope.eu/hydrogen-storage.

159. Kaur, M. and K. Pal, Review on hydrogen storage materials and methods from an electrochemical viewpoint. Journal of Energy Storage, 2019. 23: p. 234-249.

160. Boateng, E. and A. Chen, Recent advances in nanomaterial-based solid-state hydrogen storage. Materials Today Advances, 2020. 6: p. 100022.

161. Cardella, U., et al., Process optimization for large-scale hydrogen liquefaction. International Journal of Hydrogen Energy, 2017. 42(17): p. 12339-12354.

162. Zhao, D., Y. Guan, and A. Reinecke, Characterizing hydrogen-fuelled pulsating combustion on thermodynamic properties of a combustor. Communications Physics, 2019. 2(1): p. 1-10.

163. Mao, S.S., S. Shen, and L. Guo, Nanomaterials for renewable hydrogen production, storage and utilization. Progress in Natural Science: Materials International, 2012. 22(6): p. 522-534. 
164. Tan, Z., et al., Hydrogen generation by hydrolysis of Mg-Mg2Si composite and enhanced kinetics performance from introducing of $\mathrm{MgCl} 2$ and Si. International Journal of Hydrogen Energy, 2018. 43(5): p. 2903-2912.

165. Milanese, C., et al., Complex hydrides for energy storage. international journal of hydrogen energy, 2019. 44(15): p. 7860-7874.

166. Tietze, V., S. Luhr, and D. Stolten, Bulk storage vessels for compressed and liquid hydrogen. Hydrogen Science and Engineering: Materials, Processes, Systems and Technology, 2016: p. 659690.

167. Barthelemy, H., M. Weber, and F. Barbier, Hydrogen storage: recent improvements and industrial perspectives. International Journal of Hydrogen Energy, 2017. 42(11): p. 7254-7262.

168. Tarkowski, R., Underground hydrogen storage: Characteristics and prospects. Renewable and Sustainable Energy Reviews, 2019. 105: p. 86-94.

169. Matos, C.R., J.F. Carneiro, and P.P. Silva, Overview of large-scale underground energy storage technologies for integration of renewable energies and criteria for reservoir identification. Journal of Energy Storage, 2019. 21: p. 241-258.

170. Wolf, E., Large-scale hydrogen energy storage, in Electrochemical energy storage for renewable sources and grid balancing. 2015, Elsevier. p. 129-142.

171. Witkowski, A., et al., Comprehensive analysis of hydrogen compression and pipeline transportation from thermodynamics and safety aspects. Energy, 2017. 141: p. 2508-2518.

172. Hua, T.Q. and R.K. Ahluwalia, Alane hydrogen storage for automotive fuel cells-Off-board regeneration processes and efficiencies. International journal of hydrogen energy, 2011. 36(23): p. $15259-15265$.

173. Budny, C., R. Madlener, and C. Hilgers, Economic feasibility of pipe storage and underground reservoir storage options for power-to-gas load balancing. Energy Procedia, 2014. 61: p. 22012205.

174. Crotogino, F., Larger scale hydrogen storage, in Storing energy. 2016, Elsevier. p. 411-429.

175. Michalski, J., et al., Hydrogen generation by electrolysis and storage in salt caverns: Potentials, economics and systems aspects with regard to the German energy transition. International Journal of Hydrogen Energy, 2017. 42(19): p. 13427-13443.

176. Heinemann, N., et al., Hydrogen storage in porous geological formations-onshore play opportunities in the midland valley (Scotland, UK). International Journal of Hydrogen Energy, 2018. 43(45): p. 20861-20874.

177. Iordache, I., et al., Hydrogen underground storage in Romania, potential directions of development, stakeholders and general aspects. international journal of hydrogen energy, 2014. 39(21): p. 11071-11081.

178. Tarkowski, R. and G. Czapowski, Salt domes in Poland-Potential sites for hydrogen storage in caverns. International Journal of Hydrogen Energy, 2018. 43(46): p. 21414-21427.

179. Kruck, O., et al., Overview on all known underground storage technologies for hydrogen. Project HyUnder-Assessment of the Potential, the Actors and Relevant Business Cases for Large Scale and Seasonal Storage of Renewable Electricity by Hydrogen Underground Storage in Europe. Report D, 2013. 3.

180. Tengborg, P., J. Johansson, and J. Durup, Storage of highly compressed gases in underground Lined Rock Caverns-More than 10 years of experience. Tunnels for a better Life, Brazil, 2014.

181. Ozarslan, A., Large-scale hydrogen energy storage in salt caverns. International Journal of Hydrogen Energy, 2012. 37(19): p. 14265-14277.

182. Gillette, J. and R. Kolpa, Overview of interstate hydrogen pipeline systems. 2008, Argonne National Lab.(ANL), Argonne, IL (United States). 
183. Ball, M. and M. Weeda, The hydrogen economy-vision or reality? international journal of hydrogen energy, 2015. 40(25): p. 7903-7919.

184. Fekete, J.R., J.W. Sowards, and R.L. Amaro, Economic impact of applying high strength steels in hydrogen gas pipelines. International Journal of Hydrogen Energy, 2015. 40(33): p. 10547-10558.

185. James, B.D., et al., hydrogen storage system cost analysis. 2016, Strategic Analysis Inc., Arlington, VA (United States).

186. Valenti, G., Hydrogen liquefaction and liquid hydrogen storage, in Compendium of hydrogen energy. 2016, Elsevier. p. 27-51.

187. Preuster, P., A. Alekseev, and P. Wasserscheid, Hydrogen storage technologies for future energy systems. Annual review of chemical and biomolecular engineering, 2017. 8: p. 445-471.

188. Cardella, U., L. Decker, and H. Klein, Roadmap to economically viable hydrogen liquefaction. International Journal of Hydrogen Energy, 2017. 42(19): p. 13329-13338.

189. Wilhelmsen, $\varnothing$., et al., Reducing the exergy destruction in the cryogenic heat exchangers of hydrogen liquefaction processes. International Journal of Hydrogen Energy, 2018. 43(10): p. 5033-5047.

190. Berstad, D.O., J.H. Stang, and P. Nekså, Comparison criteria for large-scale hydrogen liquefaction processes. International journal of hydrogen energy, 2009. 34(3): p. 1560-1568.

191. Klell, M., Storage of hydrogen in the pure form. Handbook of hydrogen storage, 2010: p. 187214.

192. Godula-Jopek, A., W. Jehle, and J. Wellnitz, Storage of pure hydrogen in different states. Hydrogen storage technologies: new materials, transport, and infrastructure, 2012: p. 97-170.

193. Le Duigou, A., et al., Relevance and costs of large scale underground hydrogen storage in France. International Journal of Hydrogen Energy, 2017. 42(36): p. 22987-23003.

194. Amos, W.A., Costs of storing and transporting hydrogen. 1999, National Renewable Energy Lab., Golden, CO (US).

195. Berenguer-Murcia, Á., J.P. Marco-Lozar, and D. Cazorla-Amorós, Hydrogen storage in porous materials: status, milestones, and challenges. The Chemical Record, 2018. 18(7-8): p. 900-912.

196. Klebanoff, L.E., et al., Accelerating the understanding and development of hydrogen storage materials: a review of the five-year efforts of the three DOE hydrogen storage materials centers of excellence. Metallurgical and Materials Transactions E, 2014. 1(2): p. 81-117.

197. Xia, Y., Z. Yang, and Y. Zhu, Porous carbon-based materials for hydrogen storage: advancement and challenges. Journal of Materials Chemistry A, 2013. 1(33): p. 9365-9381.

198. Langmi, H.W., et al., Hydrogen storage in metal-organic frameworks: a review. Electrochimica Acta, 2014. 128: p. 368-392.

199. Germain, J., J.M. Fréchet, and F. Svec, Nanoporous polymers for hydrogen storage. small, 2009. 5(10): p. 1098-1111.

200. Weitkamp, J., M. Fritz, and S. Ernst. Zeolites as media for hydrogen storage. in Proceedings from the ninth international zeolite conference. 1993. Elsevier.

201. Blankenship II, T.S., N. Balahmar, and R. Mokaya, Oxygen-rich microporous carbons with exceptional hydrogen storage capacity. Nature communications, 2017. 8(1): p. 1-12.

202. Broom, D., et al., Outlook and challenges for hydrogen storage in nanoporous materials. Applied Physics A, 2016. 122(3): p. 151.

203. Blankenship, T.S. and R. Mokaya, Cigarette butt-derived carbons have ultra-high surface area and unprecedented hydrogen storage capacity. Energy \& Environmental Science, 2017. 10(12): p. 2552-2562.

204. Veenstra, M., et al., Ford/BASF/UM activities in support of the hydrogen storage engineering center of excellence. 2015, Ford Motor Company, Dearborn, MI (United States). 
205. García-Holley, P., et al., Benchmark study of hydrogen storage in metal-organic frameworks under temperature and pressure swing conditions. ACS Energy Letters, 2018. 3(3): p. 748-754.

206. von Colbe, J.B., et al., Application of hydrides in hydrogen storage and compression:

Achievements, outlook and perspectives. international journal of hydrogen energy, 2019. 44(15): p. 7780-7808.

207. Andersson, J. and S. Grönkvist, Large-scale storage of hydrogen. International Journal of Hydrogen Energy, 2019.

208. Demirci, U.B., About the technological readiness of the $\mathrm{H} 2$ generation by hydrolysis of $B(-N)-H$ compounds. Energy Technology, 2018. 6(3): p. 470-486.

209. Sandrock, G., A panoramic overview of hydrogen storage alloys from a gas reaction point of view. Journal of alloys and compounds, 1999. 293: p. 877-888.

210. Crivello, J.-C., et al., Review of magnesium hydride-based materials: development and optimisation. Applied Physics A, 2016. 122(2): p. 97.

211. Yartys, V., et al., Magnesium based materials for hydrogen based energy storage: Past, present and future. international journal of hydrogen energy, 2019. 44(15): p. 7809-7859.

212. Webb, C., A review of catalyst-enhanced magnesium hydride as a hydrogen storage material. Journal of physics and chemistry of solids, 2015. 84: p. 96-106.

213. Aguey-Zinsou, K.-F. and J.-R. Ares-Fernández, Hydrogen in magnesium: new perspectives toward functional stores. Energy \& Environmental Science, 2010. 3(5): p. 526-543.

214. Sun, Y., et al., Tailoring magnesium based materials for hydrogen storage through synthesis: Current state of the art. Energy Storage Materials, 2018. 10: p. 168-198.

215. Shao, H., et al., Progress and Trends in Magnesium-Based Materials for Energy-Storage Research: A Review. Energy Technology, 2018. 6(3): p. 445-458.

216. Schneemann, A., et al., Nanostructured metal hydrides for hydrogen storage. Chemical reviews, 2018. 118(22): p. 10775-10839.

217. de Rango, P., P. Marty, and D. Fruchart, Hydrogen storage systems based on magnesium hydride: from laboratory tests to fuel cell integration. Applied Physics A, 2016. 122(2): p. 126.

218. Jehan, M. and D. Fruchart, McPhy-Energy's proposal for solid state hydrogen storage materials and systems. Journal of alloys and compounds, 2013. 580: p. S343-S348.

219. Nogita, K., et al., Engineering the Mg-Mg2Ni eutectic transformation to produce improved hydrogen storage alloys. International Journal of Hydrogen Energy, 2009. 34(18): p. 7686-7691.

220. Eberle, U., M. Felderhoff, and F. Schueth, Chemical and physical solutions for hydrogen storage. Angewandte Chemie International Edition, 2009. 48(36): p. 6608-6630.

221. Wenger, D., et al., Comments on solid state hydrogen storage systems design for fuel cell vehicles. International journal of hydrogen energy, 2009. 34(15): p. 6265-6270.

222. Schlapbach, L., Surface properties and activation, in Hydrogen in Intermetallic Compunds II. 1992, Springer. p. 15-95.

223. Harries, D.N., et al., Concentrating solar thermal heat storage using metal hydrides. Proceedings of the IEEE, 2011. 100(2): p. 539-549.

224. Bevan, A., et al., Performance of a metal hydride store on the "Ross Barlow" hydrogen powered canal boat. Faraday discussions, 2011. 151: p. 353-367.

225. Orimo, S.-i., et al., Complex hydrides for hydrogen storage. Chemical Reviews, 2007. 107(10): p. 4111-4132.

226. Pasini, J.M., et al., Metal hydride material requirements for automotive hydrogen storage systems. International journal of hydrogen energy, 2013. 38(23): p. 9755-9765.

227. Møller, K.T., et al., Complex metal hydrides for hydrogen, thermal and electrochemical energy storage. Energies, 2017. 10(10): p. 1645. 
228. Liu, Y., et al., Development of Catalyst-Enhanced Sodium Alanate as an Advanced

Hydrogen-Storage Material for Mobile Applications. Energy Technology, 2018. 6(3): p. 487-500.

229. Urbanczyk, R., et al., Aluminium alloy based hydrogen storage tank operated with sodium aluminium hexahydride Na3AlH6. International journal of hydrogen energy, 2014. 39(30): p. 17118-17128.

230. Pohlmann, C., et al., Tailored heat transfer characteristics of pelletized LiNH2-MgH2 and NaAlH4 hydrogen storage materials. Journal of Power Sources, 2012. 205: p. 173-179.

231. Urbanczyk, R., et al., Design and operation of an aluminium alloy tank using doped Na3AlH6 in kg scale for hydrogen storage. Journal of Power Sources, 2016. 324: p. 589-597.

232. Li, H.-W., et al., Recent progress in metal borohydrides for hydrogen storage. Energies, 2011. 4(1): p. 185-214.

233. Puszkiel, J., et al., Tetrahydroborates: development and potential as hydrogen storage medium. Inorganics, 2017. 5(4): p. 74.

234. Ley, M.B., et al., Development of hydrogen storage tank systems based on complex metal hydrides. Materials, 2015. 8(9): p. 5891-5921.

235. Jepsen, L.H., et al., Boron-nitrogen based hydrides and reactive composites for hydrogen storage. Materials Today, 2014. 17(3): p. 129-135.

236. Rude, L.H., et al., Tailoring properties of borohydrides for hydrogen storage: A review. physica status solidi (a), 2011. 208(8): p. 1754-1773.

237. Barkhordarian, G., et al., Unexpected kinetic effect of $M g B 2$ in reactive hydride composites containing complex borohydrides. Journal of Alloys and Compounds, 2007. 440(1-2): p. L18-L21.

238. Plerdsranoy, P., S. Chanthee, and R. Utke, Compaction of LiBH4-MgH2 doped with MWCNTsTiO2 for reversible hydrogen storage. International Journal of Hydrogen Energy, 2017. 42(2): p. 978-986.

239. Demirci, U., O. Akdim, and P. Miele, Ten-year efforts and a no-go recommendation for sodium borohydride for on-board automotive hydrogen storage. International Journal of Hydrogen Energy, 2009. 34(6): p. 2638-2645.

240. Shang, Y. and R. Chen, Hydrogen storage via the hydrolysis of NaBH4 basic solution: optimization of NaBH4 concentration. Energy \& fuels, 2006. 20(5): p. 2142-2148.

241. Lapeña-Rey, N., et al., A fuel cell powered unmanned aerial vehicle for low altitude surveillance missions. International Journal of Hydrogen Energy, 2017. 42(10): p. 6926-6940.

242. Kersting, A.L., Light metal amides and imides for hydrogen storage. 2012, University of Birmingham.

243. Gregory, D.H., Lithium nitrides, imides and amides as lightweight, reversible hydrogen stores. Journal of Materials Chemistry, 2008. 18(20): p. 2321-2330.

244. Baricco, M., et al., SSH2S: Hydrogen storage in complex hydrides for an auxiliary power unit based on high temperature proton exchange membrane fuel cells. Journal of Power Sources, 2017. 342: p. 853-860.

245. Goeppert, A., et al., Recycling of carbon dioxide to methanol and derived products-closing the loop. Chemical Society Reviews, 2014. 43(23): p. 7995-8048.

246. Yousef, B.A.A., et al., Fuzzy modeling and particle swarm optimization for determining the optimal operating parameters to enhance the bio-methanol production from sugar cane bagasse. International Journal of Energy Research. $\mathrm{n} / \mathrm{a}(\mathrm{n} / \mathrm{a})$.

247. Özcan, O. and A.N. Akın, Thermodynamic analysis of methanol steam reforming to produce hydrogen for HT-PEMFC: An optimization study. International Journal of Hydrogen Energy, 2019. 44(27): p. 14117-14126. 
248. Richards, N., J. Needels, and P. Erickson, Autothermal-reformation enhancement using a stratified-catalyst technique. International Journal of Hydrogen Energy, 2017. 42(41): p. 2591425923.

249. Klerke, A., et al., Ammonia for hydrogen storage: challenges and opportunities. Journal of Materials Chemistry, 2008. 18(20): p. 2304-2310.

250. Hellman, A., et al., Ammonia synthesis: state of the bellwether reaction, in Comprehensive Inorganic Chemistry II (second Edition). 2013, Elsevier. p. 459-474.

251. Cheddie, D., Ammonia as a hydrogen source for fuel cells: a review. 2012: InTech.

252. Mukherjee, S., et al., Low-temperature ammonia decomposition catalysts for hydrogen generation. Applied Catalysis B: Environmental, 2018. 226: p. 162-181.

253. Giddey, S., et al., Ammonia as a renewable energy transportation media. ACS Sustainable Chemistry \& Engineering, 2017. 5(11): p. 10231-10239.

254. David, W.I., et al., Hydrogen production from ammonia using sodium amide. Journal of the American Chemical Society, 2014. 136(38): p. 13082-13085.

255. Grasemann, M. and G. Laurenczy, Formic acid as a hydrogen source-recent developments and future trends. Energy \& Environmental Science, 2012. 5(8): p. 8171-8181.

256. Sponholz, P., et al., Towards a practical setup for hydrogen production from formic acid. ChemSusChem, 2013. 6(7): p. 1172-1176.

257. Iguchi, M., et al., Simple Continuous High-Pressure Hydrogen Production and Separation System from Formic Acid under Mild Temperatures. ChemCatChem, 2016. 8(5): p. 886-890.

258. Kawanami, H., Y. Himeda, and G. Laurenczy, Formic acid as a hydrogen carrier for fuel cells toward a sustainable energy system, in Advances in inorganic chemistry. 2017, Elsevier. p. 395427.

259. Preuster, P., C. Papp, and P. Wasserscheid, Liquid organic hydrogen carriers (LOHCs): toward a hydrogen-free hydrogen economy. Accounts of chemical research, 2017. 50(1): p. 74-85.

260. Bourane, A., et al., An overview of organic liquid phase hydrogen carriers. International journal of hydrogen energy, 2016. 41(48): p. 23075-23091.

261. Jones, D.S. and P.P. Pujadó, Handbook of petroleum processing. 2006: Springer Science \& Business Media.

262. Uesugi, $\mathrm{H}$., et al., Industrial production of $\mathrm{MgH} 2$ and its application. Journal of alloys and compounds, 2011. 509: p. S650-S653.

263. Molinas, B., et al., Scaled-up production of a promising Mg-based hydride for hydrogen storage. international journal of hydrogen energy, 2009. 34(10): p. 4597-4601.

264. Ouyang, L., et al., Enhanced hydrogen generation properties of MgH2-based hydrides by breaking the magnesium hydroxide passivation layer. Energies, 2015. 8(5): p. 4237-4252.

265. Liu, Y., et al., Hydrogen generation from the hydrolysis of $\mathrm{Mg}$ powder ball-milled with AlCl3. Energy, 2013. 53: p. 147-152.

266. Ma, M., et al., Promoting hydrogen generation from the hydrolysis of Mg-Graphite composites by plasma-assisted milling. Energy, 2019. 167: p. 1205-1211.

267. Ouyang, L., et al., The high capacity and controllable hydrolysis rate of Mg3La hydride. Journal of alloys and compounds, 2013. 580: p. S317-S319.

268. Huang, J., et al., The effect of particle size on hydrolysis properties of Mg3La hydrides. international journal of hydrogen energy, 2014. 39(25): p. 13564-13568.

269. Xiao, Y., et al., Hydrogen generation by CaH2-induced hydrolysis of Mg17Al12 hydride. International journal of hydrogen energy, 2011. 36(24): p. 15698-15703.

270. Tessier, J.-P., et al., Hydrogen production and crystal structure of ball-milled MgH2-Ca and $\mathrm{MgH} 2-\mathrm{CaH} 2$ mixtures. Journal of alloys and compounds, 2004. 376(1-2): p. 180-185. 
271. Zhao, Z., Y. Zhu, and L. Li, Efficient catalysis by $\mathrm{MgCl} 2$ in hydrogen generation via hydrolysis of Mg-based hydride prepared by hydriding combustion synthesis. Chemical Communications, 2012. 48(44): p. 5509-5511.

272. Huang, M., et al., Hydrogen generation by hydrolysis of $\mathrm{MgH} 2$ and enhanced kinetics performance of ammonium chloride introducing. international journal of hydrogen energy, 2015. 40(18): p. 6145-6150.

273. Huang, M., et al., Hydrogen production via hydrolysis of Mg-oxide composites. International Journal of Hydrogen Energy, 2017. 42(35): p. 22305-22311.

274. Gan, D., et al., Kinetic performance of hydrogen generation enhanced by AICl3 via hydrolysis of $\mathrm{MgH} 2$ prepared by hydriding combustion synthesis. International Journal of Hydrogen Energy, 2018. 43(22): p. 10232-10239.

275. Uan, J.-Y., C.-Y. Cho, and K.-T. Liu, Generation of hydrogen from magnesium alloy scraps catalyzed by platinum-coated titanium net in $\mathrm{NaCl}$ aqueous solution. International Journal of Hydrogen Energy, 2007. 32(13): p. 2337-2343.

276. Kravchenko, O., et al., Formation of hydrogen from oxidation of $\mathrm{Mg}, \mathrm{Mg}$ alloys and mixture with $\mathrm{Ni}, \mathrm{Co}, \mathrm{Cu}$ and $\mathrm{Fe}$ in aqueous salt solutions. International journal of hydrogen energy, 2014. 39(11): p. 5522-5527.

277. Xie, X., et al., Recent advances in hydrogen generation process via hydrolysis of Mg-based materials: A short review. Journal of Alloys and Compounds, 2020. 816: p. 152634.

278. Haertling, C., R. Hanrahan Jr, and R. Smith, A literature review of reactions and kinetics of lithium hydride hydrolysis. Journal of nuclear materials, 2006. 349(1-2): p. 195-233.

279. Garlea, E., et al., Identification of lithium hydride and its hydrolysis products with neutron imaging. Journal of Nuclear Materials, 2017. 485: p. 147-153.

280. Kawakami, M., et al., Optimum hydrogen desorption properties in LiH-LiOH composites. Materials transactions, 2009: p. 0906080806-0906080806.

281. Khzouz, M., et al., Sustainable hydrogen production via LiH hydrolysis for unmanned air vehicle (UAV) applications. International Journal of Hydrogen Energy, 2020. 45(8): p. 5384-5394.

282. Chen, $\mathrm{K}$., et al., Converting $\mathrm{H}+$ from coordinated water into $\mathrm{H}$ - enables super facile synthesis of LiBH4. Green Chemistry, 2019. 21(16): p. 4380-4387.

283. Ouyang, L., et al., Enhancing the Regeneration Process of Consumed NaBH4 for Hydrogen Storage. Advanced Energy Materials, 2017. 7(19): p. 1700299.

284. Graetz, J., et al., Aluminum hydride as a hydrogen and energy storage material: past, present and future. Journal of Alloys and Compounds, 2011. 509: p. S517-S528.

285. Singh, S., et al., Hydrogen: A sustainable fuel for future of the transport sector. Renewable and Sustainable Energy Reviews, 2015. 51: p. 623-633.

286. Medina, M.F., et al., Análisis de la producción central y la entrega de hidrógeno, aplicado al Circuito Patagónico Austral. Informes Científicos Técnicos-UNPA, 2016. 8(2): p. 139-152.

287. Najjar, Y.S.H., Hydrogen safety: The road toward green technology. International Journal of Hydrogen Energy, 2013. 38(25): p. 10716-10728.

288. Cipriani, G., et al., Perspective on hydrogen energy carrier and its automotive applications. International Journal of Hydrogen Energy, 2014. 39(16): p. 8482-8494.

289. Reuß, M., et al., Seasonal storage and alternative carriers: A flexible hydrogen supply chain model. Applied Energy, 2017. 200: p. 290-302.

290. Balat, M., Potential importance of hydrogen as a future solution to environmental and transportation problems. International journal of hydrogen energy, 2008. 33(15): p. 4013-4029.

291. Liu, H., et al., Analysis of Ontario's hydrogen economy demands from hydrogen fuel cell vehicles. International Journal of Hydrogen Energy, 2012. 37(11): p. 8905-8916. 
292. Maniatopoulos, P., J. Andrews, and B. Shabani, Towards a sustainable strategy for road transportation in Australia: The potential contribution of hydrogen. Renewable and Sustainable Energy Reviews, 2015. 52: p. 24-34.

293. Hydrogen Storage,

https://www.energy.gov/eere/fuelcells/hydrogen-storage. April, 2017.

294. Standardization, I.O.f., Environmental Management: Life Cycle Assessment; Principles and Framework. 2006: ISO.

295. Karaca, A.E., I. Dincer, and J. Gu, Life cycle assessment study on nuclear based sustainable hydrogen production options. International Journal of Hydrogen Energy, 2020. 45(41): p. 2214822159.

296. Sadeghi, S., S. Ghandehariun, and M.A. Rosen, Comparative economic and life cycle assessment of solar-based hydrogen production for oil and gas industries. Energy, 2020. 208: p. 118347.

297. Salkuyeh, Y.K., B.A. Saville, and H.L. MacLean, Techno-economic analysis and life cycle assessment of hydrogen production from natural gas using current and emerging technologies. International Journal of hydrogen energy, 2017. 42(30): p. 18894-18909.

298. Ghandehariun, S. and A. Kumar, Life cycle assessment of wind-based hydrogen production in Western Canada. International Journal of Hydrogen Energy, 2016. 41(22): p. 9696-9704.

299. Hajjaji, N., et al., Life cycle assessment of hydrogen production from biogas reforming. international journal of hydrogen energy, 2016. 41(14): p. 6064-6075.

300. Li, Q., et al., Exergetic life cycle assessment of hydrogen production from biomass stagedgasification. Energy, 2020. 190: p. 116416.

301. Valente, A., D. Iribarren, and J. Dufour, Life cycle sustainability assessment of hydrogen from biomass gasification: A comparison with conventional hydrogen. International Journal of Hydrogen Energy, 2019. 44(38): p. 21193-21203. 